I -33039

CONTRACTOR REPORT

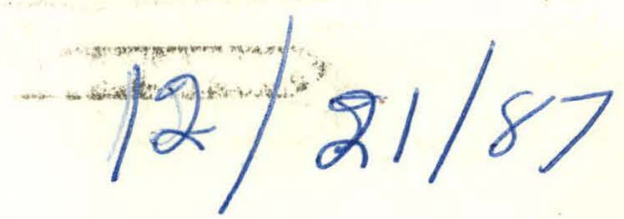

SAND $87-7041$

Unlimited Release

UC -70

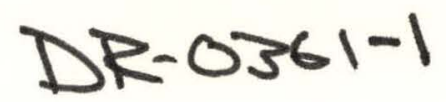

\title{
Fluid Flow Measurements of Test Series A and B for the Small Scale Seal Performance Tests
}

\author{
E. W. Peterson, P. L. Lagus, K. Lie \\ S-CUBED \\ A Division of Maxwell Laboratories, Inc. \\ PO Box 1620 \\ La Jolla, CA 92038-1620
}

Prepared by Sandia National Laboratories Albuquerque, New Mexico 87185 and Livermore, California 94550 for the United States Department of Energy under Contract DE-AC04-76DP00789

Printed December 1987

\section{DISCLAIMER}

This report was prepared as an account of work sponsored by an agency of the United States Government. Neither the United States Government nor any agency thereof, nor any of their employees, makes any warranty, express or implied, or assumes any legal liability or responsibility for the accuracy, completeness, or usefulness of any information, apparatus, product, or process disclosed, or represents that its use would not infringe privately owned rights. Reference herein to any specific commercial product, process, or service by trade name, trademark, manufacturer, or otherwise does not necessarily constitute or imply its endorsement, recommendation, or favoring by the United States Government or any agency thereof. The views and opinions of authors expressed herein do not necessarily state or reflect those of the United States Government or any agency thereof. 


\section{DISCLAIMER}

This report was prepared as an account of work sponsored by an agency of the United States Government. Neither the United States Government nor any agency Thereof, nor any of their employees, makes any warranty, express or implied, or assumes any legal liability or responsibility for the accuracy, completeness, or usefulness of any information, apparatus, product, or process disclosed, or represents that its use would not infringe privately owned rights. Reference herein to any specific commercial product, process, or service by trade name, trademark, manufacturer, or otherwise does not necessarily constitute or imply its endorsement, recommendation, or favoring by the United States Government or any agency thereof. The views and opinions of authors expressed herein do not necessarily state or reflect those of the United States Government or any agency thereof. 


\section{DISCLAIMER}

Portions of this document may be illegible in electronic image products. Images are produced from the best available original document. 
Issued by Sandia National Laboratories, operated for the United States Department of Energy by Sandia Corporation.

NOTICE: 'This report was prepared as an acounit of won spunsuicd by an agency of the United States Government. Neither the United States Government nor any agency thereof, nor any of their employees, nor any of their contractors, subcontractors, or their employees, makes any warranty, express or implied, or assumes any legal liability or responsibility for the accuracy, completeness, or usefulness of any information, apparatus, product, or process disclosed, or represents that its use would not infringe privately owned rights. Reference herein to any specific commercial product, process, or service by trade name, trademark, manufacturer, or otherwise, does not necessarily constitute or imply its endorsement, recommendation, or favoring by the United States Government, any agency thereof or any of their by the United States Government, any agency thereof or any of their
contractors or subcontractors. The views and opinions expressed herein do contractors or subcontractors. The views and opinions expressed herein do
not necessarily state or reflect those of the United States Government, any agency thereof or any of their contractors or subcontractors.

Printed in the United States of America Available from

National Technical Information Service

U.S. Department of Commerce

5285 Port Royal Road

Springfield, VA 22161

NTIS price codes

Printed copy: A07

Microfiche copy: A01 
SAND87-7041

Unl imited Release

Printed December 1987

Distribution

Category UC-70

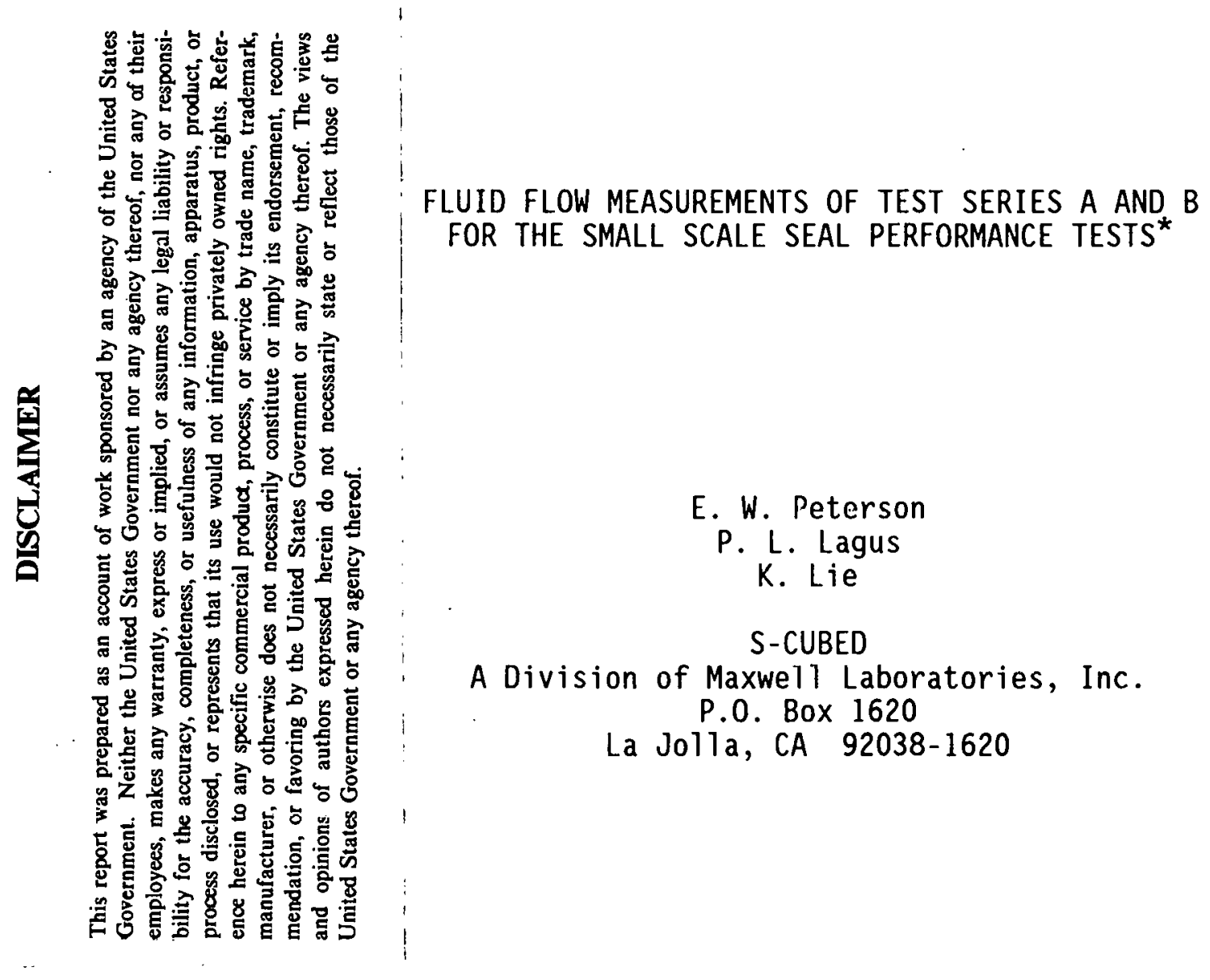

Abstract

The degree of waste isolation achieved by a repository seal system is dependent upon the fluid flow characteristics (or permeability) of the seals. In order to obtain meaningful, site-specific data on the performance of various possible seal system components, a series of in situ experiments called the Small Scale Seal Performance Tests (SSSPT) are being conducted at the Waste Isolation Pilot Plant (WIPP). This report con the results of gas flow, tracer penetration, and brine flow tests con 1960 tof on concrete seals in vertical (Test Series A) and horizontal (Test SelAere B) configurations. The test objectives were to evaluate the seal performance and to determine if there existed scaling effects which could influence future SSSPT designs. 


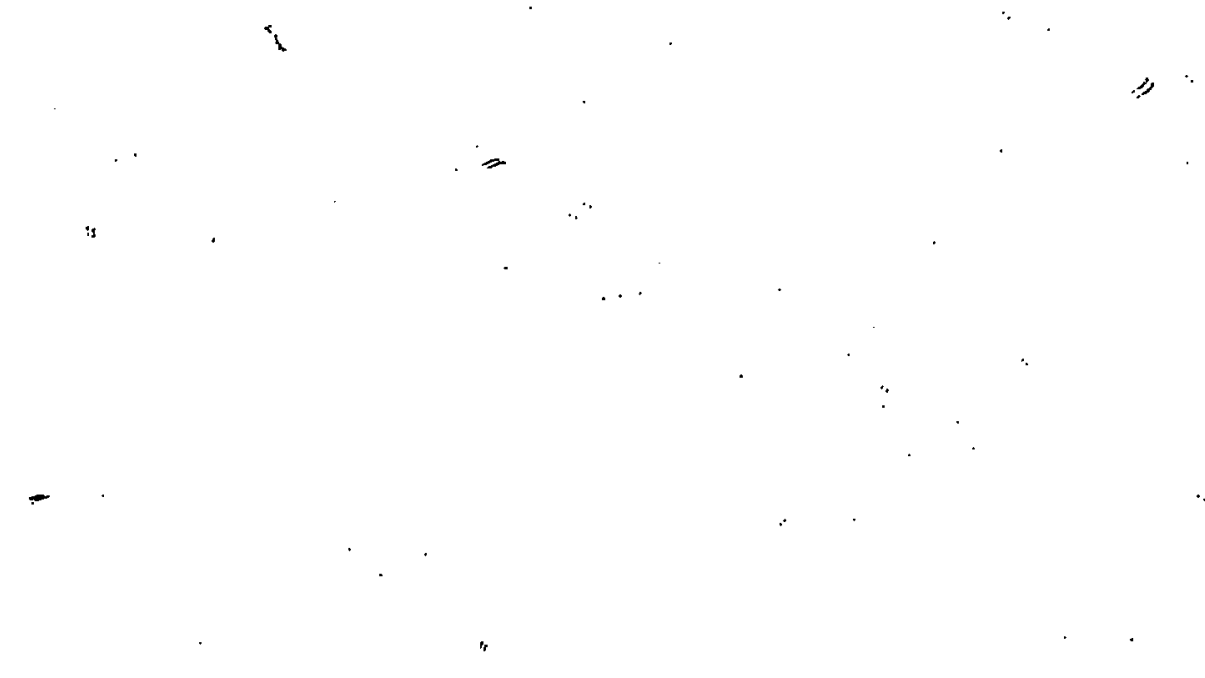

THIS PAGE

WAS INTENTIONALLY

LEFT BLANK 


\section{TABLE OF CONTENTS}

$\underline{\text { Section }}$

Page

$\begin{array}{lc}\text { ABSTRACT } & \text { ii } \\ \text { LIST OF FIGURES } & \text { iv } \\ \text { LIST OF TABLES } & \text { - }\end{array}$

1 INTRODUCTION AND BACKGROUND 1

2 TEST SERIES DESCRIPTIONS 5

2.1 TEST SERIES A CONFIGURATION 5

2.2 TEST SERIES B CONFIGURATION 5

2.3 SEAL MATERIAL 9

2.4 TEST SYSTEM 9

3 DATA ACQUISITION 11

4 DATA ANALYSIS AND EVALUATION 23

4.1 DATA ANALYSIS

4.2 DATA EVALUATION 30

5 TEST SERIES A RESULTS 35

5.1 GAS FLOW TESTS 35

5.2 BRINE FLOW TESTS 37

5.3 COMPARISON OF GAS AND BRINE TESTS 40

6 TEST SERIES B RESULTS 43

7 CONCLUSIONS $\quad 47$

REFERENCES $\quad 49$

APPENDIX A - SSSPT Fluid Flow Measurement Data 51

$\begin{array}{ll}\text { APPENDIX B - Parameter Sensitivity } & 103\end{array}$ 


\section{LIST OF FIGURES}

Figure

Page

1 Illustration showing test configuration for the Small-Scale Seal Performance Tests.

2 Plan view of WIPP facility test area.

3 Borehole locations for the Test Series A Small-Scale Seal Performance Tests.

4 Borehole locations for the Test Series B Small-Scale Seal Performance Tests.

5 Schematic showing the Permeability Test System.

6 Test region pressure history measured during the MAE22 gas flow test.

7 Guard region pressure history measured during the MAE22 gas flow test.

8 Test region temperature history measured during the MAE22 gas flow test.

9 Test region pressure history measured during the MAE22 brine flow test.

10 Brine supply pressure history measured during the MAE22 brine flow test.

11 MAE22 brine flowrate calculated from the brine supply pressure history shown on Figure 10.

12 Guard region pressure history measured during the MAE22 brine flow test.

13 Test region temperature history measured during the MAE22 brine flow test.

14 Comparison of calculated and measured MAE22 pressure decay histories assuming gas flow through the seal.

15 Comparison of calculated and measured MAE22 pressure decay histories assuming gas flow into an unsaturated formation.

16. Comparison of calculated and measured MAE22 brine flowrates assuming flow through an initially unsaturated seal. 


\section{LIST OF FIGURES (Continued)}

Figure

Page

17 Comparison of calculated and measured MAE22 brine flowrates assuming flow into a saturated formation.

(Transmissive outer boundary at $r=5$ meters.)

18 Comparison of calculated and measured MAE22 brine flowrates assuming flow into a saturated formation.

(Zero flow outer boundary at $r=5$ meters.)

A-1 Test region pressure history measured during the MAE11 gas flow test.

A-2 Guard region pressure history measured during the MAE11 gas flow test.

A-3 Test region temperature history measured during the MAE11 gas flow test.

A-4 Test region pressure history measured during the MAE12 gas flow test.

A-5 Guard region pressure history measured during the MAE12 gas flow test.

A-6 Test region temperature history measured during the MAE12 gas flow test.

A-7 Test region pressure history measured during the MAE21 gas flow test.

A-8 Guard region pressure history measured during the MAE21 gas flow test.

A-9 Test region temperature history measured during the MAE21 gas flow test.

A-10 Test region pressure history measured during the MAE22 gas flow test.

A-11 Guard region pressure history measured during the MAE22 gas flow test.

A-12 Test region temperature history measured during the MAE22 gas flow test. 


\section{LIST OF FIGURES (Continued)}

Figure

Page

A-13 Test region pressure history measured during the MAE31 gas flow test.

A-14 Guard region pressure history measured during the MAE31 gas flow test.

A-15 Test region temperature history measured during the MAE31 gas flow test.

A-16 Test region pressure history measured during the MAE32 gas flow test.

A-17 Guard region pressure history measured during the MAE32 gas flow test.

A-18 Test region temperature history measured during the MAE32 gas flow test.

A-19 Test region pressure history measured during the MAE12 brine flow test.

A-20 Brine supply pressure history measured during the MAE12 brine flow test.

A-21 MAE12 brine flowrate calculated from the brine supply pressure history shown on Figure A-20.

A-22 Guard region pressure history measured during the MAE12 brine flow test.

A-23 Test region pressure history measured during the MAE12 brine flow test.

A-24 Test region pressure history measured during the MAE22 brine flow test.

A-25 Brine supply pressure history measured during the MAE22 brine flow test.

A-26 MAE22 brine flowrate calculated from the brine supply pressure history shown on Figure A-25.

A-27 Guard region pressure history measured during the MAE22 brine flow test. 


\section{LIST OF FIGURES (Continued)}

Figure

Page

A-28 Test region temperature history measured during the MAE22 brine flow test.

A-29 Test region pressure history measured during the MAE32 brine flow test.

A-30 Brine supply pressure history measured during the MAE32 brine flow test.

A-31 MAE32 brine flowrate calculated from the brine supply pressure history shown on Figure A-30.

A-32 Guard region pressure history measured during the MAE32 brine flow test.

A-33 Test region temperature history measured during the MAE32 brine flow test.

A-34 Test region pressure history measured during the April 1986 MBE31 gas flow test.

A-35 Guard region pressure history measured during the April 1986 MBE31 gas flow test.

A-36 Test region temperature history measured during the April 1986 MBE31 gas flow test.

A-37 Test region pressure history measured during the April 1986 MBE32 gas flow test.

A-38 Guard region pressure history measured during the April 1986 MBE32 gas flow test.

A-39 Test region temperature history measured during the April 1986 MBE32 gas flow test.

A-40 Test region pressure history measured during the April 1986 MBE33 gas flow test.

A-41 Guard region pressure history measured during the April 1986 MBE33 gas flow test.

A-42 Test region temperature history measured during the April 1986 


\section{LIST OF FIGURES (Continued)}

Figure

Page

A-43 Test region pressure history measured during the May 1987 MBE 31 gas flow test.

A-44 Guard region pressure history measured during the May 1987 MBE 31 gas flow test.

A-45 Test region temperature history measured during the May 1987 MBE 31 gas flow test.

A-46 Test region pressure history measured during the May 1987 MBE 32 gas flow test.

A-47 Guard region pressure history measured during the May 1987 MBE 32 gas flow test.

A-48 Test region temperature history measured during the May 1987 MBE 32 gas flow test.

A-49 Test region pressure history measured during the May 1987 MBE 32 gas flow test.

A-50 Gauge region pressure history measured during the May 1987 MBE 33 gas flow test.

A-51 Test region temperature history measured during the May 1987 MBE 33 gas flow test.

B-1 Comparison of calculated and measured MAEEZ2 pressure decay histories assuming gas flow through the seal.

$\left(k_{\text {seal }}=2 \times 10 E-7\right.$ darcy. $\left.\phi_{\text {seal }}=0.01\right)$

B-2 Comparison of calculated and measured MAE22 pressure decay histories assuming gas flow through the seal.

( $\phi_{\text {seal }}$ changed from 0.01 to 0.001 )

B-3 Comparison of calculated and measured MAE22 pressure decay histories assuming gas flow through the seal.

( $\phi_{\text {seal }}$ changed from 0.01 to 0.1 ).

B-4 Comparison of calculated and measured MAE22 pressure decay histories assuming gas flow through the seal.

( $k_{\text {seal }}$ changed from $2 \times 10 E-7$ darcy to $2 \times 10 E-6$ darcy) 


\section{LIST OF FIGURES (Continued)}

Figure

Page

B-5 Comparison of calculated and measured MAE22 pressure decay histories assuming gas flow through the seal.

$\left(k_{\text {seal }}\right.$ changed from $2 \times 10 \mathrm{E}-7$ darcy to $2 \times 10 \mathrm{E}-8$ darcy)

B-6 Comparison of calculated and measured MAE22 pressure decay histories assuming gas flow into an unsaturated formation.

$\left(k_{\text {formation }}=6 \times 10 \mathrm{E}-9\right.$ darcy. $\left.\phi_{\text {formation }}=0.001\right)$

B-7 Comparionon of calculated and formation MAE histories assuming gas flow into an unsaturated formation. ( $\phi_{\text {formation }}$ changed from 0.001 to 0.0001 )

B-8 Comparison of calculated and measured MAE22 pressure decay histories assuming gas flow into an unsaturated formation. ( $\phi_{\text {formation }}$ changed from 0.001 to 0.01 )

B-9 Comparison of calculated and measured MAE22 pressure decay histories assuming gas flow into an unsaturated formation. ( $k_{\text {formation }}$ changed from $2 \times 10 \mathrm{E}-9$ darcy to $2 \times 10 \mathrm{E}-8$ darcy)

B-10 Comparison of calculated and measured MAE22 pressure decay ( $k_{\text {formation }}$ changed from $2 \times 10 \mathrm{E}-9$ darcy to $2 \times 10 \mathrm{E}-10$ darcy)

B-11 Comparison of calculated and measured MAE22 brine flowrates assuming flow through an initially unsaturated seal.

$\left(k_{\text {seal }}=2 \times 10 \mathrm{E}-7\right.$ darcy. $\left.\phi_{\text {seal }}=0.0015\right)$

B-12 Comparison of calculated and measured MAE22 brine flowrates assuming flow through an initially unsaturated seal. $\left(\phi_{\text {seal }}\right.$ changed from 0.0015 to 0.00015 )

B-13 Comparison of calculated and measured MAE22 brine flowrates assuming flow through an initially unsaturated seal. $\left(\phi_{\text {seal }}\right.$ changed from 0.0015 to 0.015 )

B-14 Comparison of calculated and measured MAE22 brine flowrates assuming flow through an initially unsaturated seal. ( $k_{\text {seal }}$ changed from $2 \times 10 E-7$ darcy to $2 \times 10 E-6$ darcy)

B-15 Comparison of calculated and measured MAE22 brine flowrates assuming flow through an initially unsaturated seal. ( $k_{\text {seal }}$ changed from $2 \times 10 \mathrm{E}-7$ darcy to $2 \times 10 \mathrm{E}-8$ darcy) 


\section{LIST OF FIGURES (Concluded)}

Figure

Page

B-16 Comparison of calculated and measured MAE22 brine flowrates assuming flow into a saturated formation.

$\left(k_{\text {formation }}=1.2 \times 10 \mathrm{E}-8\right.$. $\left.\phi_{\text {formation }}=0.001\right)$

B-17 Comparison of calculated and measured MAE22 brine flowrates assuming flow into a saturated formation.

( $\phi_{\text {formation }}$ changed from 0.001 to 0.01 )

B-18 Comparison of calculated and measured MAE22 brine flowrates assuming flow into a saturated formation.

( $\phi_{\text {formation }}$ changed from 0.001 to 0.0001 )

B-19 Comparison of calculated and measured MAE22 brine flowrates assuming flow into a saturated formation.

( $k_{\text {formation }}$ changed from $1.2 \times 10 \mathrm{E}-8$ to $1.2 \times 10 \mathrm{E}-7$ )

B-20 Comparison of calculated and measured MAE22 brine flowrates assuming flow into a saturated formation.

( $k_{\text {formation }}$ changed from $1.2 \times 10 \mathrm{E}-8$ to $1.2 \times 10 \mathrm{E}-9$ ) 


\section{LIST OF TABLES}

Table

Page

1 Summary of Series A Tracer Gas Flow Tests

2 Summary of Series A Brine Flow Tests

3 Summary of Analysis of MAE22 Gas and Brine Flow Tests

4 Comparison of the April 1986 and May 1987 Series B Tracer Gas Flow Tests 


\section{INTRODUCTION AND BACKGROUND}

The U.S. Department of Energy (DOE) is developing the Waste Isolation Pilot Plant (WIPP) facility in southeast New Mexico. The WIPP disposal horizon is located approximately $656 \mathrm{~m}$ (2150 feet) below ground surface in a bedded salt deposit. The WIPP facility is being developed for the purpose of providing a research and development facility to demonstrate the safe disposal of radioactive waste resulting from defense programs of the United States (Public Law 96-164). A part of the WIPP Research and Development (R\&D) Program conducted by Sandia National Laboratories (SNL) is the Plugging and Sealing Program (PSP). The Plugging and Sealirg Program is an integrated program of modeling. laboratory materials testing, and in situ testing directed toward developing acceptable sealing technology for the eventual decommissioning of the WIPP facility.

To validate seal design concepts, in situ testing of seal components is required. Because of the extremely large size difference between laboratory tests and full-scale in situ emplacements. the conduct of a series of intermediate in situ experiments is required. Such testing will provide valuable experience with regard to in situ seal performance, and thus will be fundamental in evaluating present design concepts and planning for full-scale tests. These tests are called the Small Scale Seal Performance Tests (SSSPT).

The SSSPT involve the emplacement of candidate seal materials in various configurations. Each group of tests is referred to as a test series. From the time of seal emplacement until the termination of a specific test series. thermal and mechanical data will be obtained by instrumentation in boreholes in the rock adjacent to the seal and by instrumentation embedded in the seal itself. Flow characteristics of the seal system will be evaluated by fluid flow measurements. These measurements will use both brine and gas as the working fluid and will be conducted at various working pressures. 
The following five test series are currently planned, or are in progress:

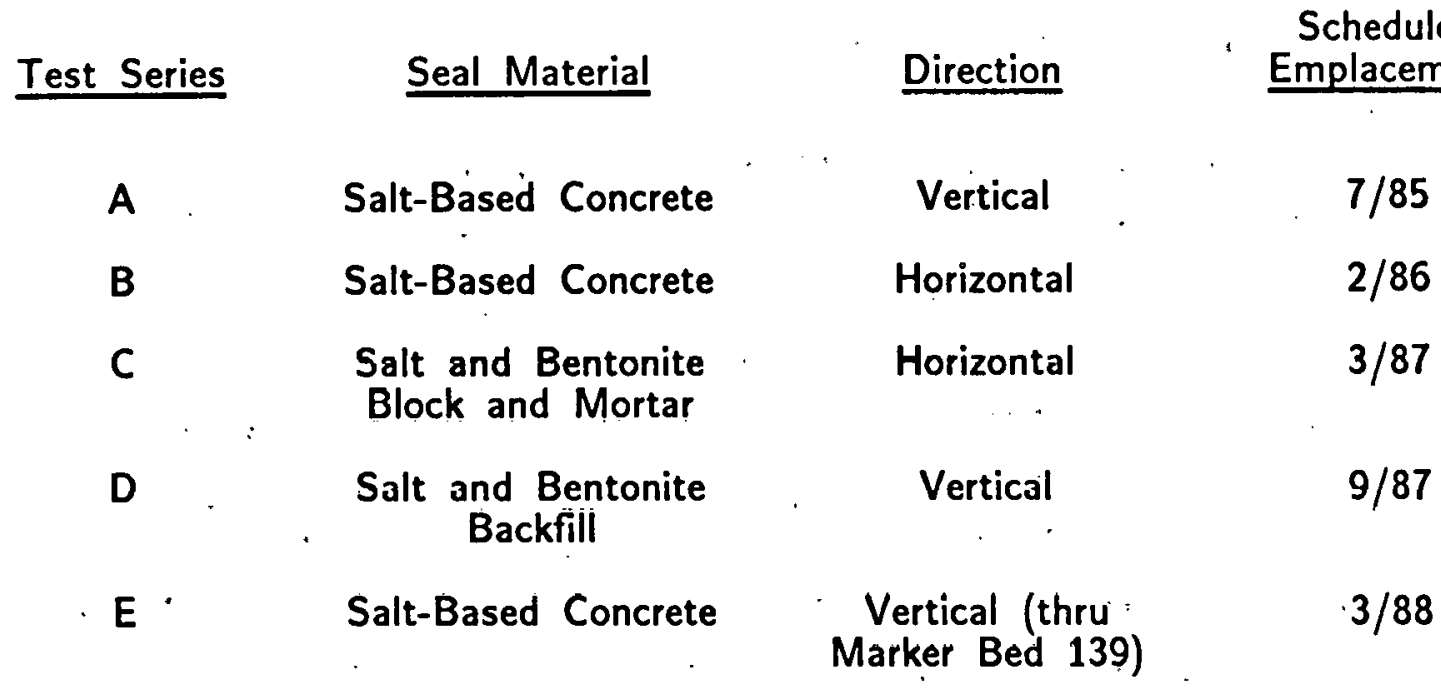

Figure 1 illustrates the rgeneral test configuration. An emplacement hole is drilled either in the rib (wall) or invert (floor) of the excavation. Seal material. in some cases containing instrumentation, is emplaced over a selected interval in this hole. Small-diameter holes for rock instrumentation are also sometimes drilled adjacent to the emplacement hole. An access hole, to be used for gas or brine injection. is drilled at an angle which allows it to intersect the bottom of the emplacement hole. A dual-packer system is used to seal this access hole so that the interval beneath the plug can be pressurized as required for fluid flow measurements.

The SSSPT program is designed to obtain in situ seal design and performance data. These data are important to the selection of materials and configurations suitable for conceptual seal designs at the WIPP. In particular, objectives of the SSSPT are to:

- Determine in situ fluid flow performance for various seal systems:

- Determine in situ structural performance of the host-rock and seal materials:

- Assess seal emplacement techniques: and

- Support the development of numerical predictive capabilities. 


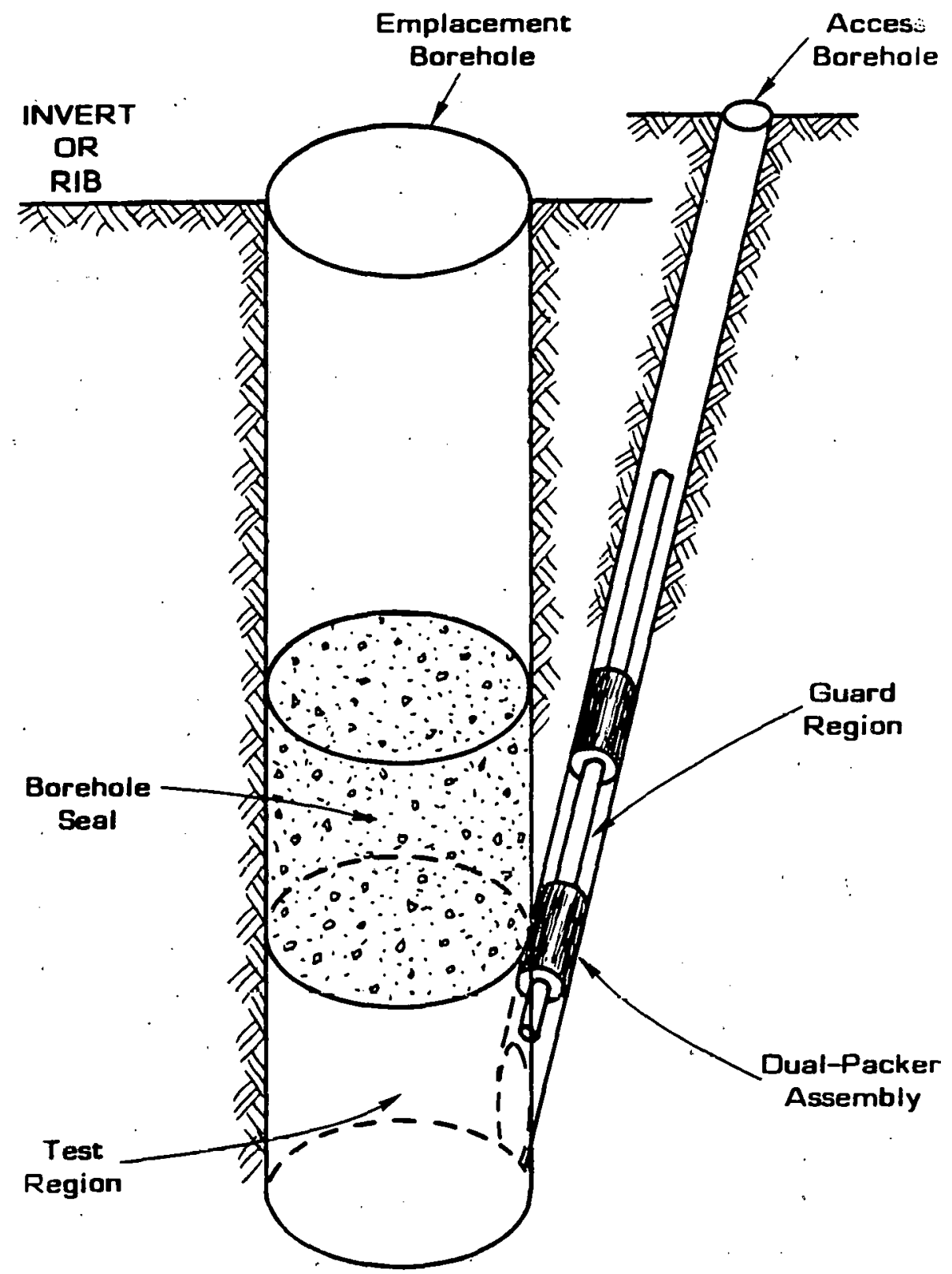

Figure 1. Illustration showing test configuration for the Small-Scale Performance tests. 
This report describes results of flow tests conducted on the Test Series $A$ and Test Series $B$ seals. Other pertinent information regarding Test Series A and B are contained in the following reports.

J. C. Stormont, Test Plan: Small-Scale Seal Performance Tests. Sandia National Laboratories. March 1985.

J. C. Stormont, Technical Editor. Development and Implementation: Test Series A of the Small-Scale Seal Performance Tests. SAND85-2602. Sandia National Laboratories. May 1986.

L. D. Wakeley and D. M. Walley, Development and Placement of an Expansive Salt-Saturated Concrete (ESC) for the Waste Isolation Pilot Plant (WIPP). SL-86-36. Waterways Experiment Station. September 1986.

L. L. Van Sambeek and J. C. Stormont. Thermal/Structural Modeling of Test Series A of the Small-Scale Seal Performance Tests, SAND87-0177. Sandia National Laboratories. 1987. (In preparation.)

G. Cones, et al. Small-Scale Seal Performance Tests Lahoratory Testing: Results of Test Series A and B. SL------. Waterways Experiment Station, 1987. (In preparation.)

J. C. Stumunt, Thermal/Structural Data Thruugh 180 Days of Test Series A of the Small-Scale Seal Performance Tests. SAND 87 -.. Sandia National Laboratories. 1987.

J. C. Stormont and C. L. Howard. Development and Implementation: Test Series B of the Small-Scale Seal Performance Tests, SAND 86-1329. Sandia National Laboratories. December 1986.

This report is arranged as follows. A test description is provided in Section 2. Data obrained during the Series $A$ and $B$ tests is described in Section 3. Analyses of these data and the associated uncertainties inherent in the data interpretation are presented in Section 4, with the discussion focusing on the MAE22 test results. Section 5 presents the Series $A$ test results. The Series $B$ test results are summarized in Section 6 . Conclusions are provided in Section 7. There are also two Appendices: Appendix A contains plots of the field data. while Appendix B contains results of a sensitivity study. 


\section{TEST SERIES DESCRIPTIONS}

\subsection{TEST SERIES A CONFIGURATION.}

Test Series $A$ involves the placement and testing of salt-saturated. expansive concrete seals in vertical (down) boreholes. Six seals, two each of three sizes (e.g., $15.2 \mathrm{~cm}$ diameter by $30.4 \mathrm{~cm}$ length: $40.6 \mathrm{~cm}$ diameter by $60.8 \mathrm{~cm}$ length: and. $91.4 \mathrm{~cm}$ diameter by $91.4 \mathrm{~cm}$ length) were emplaced during July 1985. One seal of each size contained thermal/structural instrumentation both in the seal and adjacent rock; the other seal contained no instrumentation. Fluid flow measurements were made on both the instrumented and noninstrumented seals.

Test Series $A$ was located in the area designated as the M-Room in the WIPP facility, as shown on Figure 2. A plan view of the holes associated with Test Series A layout is given in Figure 3. A complete description of the as-built test hole locations, dimensions, and configurations is given in the Development and Implementation Report (Stormont. 1986).

\subsection{TEST SERIES B CONFIGURATION.}

Test Series $B$ involves the placement and testing of salt-saturated. expansive concrete seals in horizontal boreholes. The three Series B seals emplaced in February 1986 were $91.4 \mathrm{~cm}$ in diameter by $91.4 \mathrm{~cm}$ in length. Two seals contained thermal/structural instrumentation, the remaining seal had no instrumentation. Fluid flow measurements were made on all seals.

Test Series B was also located in M-Room of the WIPP facility (see Figure 2). An elevation view of the Test Series $B$ boreholes is given in Figure 4. A complete description of the as-built test hole locations, dimensions. and configurations is given in the Development and Implementation Report (Stormont and Howard, 1986). 


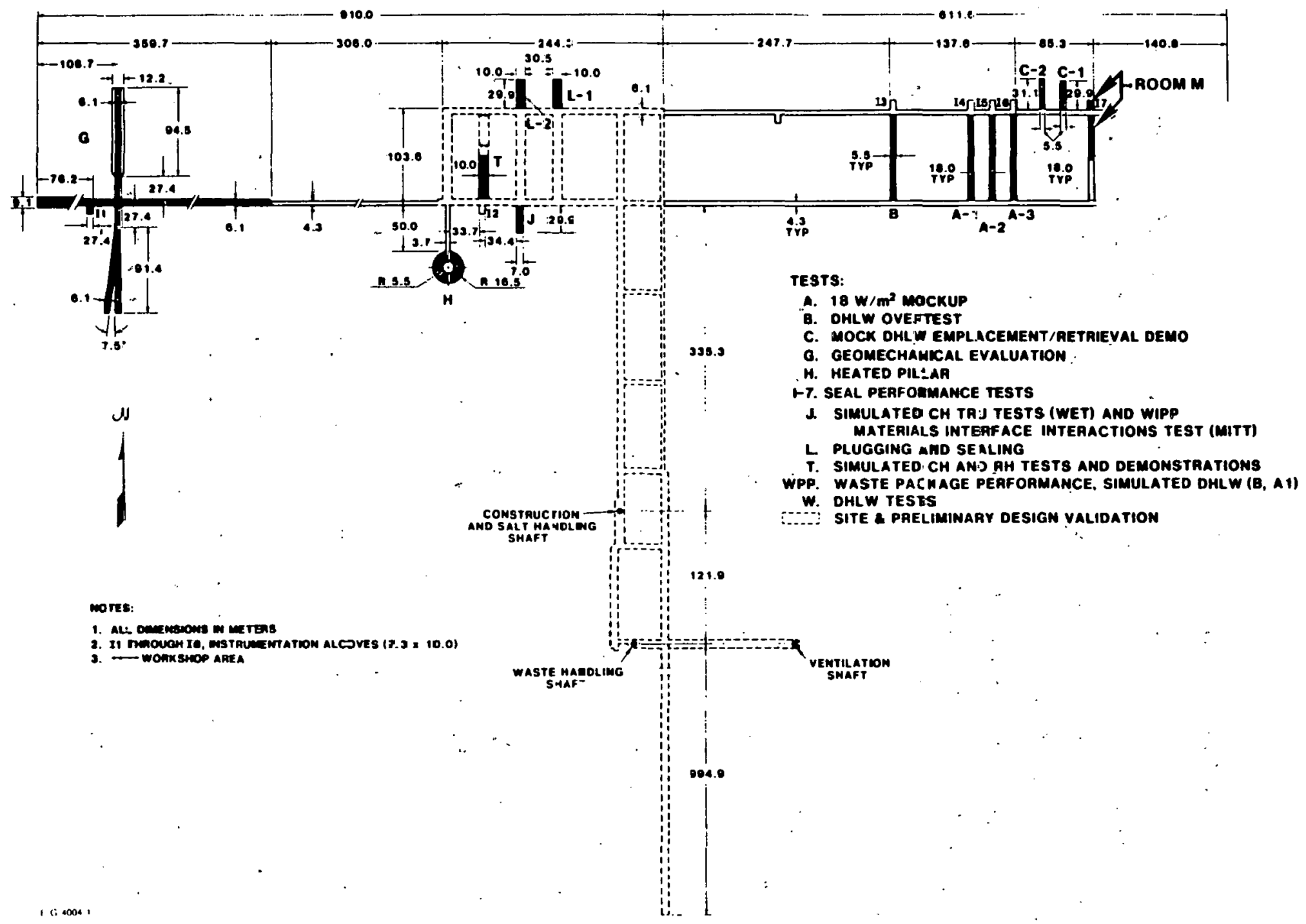

Alt ancmenows in me Tr

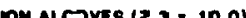

Figure 2. Plan vien of WIPP facility test area. 


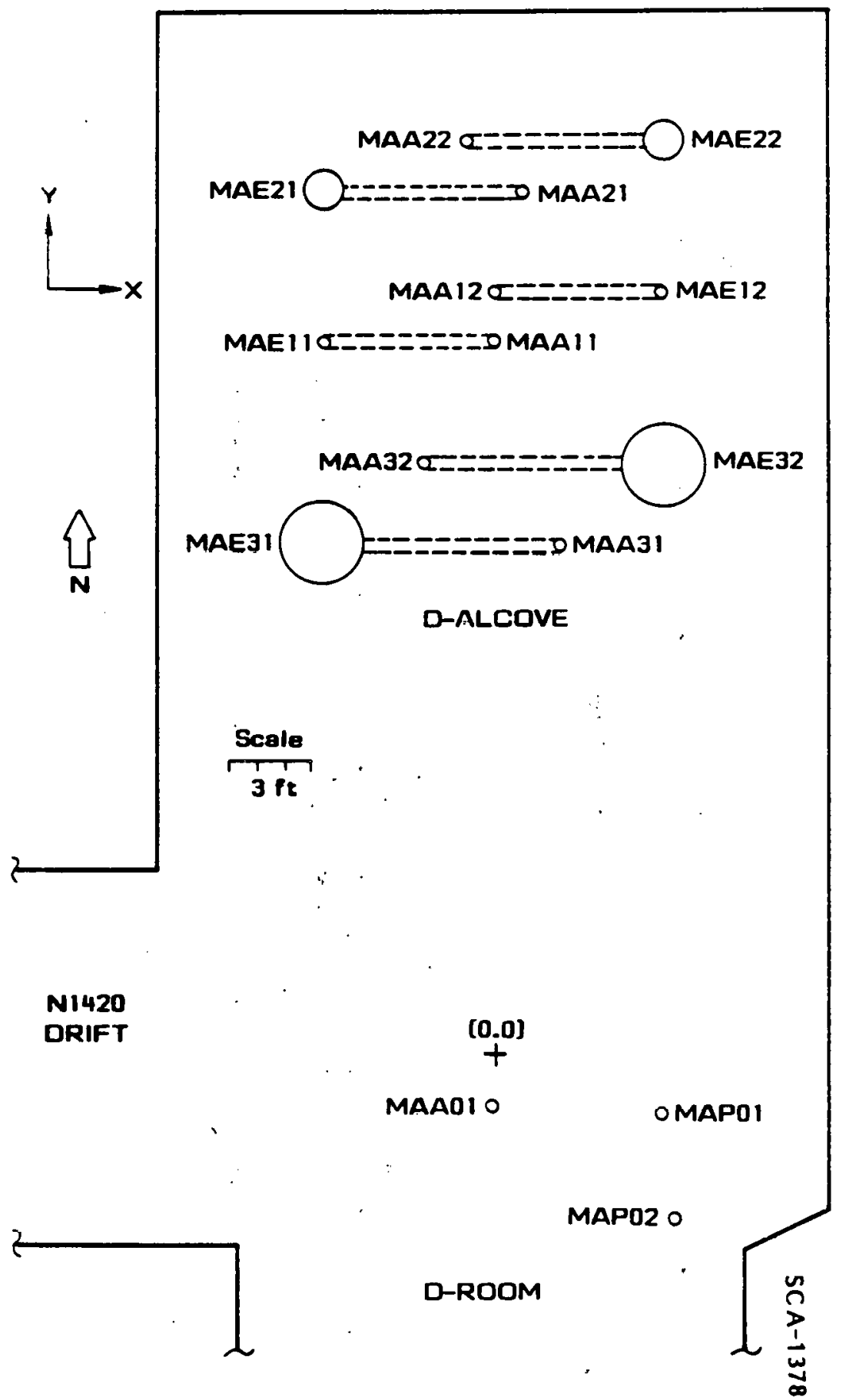

Figure 3. Borehole locations for the Test Series A:Small-Scale Seal Performance Tests. 
Scale

3 fo

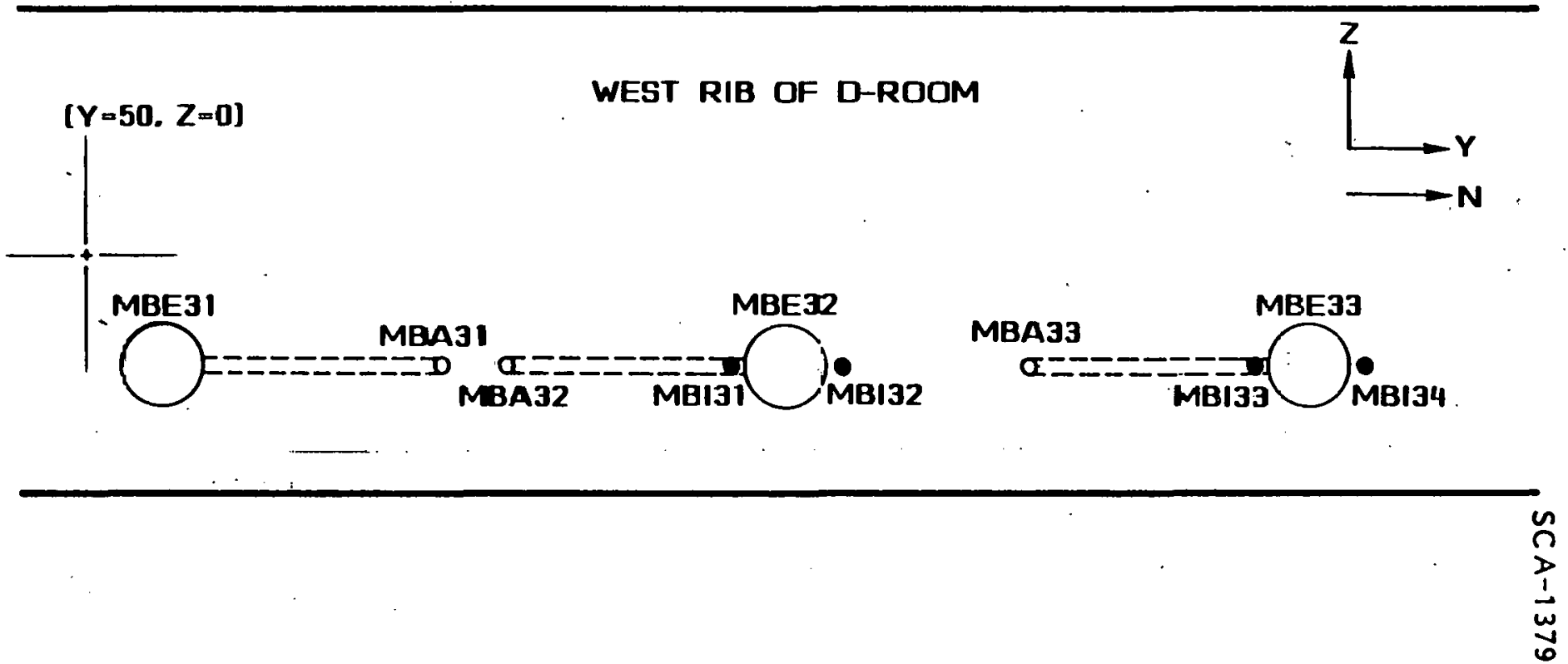

Figure 4. Borehole locations for the Test Series B Small-Scale Seal Performance Tests. 


\subsection{SEAL MATERIAL.}

The Test Series A and B seals were made from a salt-saturated expansive concrete designated ESC. Development of the ESC was detailed by Wakeley and Valley (1986). Its placement in Test Series $A$ is described by Stormont (1986), and in Test Series B by Stormont and Howard (1986). Laboratory measurements of physical properties of the ESC were contained in Comes, et al (1987). The ESC properties at 90 days were reported to be:

Unconfined Compressive Strength

Modulus of Elasticity

Poisson's Ratio

Density

Permeability
48.3 $\mathrm{MPa}$

24.1 GPa

0.19

$2422 \mathrm{~kg} / \mathrm{m}^{3}$

$0.8 \times 10^{-6}$ darcy

\subsection{TEST SYSTEM}

A schematic of the test system used to perform the gas flow, tracer penetration. and brine flow tests is shown on Figure 5. This measurement system, and the associated data analysis technique. is described in Reference 1. 


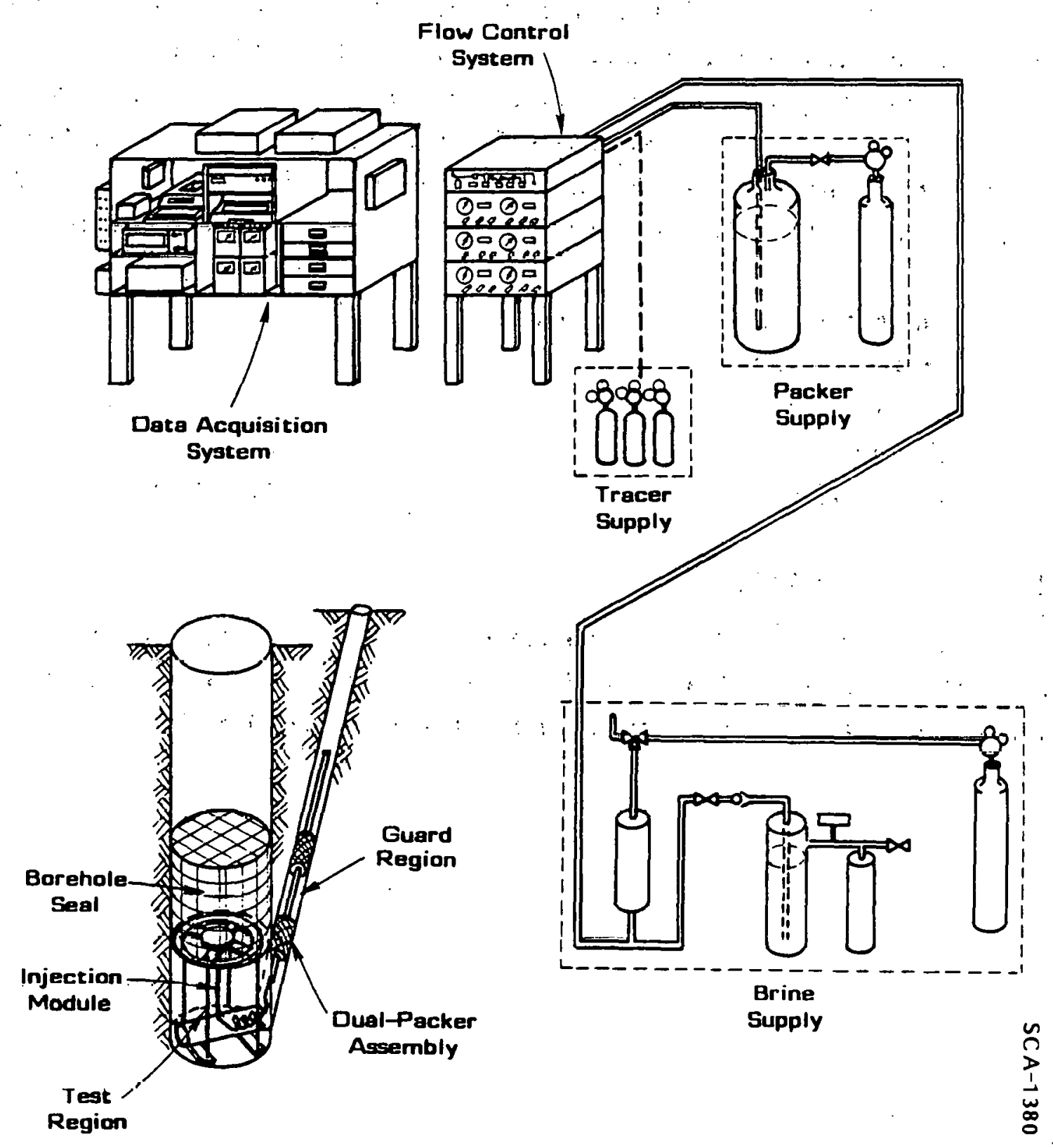

Figure 5. Schematic showing the Permeability Test System. 


\section{DATA ACQUISITION}

The complete suite of data obtained during the Series $A$ and $B$ tests is included in Appendix A. A general description of these data will be provided using results obtained from the MAE22 Series $A$ tests as examples. These MAE22 data are typical of the data obtained during Test Series $A$ and $B$.

Tests were performed on the MAE22 (41 cm diameter seal) in the following sequence. First. the test region shown on Figure 1 was pressurized to approximately $2.0 \mathrm{MPa}$ using ${ }^{\text {l. }}$ Witrogen. Once a steady flow had been established, tracer was then injected into the test region, and the test was either continued until the tracer was detected above the seal or until some preestablished time period had elapsed. These data were then used to determine the seal and/or formation permeabilities and to estimate the maximum aperture of any fractures which may connect the test region with the open hole above the seal. Once the tracer-gas/flow tests were completed, gas was evacuated from the test region using a vacuum pump. This region was then filled with brine and a brine flow test was initiated. During these tests, measurements were made of the test region pressure and brine flowrate. In addition. the seal surface was periodically checked for evidence of brine flow through the seal. These brine flow data were then used to determine the seal and/or formation brine permeabilities and to estimate the maximum brine flow fracture apertures. A detailed description of the data follows.

The MAE22 gas flow test region pressure history is shown on Figure 6. The region below the seal was initially pressured to approximately $2.0 \mathrm{MPa}$ for 15 hours to establish the gas flow and to determine the resulting flowrate. Nitrogen containing a $2 \times 10^{-9}$ concentration of bromochlorodifluoromethane as a tracer was slowly injected into the test region through the injection module located at the base of the seal. This process increased the test region pressure to about 2.3 MPa. The borehole was then shut in. and the pressure decay was monitored as a function of time. Simultaneously, gas samples taken in the 


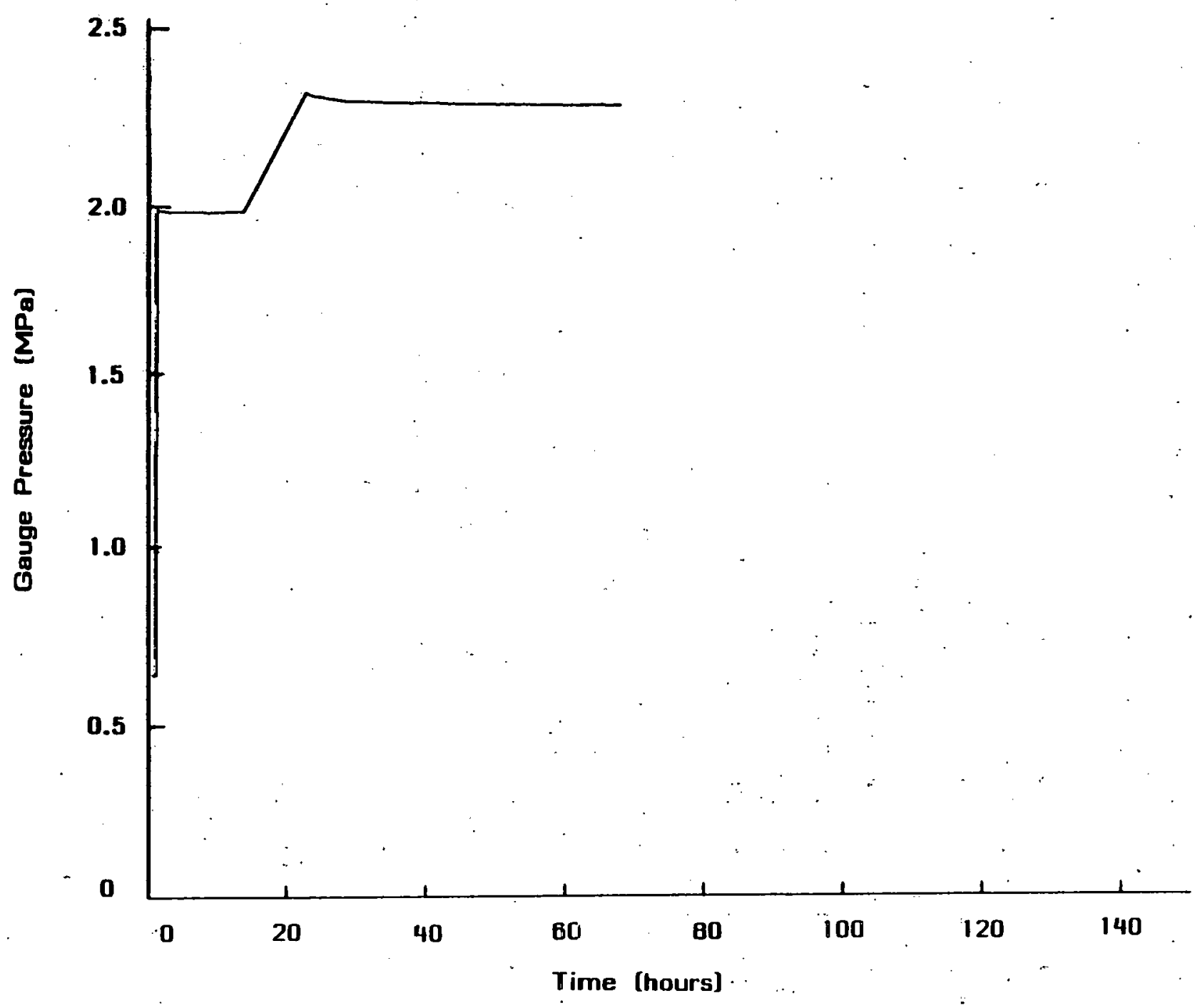

Figure 6. Test region pressure history measured during the MAE22 gas flow test. 
region above the borehole, were examined for evidence of tracer in order to verify whether flow did occur through or around the seal; and. if it did. to establish the travel time. The gas flow portion of the test was terminated after about 70 hours.

During the test. the pressure was monitored in the guard region of the dual-packer assembly shown on Figure 1. This measurement was made to ensure that the flowrate inferred by the pressure decay data shown on Figure 6 actually represented flow into or through the seal/formation system rather than leakage past the packer assembly. If, for example. significant flow occurred past this assembly. the dual-packer system would be moved within the borehole and re-set at a position where leakage past the packer was small compared to the measured test region flowrate. The guard region pressure history for the MAE22 gas flow test is shown on Figure 7. In this test, there was no flow out of the test region around the test region packer into the guard region.

Changes in gas temperature must be considered when calculating the volumetric flowrate from measured changes in pressure. As expected, the gas temperature increases during pressurization of the test region. However, within a few hours (as shown on Figure 8) the temperature decays to the ambient level where it remains for the duration of the test. In effect, these tests are conducted under isothermal conditions.

During the MAE22 brine flow test. flow to the test region was measured while maintaining an approximate $3.5 \mathrm{MPa}$ downhole pressure for approximately 140 days. As shown on Figure 9. slight variations in pressure occurred during this time. These generally occurred when flow to the test region was stopped and the region isolated in order to measure the associated pressure decay rate or to refill the high-pressure brine supply system. Even with these small pressure excursions, the downhole pressure was maintained between 3.4 and $3.7 \mathrm{MPa}$ for the duration of the test.

During the test. the top of the borehole seal was periodically checked for evidence of brine. A finding of brine above the seal would verify that flow 


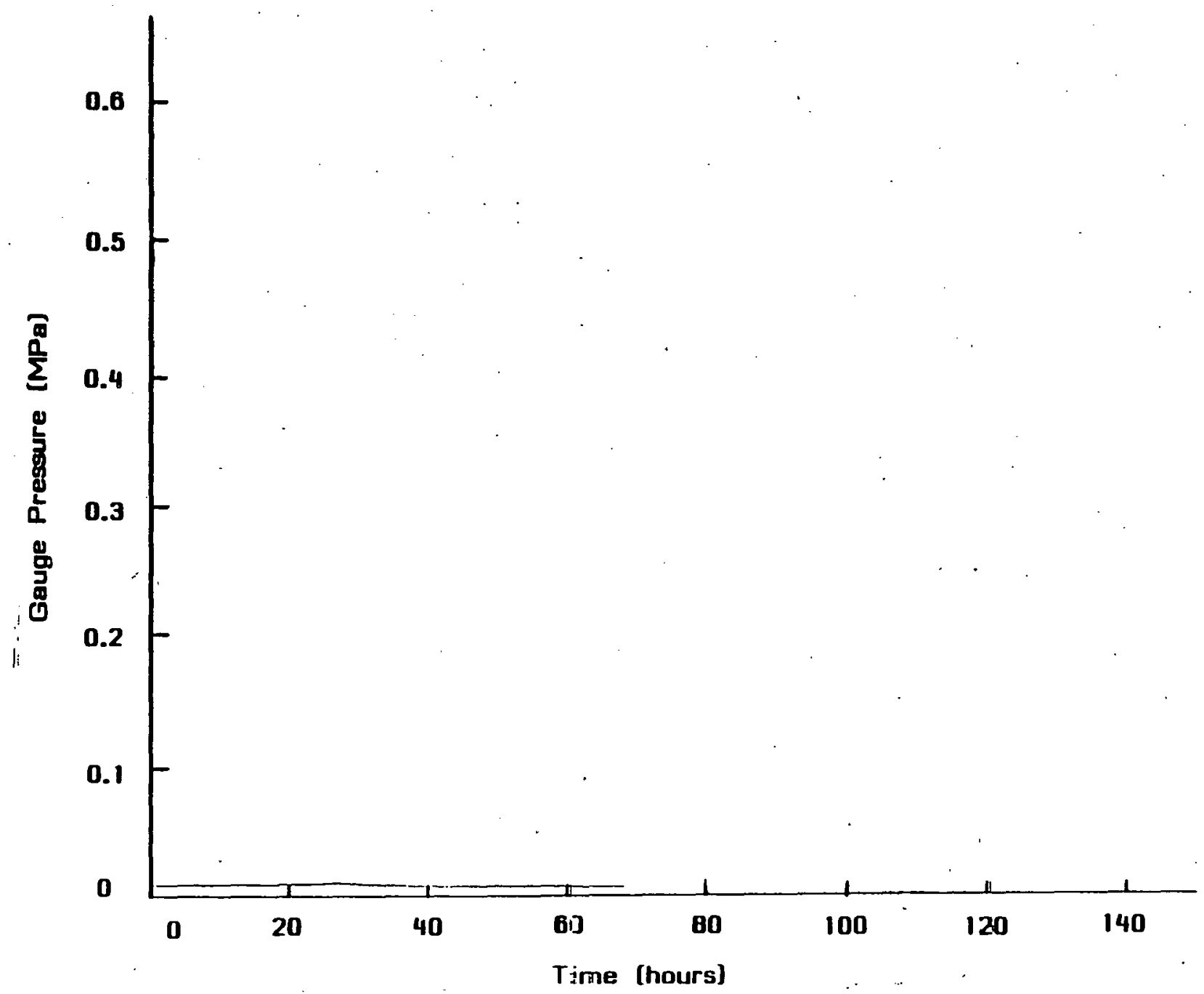

Figure 7. Guard ragion pressure hist Jry measured during the MAE22 gas flow test. 


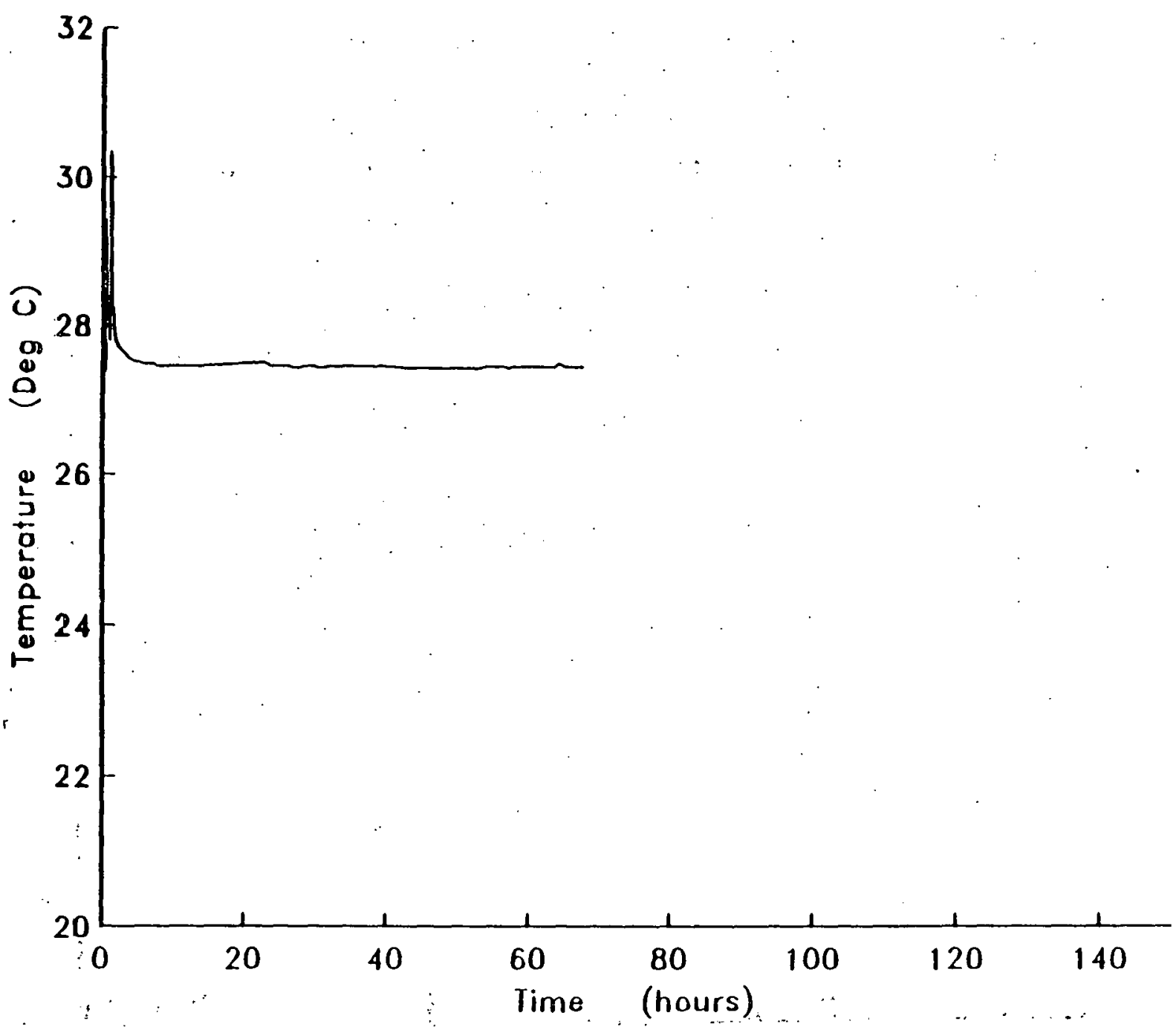

Figure 8. Test region temperature history measured during the MAE22 gas flow test. 


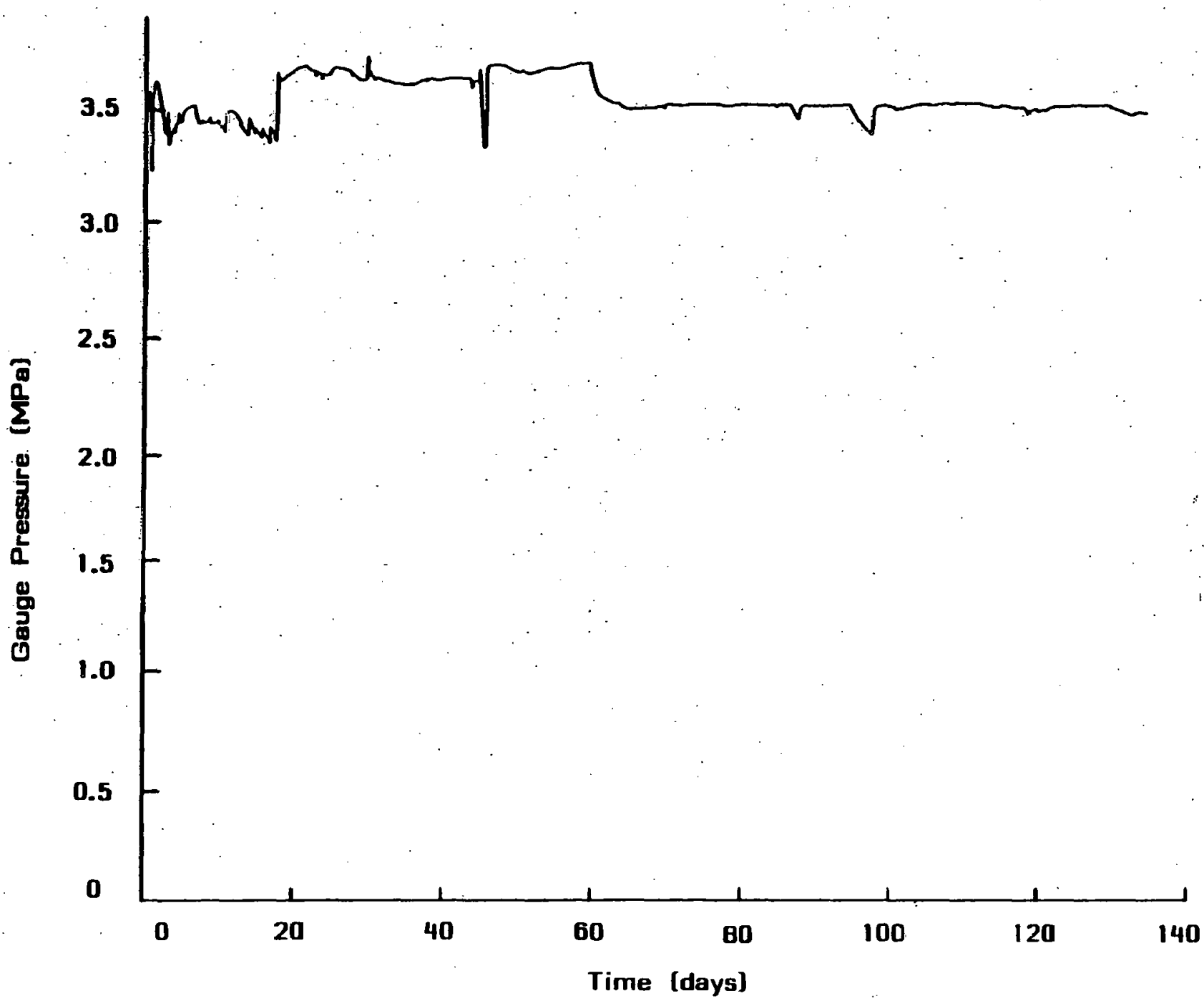

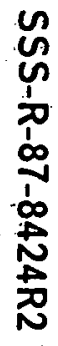

Figure 9. Test region pressure history measured during the MAE22 brine flow test. 
occurred either through or around the seal. The associated brine arrival time would be used to estimate the maximum aperture of those fractures which may connect the test region to the open borehole above the seal.

An average brine flowrate was determined each time the high-pressure brine reservoir was filled from the low-pressure supply system. Flowrates were calculated from the measured low-pressure brine supply pressure drop rate. The MAE22 low-pressure brine supply pressure history is shown on Figure 10. Corresponding brine flowrates are given on Figure 11. Flow into the MAE22 test region remained approximately constant at a rate of $0.01 \mathrm{cc} / \mathrm{min}$ throughout the test.

Flow into the seal/formation system is taken as the measured total flow into the test region (shown on Figure 11) minus that going from the test region to the guard region enclosed by the dual-packer assembly. Flow past the lower packer (shown on Figure 5) was determined from the measured guard region pressure changes. Continuous excursions in guard region pressure were seen to occur. and are shown on Figure 12 . The pressure drops result because the guard region was vented once the pressure approached $0.80 \mathrm{MPa}$. The large pressure spike, at about 19 days, was a result of system adjustments. However. the remaining excursions represent flow into the guard region.

One should note that if the $0.01 \mathrm{cc} / \mathrm{min}$ flow into the test region were instead to enter the guard region, the guard region pressure would increase to the test region value in about 2 hours. For these tests, the flow to the guard region represents less than $1 \%$ of that which is being injected into the test region. Reasons for the higher flow to the guard region at around 120 days remain unknown. Note that even at the higher flowrates. flow to the guard region represented less than $10 \%$ of that entering the test region.

Test region temperatures were also measured during the brine flow tests. The MAE22 results are shown on Figure 13. During the first 25 days, the test region temperature remained constant. After this time. the indicated temperature value gradually increased until the RTD used to measure temperature failed after 


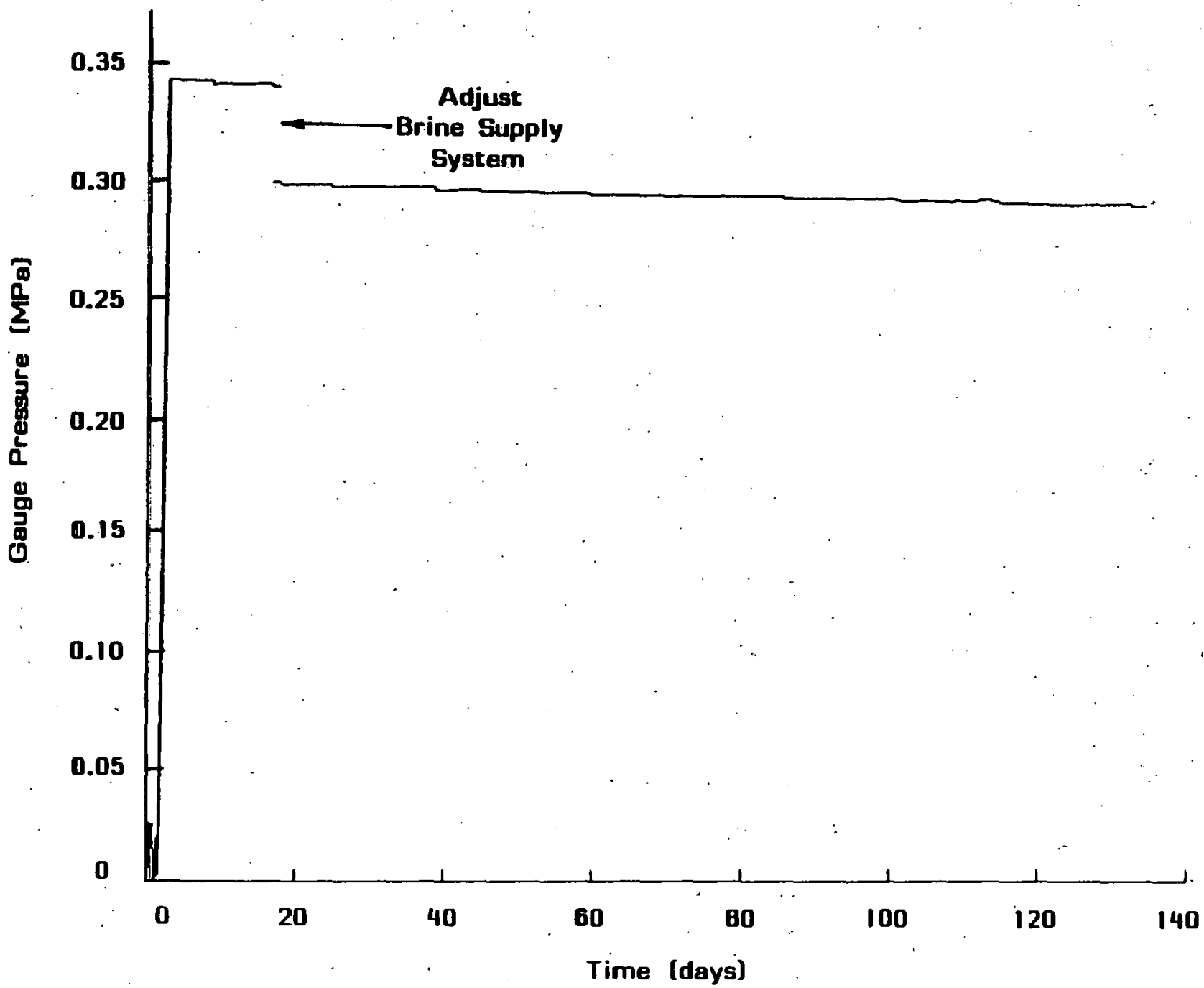

Figure 10. Brine supply pressure history measured during the MAE22 brine flow test. 


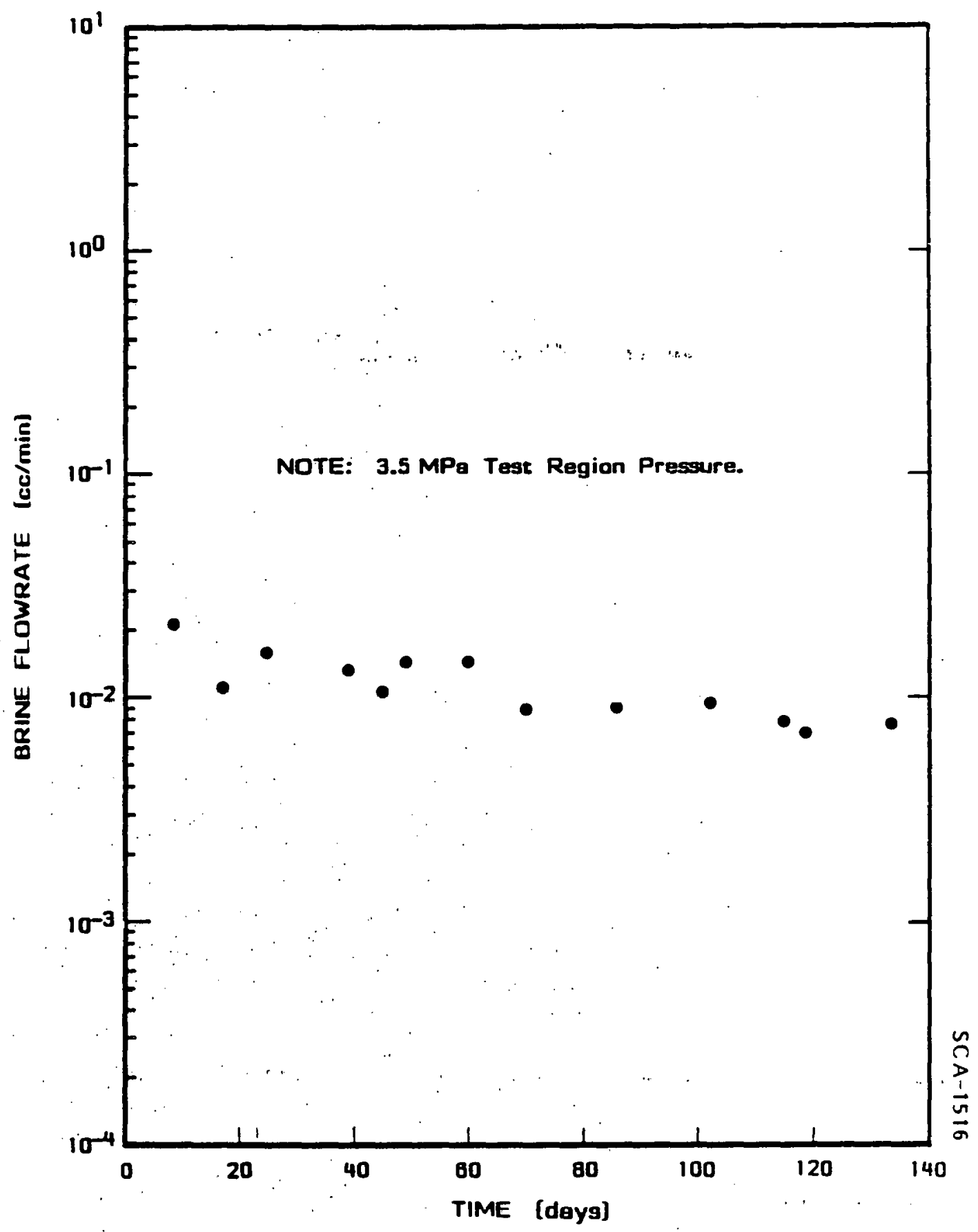

Figure 11. MAE 22 brine flowrate calculated from the brine supply pressure history shown on Figure 10. 


$$
\text { Hnd }
$$




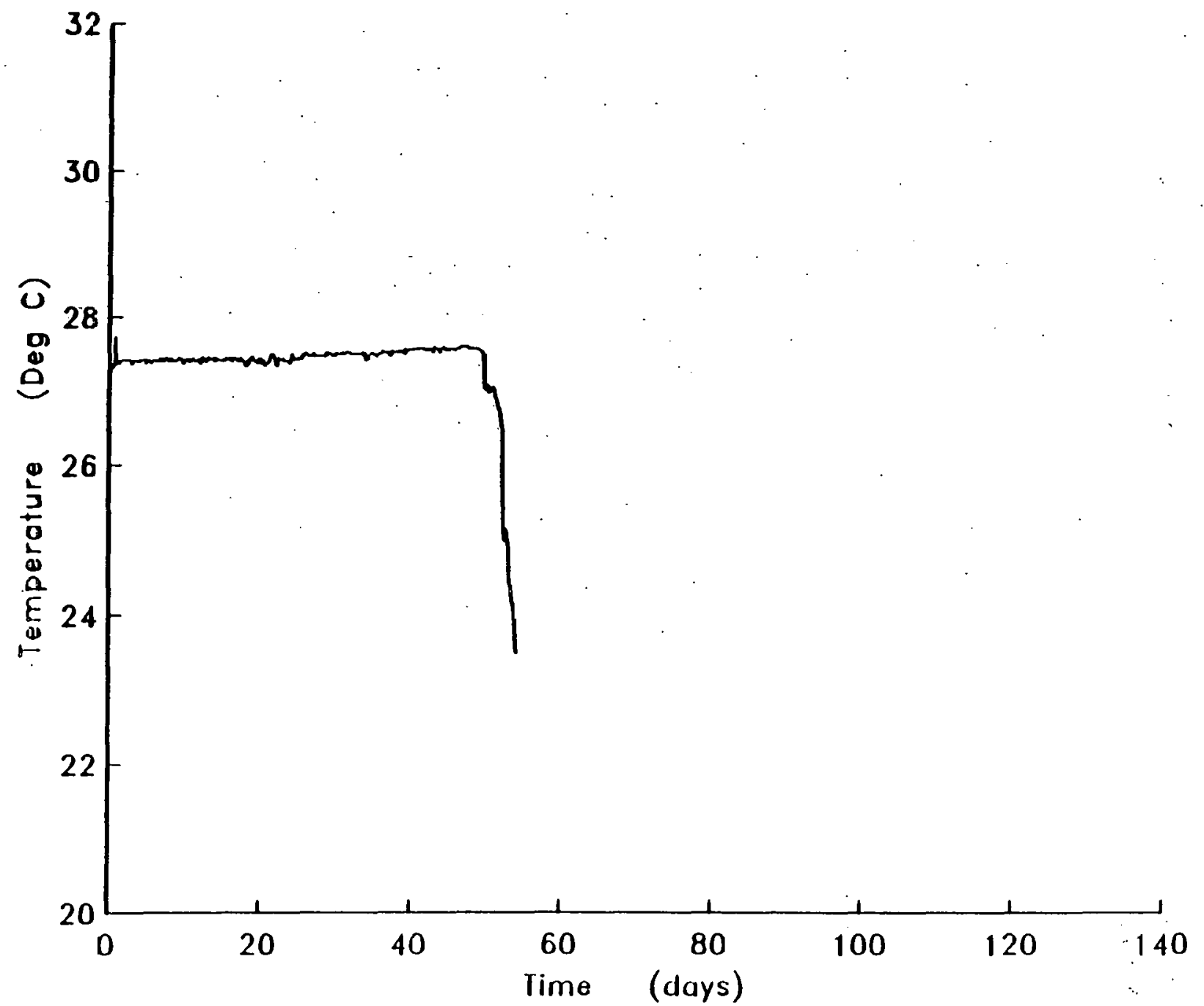

Figure 13. Test region temperature history measured during the MAE22 brine flow test. 
approximately 50 days. The small variations in temperature observed during the brine flow tests were insignificant in terms of evaluating brine flowrates.

In summary, data obtained during the MAE22 borehole seal tests are shown on Figures 6 through 13. These data are typical of data obtained during Series $A$ and $B$ tests. 


\section{DATA ANALYSIS AND EVALUATION}

The data analysis methods are summarized in Section 4.1. again using the MAE22 test results as examples. Uncertainties inherent in these analyses and interpretations are addressed in the discussion presented in Section 4.2.

\subsection{DATA ANALYSIS.}

The majority of the Test Series $A$ and $B$ data were analyzed using the one-dimensional steady-state planar and radial flow formulae given in Reference 1 : These formulae were used to estimate seal permeabilities. formation permeabilities, and fracture dimensions. Typically, seal permeabilities were determined assuming the surrounding formation was impermeable, while formation permeabilities were estimated assuming an impermeable seal. Clearly. flow in the seal/formation system could result from any combination of these two effects. Reported permeability numbers should, therefore, be interpreted as maximum possible values, rather than actual values.

An extensive quantity of gas flow and brine flow data were obtained during the MAE22 seal tests. These data were analyzed in detail using oneand two-dimensional numerical codes. These analyses will be described in the following paragraphs. The simple one-dimensional calculations used to analyze the majority of the experimental data provide estimates of formation and/or seal permeability values which agree within factors of two of those obtained from the detailed numerical analyses. This agreement is considered acceptable in light of the uncertainties in data interpretation discussed in Section 4.2.

Seal and formation permeability values were determined from the measured data in an iterative manner using one- or two-dimensional axisymmetric numerical solutions to the appropriate diffusion equations described in Reference 1. To determine a permeability for a gas flow test, the test region shut-in pressure decay was calculated as a function of time for selected permeability and porosity values. If the calculated decay rate corresponded to the measured value. the assumed properties were taken as correct. Recall that 
during a gas flow test. the test region shown on Figure 1 was pressured to some desired level, then shut-in, and the subsequent pressure decay history monitored as a function of time.

To determine permeability for a brine flow test. the test region flowrate was calculated as a function of time using the measured test region pressure history together with selected permeability and porosity values. If the calculated flowrate corresponded to the measured value, the assumed properties were taken as correct. Recall that during a brine flow test the test region was maintained at a constant pressure and the corresponding flowrate was measured.

Permeability values were determined for the MAE22 seal and surrounding formation based on the gas flow and brine flow test results. Comparisons of the measured pressure and flow histories with those calculated using the selected seal and formation permeability and porosity values are discussed in the following paragraphs.

Additional comparisons between the calculated and measured responses are provided in Appendix B. For example. the ordinate on the pressure decay curves has been amplified in the 2.0 to $2.5 \mathrm{MPa}$ region so that a more detailed comparison of the pressure decay histories can be made. In addition. results are also presented in Appendix B which show the sensitivity of the calculated responses to the selected permeability and porosity values.

The formation permeability has been determined for both the brine and gas flow tests based on an arbitrarily selected 0.001 porosity. As shown in Appendix B. at these low porosity values. the calculated results are quite insensitive to further reductions in porosity but moderately sensitive to increased porosity values. The calculated results are however quite sensitive to changes in the selected permeability values since the quasi-steady flow is approximately proportional to the permeability.

To determine the seal gas flow permeability, the seal porosity was arbitrarily selected as 0.01 . For gas flow through the seal, the sensitivity of the 
calculated results to changes in permeability and porosity are as described in the preceding paragraph.

The calculated brine flow through the seal is sensitive to both permeability and porosity since the quasi-steady flow, which is primarily sensitive to permeability, may not be established for a significant portion of the approximate 140-day test period. In contrast, quasi-steady gas flow through the seal is quickly established because the gas viscosity is much lower than that of brine.

A comparison of the calculated and measured MAE22 pressure decay histories obtained assuming gas flow through a seal surrounded by an impermeable formation is shown on Figure 14. The measured and calculated values compare favorably when the seal is assumed to have a $2 \times 10^{-7}$ darcy permeability and 0.01 porosity. Figure 15 shows results of a calculation in which an impermeable seal was surrounded by a permeable formation. In this case. the measured and calculated pressure histories are compatible. assuming a $6 \times 10^{-9}$ darcy formation permeability and 0.001 porosity.

A comparison of the calculated and measured MAE22 brine flowrates obtained assuming flow through an initially unsaturated seal surrounded by an impermeable formation is shown on Figure 16. The calculated and measured values are seen to be reasonably compatible, assuming a $2 \times 10^{-7}$ darcy permeability and 0.03 porosity. Results shown on Figure 16 were obtained using a one-dimensional analytical solution. Initially, the seal fills with brine and, as a result, the flow continues to decrease until it reaches a steady-state level after about 85 days. At this time, brine should begin flowing through the top surface of the seal. An absence of brine at the top surface suggests that at least some of the brine does not flow through the seal.

Results shown on Figure 17 were obtained assuming brine flow into a permeable saturated formation surrounding an impermeable seal. The calculated and measured results are in rough agreement for a $1.2 \times 10^{-8}$ darcy permeability and 0.001 porosity. For calculational purposes, a transmissive outer boundary was located at a distance $5 \mathrm{~m}$ from the cylindrical borehole. 


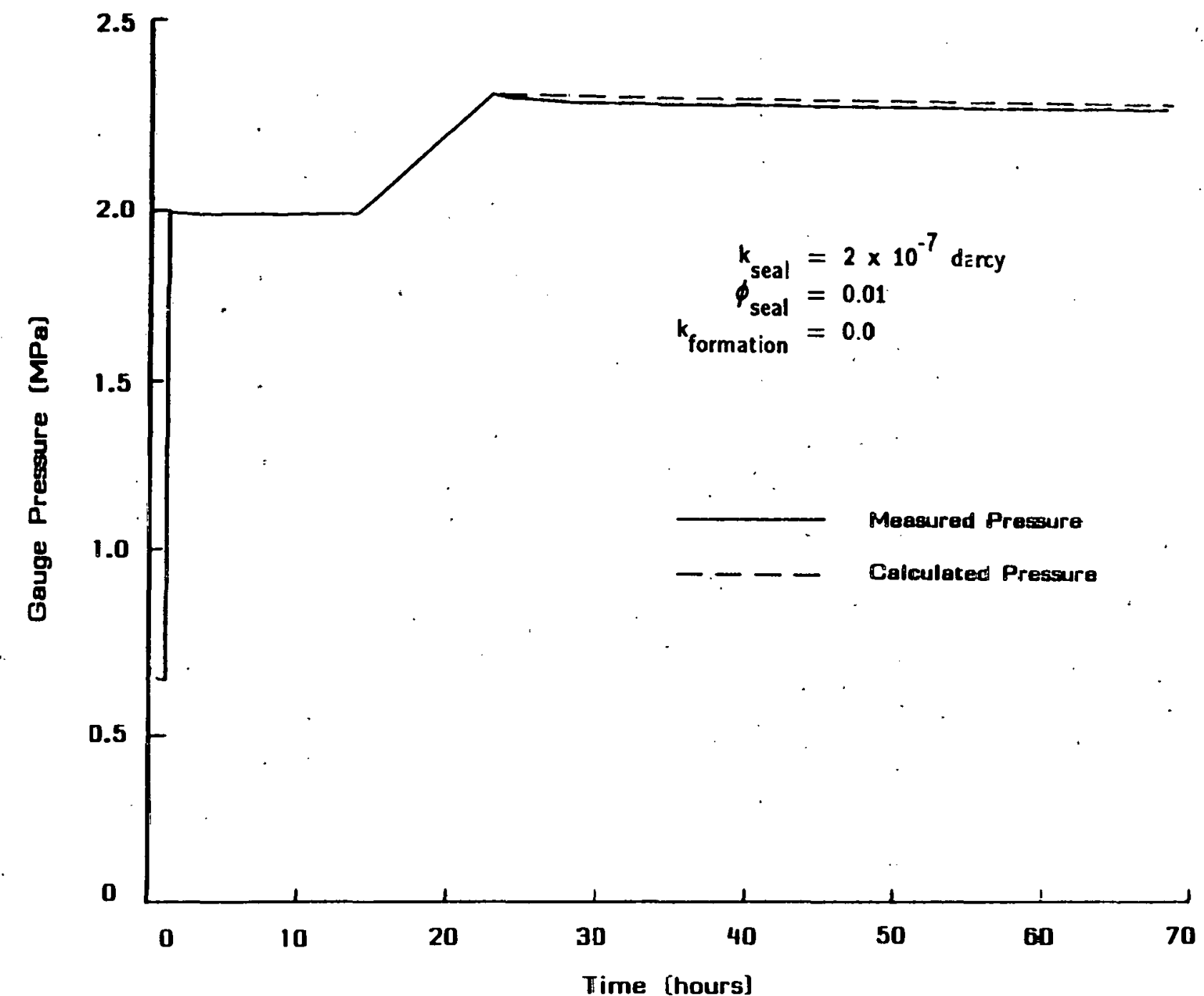

Figure 14. Comparison of calculated and measured MAE22 pressure decay histories asstming gas flow through the seal. 




Figure 15. Comparison of calculated and measured MAE22 pressure decay histories assuming gas flow into an unsaturated formation. 
$\stackrel{N}{\infty}$

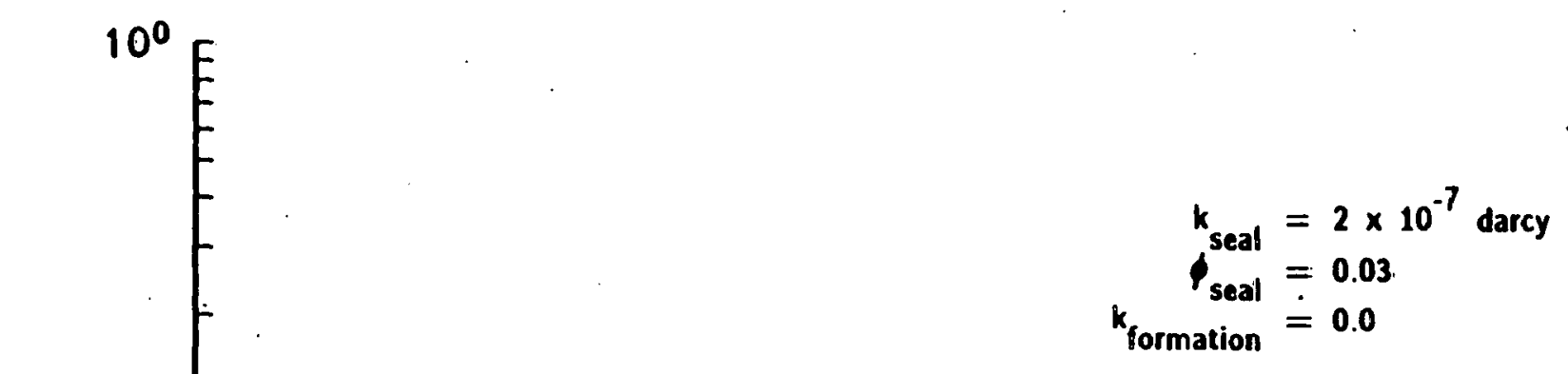

$n$
$N$
1
1
1
$\infty$
1
$\infty$
0
$N$
1
0
$N$

Brine Flow through

Top Surface of Seal

口

0 o 0

$\frac{3}{4}$

-

o

口

口

口

口

a a o a Measured Flow Rate

Calculated Flow Rate

$10^{-3} L_{0}$

20

$40 \quad 60$

Time (days)

Figure 16. Comparison of calculated and measured MAE22 brine flowrates assuming flow through and initially unsaturated seal. 


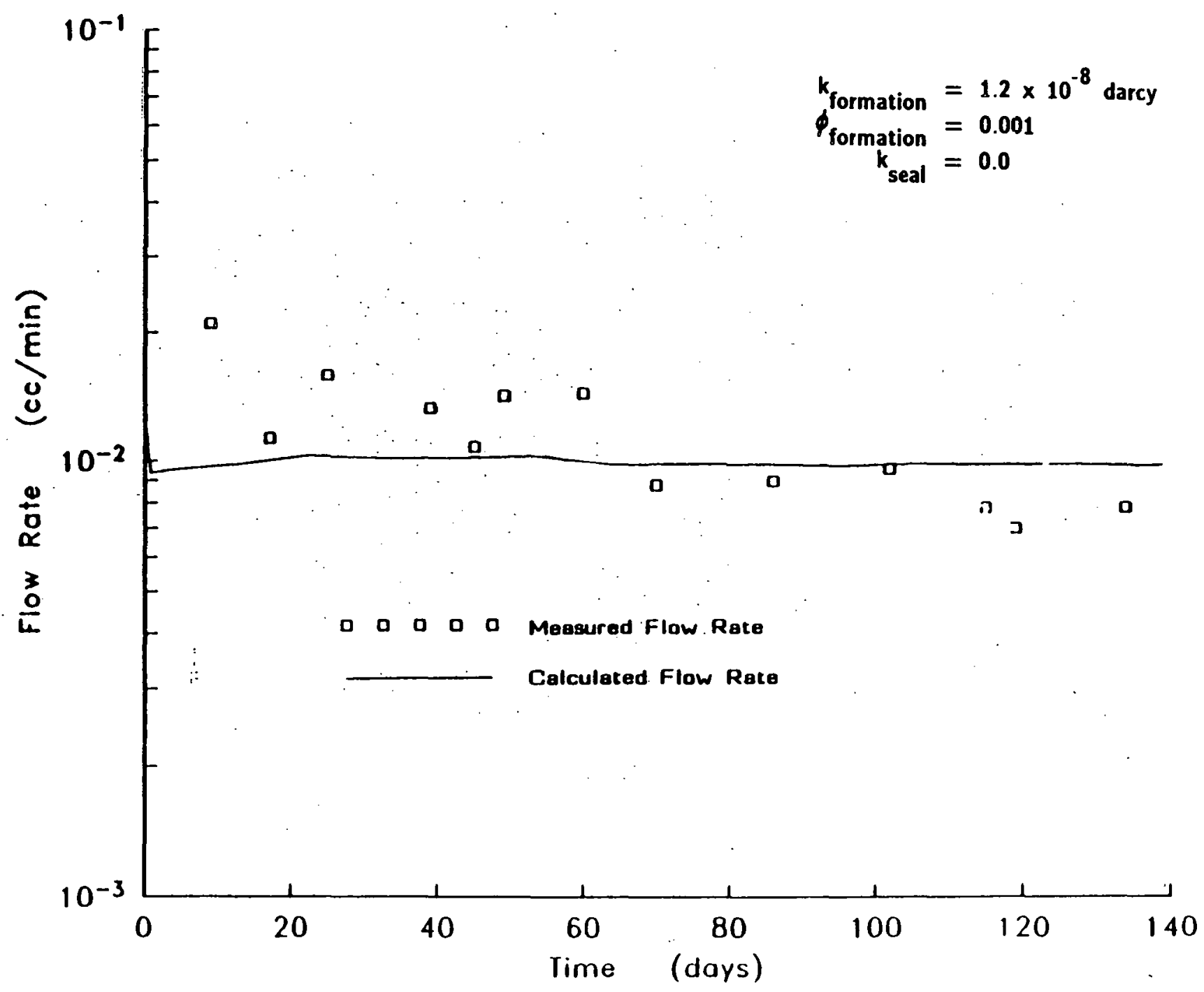

Figure 17. Comparison of calculated and measured MAE22 brine flowrates assuming flow into a saturated formation. (Transmissive outer boundary at $r=5$ meters.) 
The influence of the outer boundary condition used in the numerical calculation may be evaluated by comparing results shown on Figure 17 with those on Figure 18. Replacement of the transmissive boundary located at the $5 \mathrm{~m}$ radius with a zero flow boundary is seen to change the calculated flowrate by less than $10 \%$.

It can be seen on Figures 16 through 18 that the measured flowrate continually decreased with time. This decrease may be simulated to an extent by assuming the flow is through an initially unsaturated seal. However, even after the time at which the calculations suggest the flowrate should become constant. it continues to decrease. The reasons why the measured flowrate decreases with time cannot be determined from the simple Test Series A pressure and flow measurements.

\subsection{DATA EVALUATION.}

Many in situ flow reports emphasize that permeability values inferred from the data are accurate to within an order-of-magnitude. Reasons for these uncertainties. as they apply to seal testing, will be discussed briefly in this subsection.

First. it is important to realize that for Test Series A and B, the orderof-magnitude uncertainty in the inferred permeability values is not associated with the accuracy of the measurement system. This measurement system can determine pressures and temperatures to within a few percent (as reported in Reference 1). Flowrates can easily be inferred from these data to within a factor of two. even for the very low rates shown on Figure 11 . In fact. flowrates which are at least one order-of-magnitude lower could also be determined to within factors of two by simply testing over longer time intervals.

The major uncertainties are introduced by the assumptions which must be made when calculating formation characteristics, such as permeability. from measured data. Some of these uncertainties will be described in a qualitative manner in the following paragraphs. 


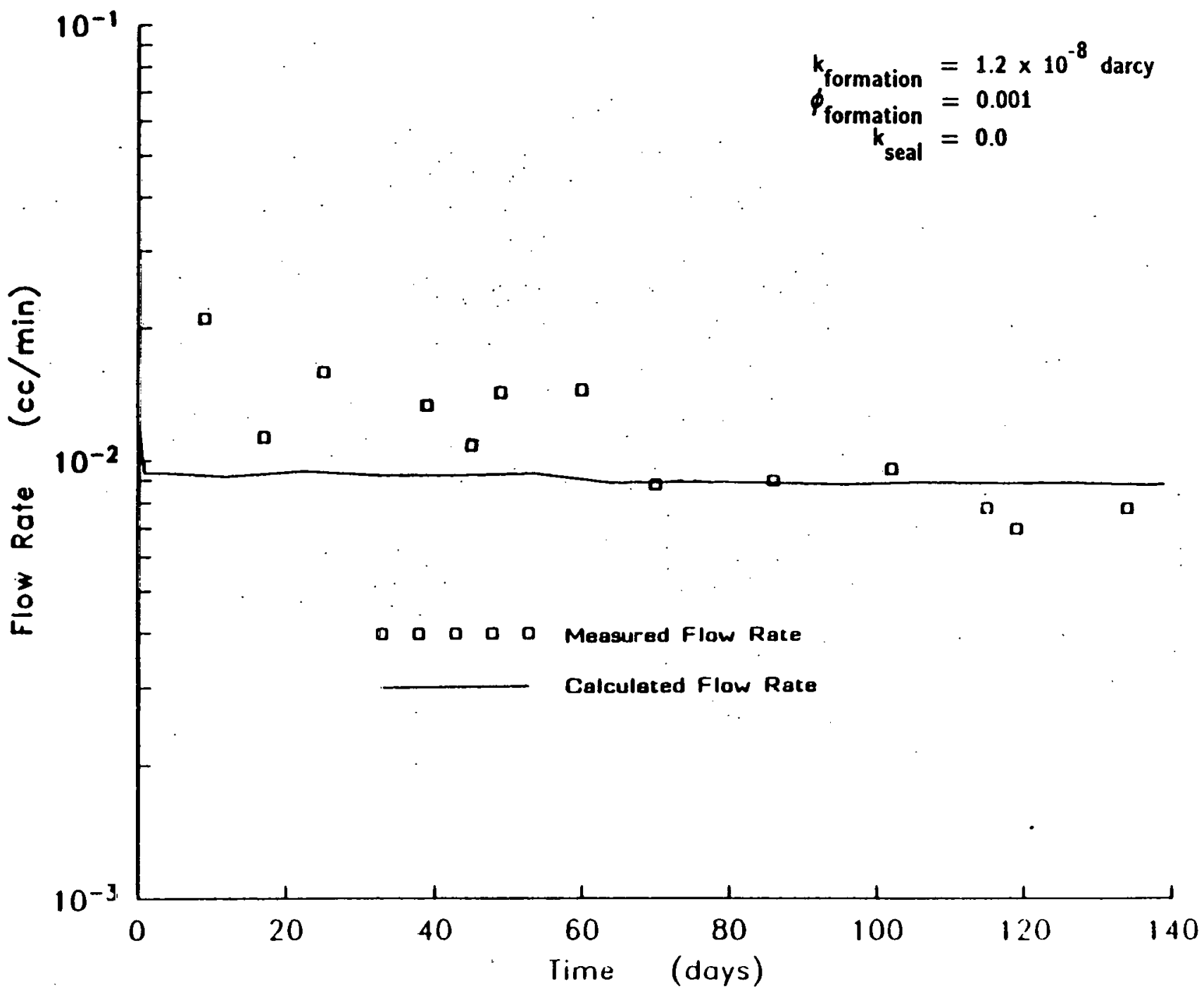

Figure 18. Comparison of calculated and measured MAE22 brine flowrates assuming flow into a saturated formation. (Zero flow outer boundary at $r=5$ meters.). 
In Test Series A and B, the parameter of primary interest is the seal permeability. Maximum values for seal permeability have been determined by assuming all flow goes through the seal. However, as discussed in this report. one cannot determine whether the flow is going through the seal, into the surrounding formation, or some combination thereof. Furthermore. the test itself may perturb the formation--thereby affecting apparent flowrates. Such perturbations may not always be as readily identifiable as those which occurred during the MAE12 and MAE32 brine tests described in Section 5.2. Consequently, the reported seal and formation permeabilities represent maximum values. In fact, actual permeabilities may be orders-of-magnitude lower than this maximum reported value.

Since the flow paths cannot be identified, reporting a seal permeability may itself be misleading since the flow could possibly occur through the seal/formation interface. In that case, it may be more enlightening to describe the performance of the various diameter seals in terms of flow-per-unit interface length.

The measured flow into the test region may not represent flow through the seal or into the formation at all. For instance. if the brine mix (which is saturated at ambient pressure) is undersaturated at the $3.5 \mathrm{MPa}$ downhole pressure. the back-fill and borehole walls may slowly dissolve. In fact. if one assumes a $10 \%$ undersaturated brine initially. then approximately $15 \%$ of the measured MAE22 brine flow into the test region could be due solely to dissolution of the halite formation. The relative salt/water volume change associated with dissolution of the halite represents approximately $12 \%$ of the actual value of the halite which is dissolved. Another possible volume change involves borehole closure due to salt creep. The maximum estimated hole closure rate at $3.4 \mathrm{MPa}$ is consistent with a change in the measured flowrate of less than $1 \mathrm{~cm}^{3} /$ day or about $7 \%$ of the total measured flow. If this occurs. then the flow through the formation/seal system would be larger than that indicated by the brine flow measurements. 
The fact the MAE22 seal brine flowrate decreased slowly with time (as illustrated on Figure 18) can be extremely important when modeling the very long-term response. Possible mechanisms causing this decrease can include precipitation. healing. or creep closure of the open pore spaces. particularly if the flow is into the formation. However, a decay similar to this may also result if there exists a non-uniform stress-field surrounding the hole with stresses increasing and the pore volume decreasing with increasing distance from the hole.

In these low permeability formations. threshold pressure effects may also be important. If so, a higher test region pressure could substantially increase the flowrate compared to that which would be anticipated from pressure changes alone. Furthermore, gas flow permeabilities may be in error by factors of two to three as a result of the Klinkenberg effect. Estimates of gas and brine permeabilities also depend strongly on the degree of pore saturation, and this is unknown for the WIPP Site formation.

With the exception of brine flow through the seal. for the tests described here. the transient effects associated with filling the pore space or developing a steady-state pressure profile are generally negligible due to the extended test time. These effects occur on time scales which are short compared to those associated with creep closure precipitation, dissolution, etc.

Temperature changes can be very important when testing with gas, and possibly with brine. Fortunately, the temperatures of the formation surrounding the WIPP facility are essentially constant; hence. the flow can be considered isothermal.

Tracers are primarily used to identify flow paths and to provide conclusive evidence that the flow does or does not go through the seal. However. tracer flow arrival times can also be measured and can then be used to estimate maximum fracture aperture dimensions.

A number of factors significantly limit the accuracy to which fracture aperture dimensions can be determined. First. operational realities are such that 
rapid arrival times under the 0.1 to 0.2 -hour period are not accurately measured, and are therefore often overestimated. Second. if the total fracture dimension is very small, the quantity of tracer which comes through may be small and hence may not be detectable for some period of time following its initial arrival. Finally, the fracture path length (which, for analysis purposes, is taken as the seal length) may actually be quite tortuous and be much longer than assumed. All of these factors tend to lead to estimates of the fracture aperture which are. in effect, too small. 


\section{TEST SERIES A RESULTS}

Results of the gas and brine flow tests performed on the Test Series A seals are described in Sections 5.1 and 5.2 respectively. The seal performances with the different flow media are then compared in Section 5.3.

\subsection{GAS FLOW. TESTS.}

A summary of the Test Series A tracer-gas/flow tests is provided in Table 1. The listed seal test characteristics will be described separately in the following paragraphs.

The permeability values shown were calculated assuming either a permeable seal placed in an impermeable formation. or an impermeable seal placed in a permeable formation. Clearly. some combination of these models is more realistic. All permeability values shown were determined from the data using simple one-dimensional steady-state flow models.

The Test Series A seals, with the exception of MAE31: (which had an obvious leak). had calculated permeabilities of approximately $5 \times 10^{-7}$ darcy for an assumed 0.01 porosity. In contrast. calculated formation permeability values steadily increased with increasing borehole diameter. This result suggests that the flow may actually occur through the seal, or through some formation discontinuity that exhibits flow dimensions which change as the ratio of seal area divided by seal length. If flow occurred only at the seal/formation interface, then the permeabilities calculated based on the seal cross-section areas should decrease with increasing seal diameter.

It should be noted that the formation permeability values shown on Table 1 are consistent with those determined during the formation permeability tests described in Reference 2. Furthermore, the variation in permeability values shown in Table 1 are within the data scatter obtained during the Reference 2 tests. 
Table 1

Summary of Series A Tracer Gas Flow Tests

\begin{tabular}{|c|c|c|c|c|c|}
\hline \multirow{2}{*}{ SEAL } & \multicolumn{2}{|c|}{$\begin{array}{c}\text { PERMEABILITY I } \\
\text { [dercy] }\end{array}$} & \multirow{2}{*}{$\begin{array}{l}\text { TRACER } \\
\text { ARRIVAL } \\
\text { (hours) }\end{array}$} & \multirow{2}{*}{$\begin{array}{l}\text { ESTIMAATED } 2 \\
\text { MAXIMUMI } \\
\text { FRACTURE } \\
\text { APERTURE Ccml }\end{array}$} & \multirow{2}{*}{ COMMENTS } \\
\hline & SEAL & FORMATION & & & \\
\hline MAE 11 & $3 \times 10^{-7}$ & $5 \times 10^{-8}$ & No Arrival & {$\left[<10^{-6}\right]$} & -- \\
\hline MAE 12 & $6 \times 10^{-7}$ & $4 \times 10^{-8}$ & No Arrival & {$\left[<10^{-6}\right]$} & -- \\
\hline MAE2I & $4 \times 10^{-7}$ & $1 \times 10^{-\theta}$ & No Arrival & {$\left[<10^{-6}\right]$} & -- \\
\hline MAE22 & $3 \times 10^{-7}$ & $1 \times 10^{-8}$ & No Arrival & {$\left[<10^{-6}\right]$} & -- \\
\hline MAE3I & $2 \times 10^{-5}$ & $2 \times 10^{-6}$ & 1.5 & $1.3 \times 10^{-5}$ & $\begin{array}{l}\text { Obvious Leak } \\
\text { Through Seal }\end{array}$ \\
\hline MAE32 & $5 \times 10^{-7}$ & $3 \times 10^{-8}$ & No Arrival & {$[<2=10-6]$} & -- \\
\hline
\end{tabular}

1 Calculated assuming all flow is either through the seal or thraugh the formation.

[4 formation $=0.001$. $\phi_{\text {seal }}=0.011$

2 Numbers in parentheses suggest test sensitivity in that tracer arrival should have occurred by the end of the test if the fracture aperture were greater than the value shown. 
Tracer flow tests were performed on each of the Test Series A seals. For these tests, a different tracer was injected below each seal. With the exception of MAE31. no tracer was detected above a seal. Failure to detect tracer above a given seal implies that, if fractures exist. their maximum apertures are less than the dimension shown. It should be noted for reference purposes. that under uniform porous flow conditions. a tracer would travel through the $3 \times 10^{-7}$ darcy MAE22 seal in about 36 hours.

The MAE31 seal clearly leaked. Gas could be seen bubbling through a thin layer of brine covering the seal surface. Furthermore, as shown in Table 1. its calculated permeability was approximately two orders-of-magnitude greater than the values determined for the other Test Series A seals.

Tracer was first injected below the MAE31 seal. following the same procedure used to test the other Test Series A seals. Even though the seal was known to leak. there was no tracer found above the seal within 48 hours following injection. A second tracer, having a higher concentration (which increased its detectability by a factor of $10^{5}$ ). was therefore introduced. Its arrival was measured at the time shown in Table 1.

Since all the Test Series A seals were tested using the lower concentration tracer gas mix, it is possible that minute fractures exist in the other seals that were not detected. However. this possibility is considered slight in light of the fact that the relative seal/formation permeabilities of these other systems were almost two orders-of-magnitude below that of MAE31.

\subsection{BRINE FLOW TESTS.}

Brine flow tests were conducted on the MAE12, MAE22, and MAE32 seals. During these tests. the test region pressure and flowrate were measured. In addition. the top surface of the seal was continuously monitored for evidence of brine penetration. Results of these tests are summarized in Table 2. 
Table 2

Summary of Series A Brine Flow Tests

\begin{tabular}{|c|c|c|c|c|}
\hline \multirow{2}{*}{ SEAL } & \multicolumn{2}{|c|}{$\begin{array}{l}\text { PERMEABIEITY/POROSITY } \\
\text { [darcy] }\end{array}$} & \multirow{2}{*}{$\begin{array}{l}\text { ESTIMATED } 4 \\
\text { MAXIMUM } \\
\text { FRACTURE } \\
\text { APERTURE [cm] }\end{array}$} & \multirow{2}{*}{ COMMENTS } \\
\hline & SEAL & FORMATION & & \\
\hline MAE 12 & --1 & -- & $<7 \times 10^{-7}$ & $\begin{array}{l}\text { No Visible Flow Through Seal } \\
\text { During 140-day Test } \\
\text { With } 250 \text { psig Brine Pressure }\end{array}$ \\
\hline MAE22 & $2.0 \times 10^{-7} / 0.03^{2}$ & $1.2 \times 10^{-8} / 0.01 \leftrightarrow 0.0013$ & $<1 \times 10^{-6}$ & $\begin{array}{l}\text { No Visible Flow Through Seal } \\
\text { During } 140 \text {-day Test } \\
\text { With } 500 \text { psig Brine Pressure }\end{array}$ \\
\hline MAE32 & --1 & - & $<2 \times 10^{-6}$ & $\begin{array}{l}\text { No Visible Flow Through Seal } \\
\text { During 140-day Test } \\
\text { With } 250 \text { psig Brine Pressure }\end{array}$ \\
\hline
\end{tabular}

I Plug and formation permeabilities could not be determined as brine llowed to adjacent boreholes - - possibly along horizontal fractures. The test pressures were reduced from the $3.5 \mathrm{MPa}$ design level [at which the flowrates continued to increase as

a func:ion of time] to $1.1 \mathrm{M} \mathrm{MPa}$ (where the rates remained constart.

2 Assumes seal is initially unsaturated.

3 Assumes formation is saturated.

4 Suggests test sensitivity in that tracer arrival should have occurred by the end of the test if the fracture aperture were greater than the value shown. 
Permeability values could only be determined for the MAE22 seal/formation system during the Test Series A brine flow tests. Horizontal fractures apparently opened in the floor when the MAE12 and MAE32 test regions were pressured to $3.5 \mathrm{MPa}$, resulting in rapidly increasing flowrates as shown in the Appendix A data. Subsequently, the test region pressure was lowered to the 1.8 MPa level in order to maintain a constant flowrate. Even at this lower test region pressure. flow was still observed to be traveling from the test regions to nearby access holes. As a result, the MAE12 and MAE32 tests can only be used to determine whether flow occurs through the seal. given a $1.8 \mathrm{MPa}$ test region pressure.

The MAE22 test data are consistent with a brine flow through a seal having a $2 \times 10^{-7}$ darcy permeability and 0.03 porosity. or through a saturated formation having a $1.2 \times 10^{-8}$ darcy permeability and 0.01 to 0.0001 porosity. Note that these permeability values were determined using the numerical techniques described in Section 4.1.

During the brine flow tests there was no visible evidence of flow through any seal during the approximate 140-day test period. Absence of flow through the seals suggests that if fractures do exist connecting the test region to the open volume above the seal, their maximum aperture should be less than the listed values.

Brine flow tests had previously been performed on a $1.8 \mathrm{~m}$ long by $20 \mathrm{~cm}$ diameter cement grout seal installed in anhydrite at the $1370 \mathrm{~m}$ depth in the AEC-7 borehole. This $20 \mathrm{~cm}$ diameter seal was found to have a brine flow permeability of about $5 \times 10^{-5}$ darcy. Tracer flow studies performed during that test (described in Reference 3 ) suggested a maximum fracture aperture of approximately $2 \times 10^{-5} \mathrm{~cm}$. which is similar to that found during the gas flow tests conducted in the MAE31 borehole. 


\subsection{COMPARISON OF GAS AND BRINE TESTS.}

A comparison of the MAE22 seal gas and brine flow test results is shown in Table 3. Values shown for the plug and formation permeabilities were determined using the multi-dimensional numerical analyses described in Section 4.1. The gas flow results, therefore, differ slightly from the Table 1 values obtained using simple one-dimensional steady-flow models.

If all flow is assumed to go through the seal, then the MAE22 seal gas and brine flow permeability values are seen to be identical. This would be expected if the connected pore space were unsaturated over the duration of the gas flow tests. and saturated during the brine flow tests.

If all flow is assumed to enter the formation, then the formation permeability to gas (calculated assuming an unsaturated formation) differs only by a factor of two from the brine permeability value calculated assuming a saturated formation. The similarity in these permeability values, calculated under very different assumptions, is striking. It suggests that if the flow were into the formation. those flow channels responsible for these measurements were indeed unsaturated. If the flow channels were saturated and the gas flow data had been analyzed assuming an unsaturated formation, the resulting gas permeability value would be about a factor of 30 less than the indicated brine permeability value.

Both tracer gas and brine flow tests were conducted on the MAE22 seal in order to determine flow arrival times. Steady-state gas flow through a uniform seal having a $2 \times 10^{-T}$ darcy permeability and 0.01 porosity would yield a flow arrival of about 54 hours. given a $2.3 \mathrm{MPa}$ test region pressure. Similarly, brine flow through an initially unsaturated seal having a $2 \times 10^{-7}$ darcy permeability and 0.03 porosity would yield an arrival in 85 days. for a $3.5 \mathrm{MPa}$ test region pressure. No arrivals were seen in 50 hours for gas or 137 days for brine. The inability of the tracer gas or brine to penetrate the seal in these times suggests that its permeability may be less than the $2 \times 10^{-7}$ darcy value. 
Table 3

Summary of Analysis of MAE22 Gas and Brine Flow Tests

\begin{tabular}{|c|c|c|c|}
\hline \multirow{2}{*}{ TEST } & \multicolumn{2}{|c|}{$\begin{array}{c}\text { PERMEABILITY/POROSITY } \\
\text { [darcy] }\end{array}$} & \multirow{2}{*}{ COMMENTS } \\
\cline { 2 - 4 } & SEAL & FORMATION & \\
\hline Gas Flow & $2.0 \times 10^{-7} / 0.011$ & $6.0 \times 10^{-9} / 0.0012$ & $\begin{array}{c}\text { No Measured Tracer Gas } \\
\text { Penetration Through Seal }\end{array}$ \\
\hline Brine Flow & $2.0 \times 10^{-7}, 0.033$ & $1.2 \times 10^{-8} / 0.01 \leftrightarrow 0.0014$ & $\begin{array}{c}\text { No Visible Brine Flow } \\
\text { Through Seai }\end{array}$ \\
\hline
\end{tabular}

I Assumes seal is unsaturated.

2 Assumes formation is unsaturated.

3 Assumes seal is initially unsaturated.

4 Assumes formation is saturated 
SSS-R-87-8424R2 


\section{TEST SERIES B RESULTS}

A summary of the Test Series B tracer gas flow test results is provided in Table 4. There were no brine flow tests performed on the horizontallyemplaced Series B seals.

The shut-in pressure decay rates measured during the April 1986 MBE31. MBE32, and MBE33 tests implied formation and seal permeability values which were within a factor of two of those determined during tests on the vertically-emplaced MAE32 seal. Only the MBE31 seal/formation system had a permeability value larger than obtained in the MAE32 test. Recall that in the MAE32 test there was no observable leakage through or around the seal.

All the Test Series B seals leaked during the April 1986 tests. However, the leak rates were small. Measured tracer arrival times ranged between 0.1 and 0.3 hours--although the actual arrivals were thought to be much sooner. Actual maximum fracture aperture dimensions are, therefore, thought to be greater than or equal to the dimensions listed in Table 4. The tracer concentrations used for the Series B tests were essentially the same as those used on the second MAE31 test.

A dominant leak path was identified in each of the Test Series B seals. In the uninstrumented MBE31 seal/formation system, the leak (at least in the region of the seal face) was through a small formation fracture located below the seal center-line. In the instrumented MBE32 and MBE33 seals, the leak occurred along the instrumentation bundle. There was no detectable leakage at the seal/formation interface on any of these seals. However, due to the high concentration of tracer being emitted from the small observed leaks. the seal/formation interface leakage measurement was not extremely sensitive.

The tracer gas/flow tests were repeated in May 1987. Results of those tests are included in Table 4. 
Table 4

Comparison of the April 1986 and May 1987 Series B Tracer Gas Flow Tests

\begin{tabular}{|c|c|c|c|c|c|}
\hline \multirow{2}{*}{ SEAL } & \multicolumn{2}{|c|}{$\begin{array}{l}\text { PERMEAB ILITY* } \\
\text { [darcy] }\end{array}$} & \multirow{2}{*}{$\begin{array}{c}\text { TRACER } \\
\text { ARR I YAL } \\
\text { [hours] }\end{array}$} & \multirow{2}{*}{$\begin{array}{c}\text { ESTIMATED } \\
\text { MAXIMUM } \\
\text { FRACTURE } \\
\text { APERTURE }[\mathrm{cm}]\end{array}$} & \multirow{2}{*}{ COMMENTS } \\
\hline & SEAL & FORMATION & & & \\
\hline $\begin{array}{l}\text { MBE3I } \\
\text { April } 1986\end{array}$ & $1 \times 10^{-6}$ & $B \times 10^{-8}$ & $<0.3$ & $>2 \times 10^{-5}$ & $\begin{array}{l}\text { Leak Through Fracture } \\
\text { In Farmation Below Seal }\end{array}$ \\
\hline $\begin{array}{l}\text { MBE31 } \\
\text { May } 1987\end{array}$ & $2 \times 10^{-7}$ & $1 \times 10^{-8}$ & $\begin{array}{l}\text { Mo Arriva I } \\
\text { [264 hours] }\end{array}$ & $<8 \times 10^{-7}$ & - \\
\hline $\begin{array}{l}\text { MBE32 } \\
\text { April } 1986\end{array}$ & $4 \times 10^{-7}$ & $3 \times 10^{-8}$ & $<0.2$ & $>3 \times 10^{-5}$ & $\begin{array}{l}\quad \text { Leak Along } \\
\text { Instrumentation Bundle }\end{array}$ \\
\hline $\begin{array}{l}\text { MBE32 } \\
\text { May 1987 }\end{array}$ & $2 \times 10^{-7}$ & $1 \times 10^{-\theta}$ & $\begin{array}{l}\text { Mo Arsival } \\
\text { (26 hours) }\end{array}$ & $<3 \times 10^{-6}$ & - \\
\hline $\begin{array}{c}\text { MBE33 } \\
\text { April } 1986\end{array}$ & $2 \times 10^{-7}$ & $1 \times 10^{-8}$ & $<0.1$ & $>4 \times 10^{-5}$ & $\begin{array}{l}\text { Leak Along } \\
\text { Instrumentation Bundle }\end{array}$ \\
\hline $\begin{array}{l}\text { MBE33 } \\
\text { May } 1987\end{array}$ & $7 \times 10^{-7}$ & $5 \times 10^{-8}$ & $\begin{array}{l}\text { No Arrival } \\
{[24 \text { hours ] }}\end{array}$ & $<3 \times 10^{-6}$ & - \\
\hline MAE 32 & $5 \times 10^{-7}$ & $3 \times 10^{-8}$ & Ma Arrival & $<2 \times 10^{-6}$ & - \\
\hline
\end{tabular}

- Calculated assuming all flow is e:ther

through the seal or through the formation.

I $\phi_{\text {formation }}=0.001 . \phi_{\text {seal }}=0.01 \mathrm{l}$ 
During the second series of tests. no measurable quantity of tracer penetrated the seals. Clearly a significant reduction in flow path size had occurred during the interim period. For example. during the April 1986 tests. tracer penetration occurred through all seals in less than .3 hours. In contrast. no measurable tracer arrivals occurred during the May 1987 test periods (shown in parenthesis on Table 4).

During the May 1987 tests. the seal permeabilities were found to be less than $7 \times 10^{-7}$ darcy, under the assumption that all flow went through the seal. If the seals were assumed impermeable, with all flow going into the formation. the resulting formation permeabilities would be less than $5 \times 10^{-8}$ darcy. These values are similar to those obtained for the $91 \mathrm{~cm}$ diameter MAE32 vertical seal. 
SSS-R-87-8424R2 


\section{CONCLUSIONS}

A series of tests has been performed to evaluate the flow characteristics of salt-based concrete plugs placed in both vertically-down boreholes and horizontal boreholes. Both gas-with-tracer tests and brine flow tests were conducted on the seals placed in the vertically-down boreholes. Only the gaswith-tracer tests were performed on the seals placed in the horizontal boreholes.

The permeabilities of the $15 \mathrm{~cm} .41 \mathrm{~cm}$, and $91 \mathrm{~cm}$ seals placed in the vertical boreholes were (with one exception) found to be less than $5 \times 10^{-7}$ darcy. under the assumption that all flow went through the seal. If the seals were assumed to be impermeable. with all flow going into the formation. the resulting formation permeabilities would be less than $3 \times 10^{-8}$ darcy. These formation permeabilities are consistent with results determined during previous formation tests.

There was little indication that the performance of the vertically-emplaced seals depended on the seal diameter. However, the influence, if any. of such scaling effects could not be determined with certainty. since the relative fraction of the flow which went through the seal or into the formation during these tests could not be determined.

For five of the six seals emplaced in the vertical boreholes, there was no measurable tracer gas or brine penetration through the seal or along the seal/formation interface. This result is consistent with the measured permeability values. The $91 \mathrm{~cm}$ diameter instrumented seal leaked: however, the leak path could not be identified.

Tracer-gas/flow tests conducted in April 1986 showed that all three horizontally-emplaced, $91 \mathrm{~cm}$ diameter seals had small leaks. The uninstrumented seal leaked through a small formation fracture located directly below the seal. The two instrumented horizontal seals leaked along the instrumentation bundles. There was no evidence during tests on the 
horizontally-emplaced seals that leakage occurred around the seal/formation interface.

The tracer-gas/flow tests were repeated on the horizontal seals in May 1987. During these tests, no detectable quantity of tracer penetrated the seals. Clearly a significant reduction in flow path size had occurred during the interim period between tests. The permeabilities of the horizontal seals, during the May 1987 tests, were found to be less than $7 \times 10^{-7}$ darcy under the assumption that all flow went through the seal. If the seals were assumed impermeable. the resulting formation permeabilities would be less than $5 \times 10^{-8}$ darcy. These values are essentially identical to those obtained for the $91 \mathrm{~cm}$ diameter vertical seal.

Brine flow test results obtained on the $41 \mathrm{~cm}$ diameter seal placed in the MAE22 vertical borehole were consistent with a $2 \times 10^{-7}$ darcy seal permeability and $10^{-8}$ darcy formation permeability. These values agreed with those determined from the gas flow tests. suggesting that those flow paths responsible for the measured flow results were initially unsaturated.

Additional tests remain to be performed. The most important of these is to determine whether the measured flow characteristics of both the horizontally and vertically-emplaced seals continue to change with time. These tests. or similar tests, will therefore be repeated on the already-tested boreholes at some later date. Those data will subsequently be compared to the data presented in this report. 


\section{REFERENCES}

1. Peterson. E. W. and Lagus. P. L.. "WIPP Horizon In Situ Permeability Measurements/Permeability Test System". S-CUBED Document No. 31062-08-01. November 1985.

2. Peterson. E. W.. Lagus. P. L.. Brown. J.: H.. and Lie, K.. "WIPP Horizon In Situ Permeability Measurements". SAND 85-7166. Sandia National Laboratories. Albuquerque. New México, January 1985.

3. Peterson. E. W.. et al.. "Analysis of Bell Canyon Test Results", S-CUBED Document No. SSS-R-80-4474-2, February 19.81. 


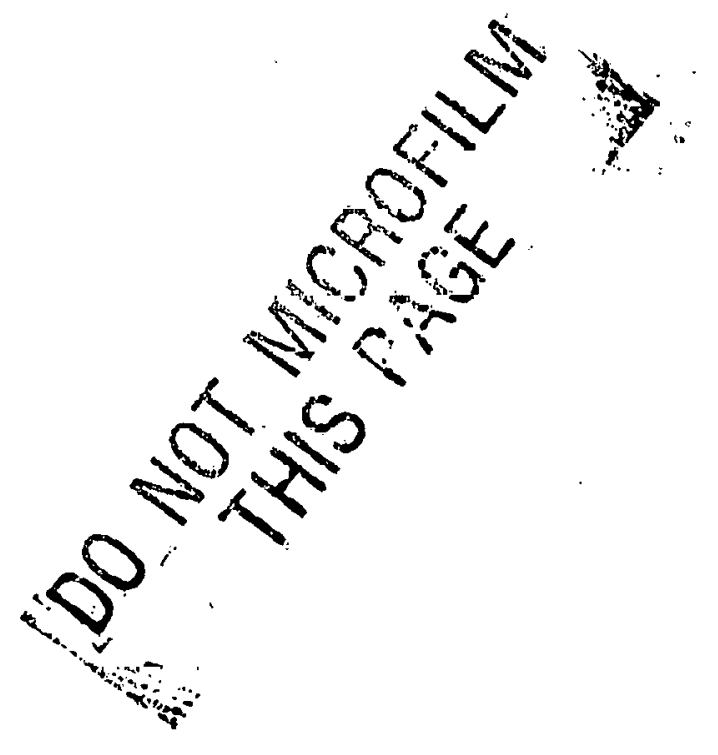




\section{APPENDIX A \\ SSSPT FLUID FLOW MEASUREMENT DATA}

This Appendix contains plots of the field data used to determine the results presented in the body of this report. These data were originally recorded on a Hewlett Packard Model 3056 Data Logger. A general description of these data is provided in Section 2.

The pressure acquisition system was calibrated in psi units. Note that $14.7 \mathrm{psi}$ is equivalent to $0.1 \mathrm{MPa}$, and 1 psi equals $6.8 \times 10^{-3} \mathrm{MPa}$. 


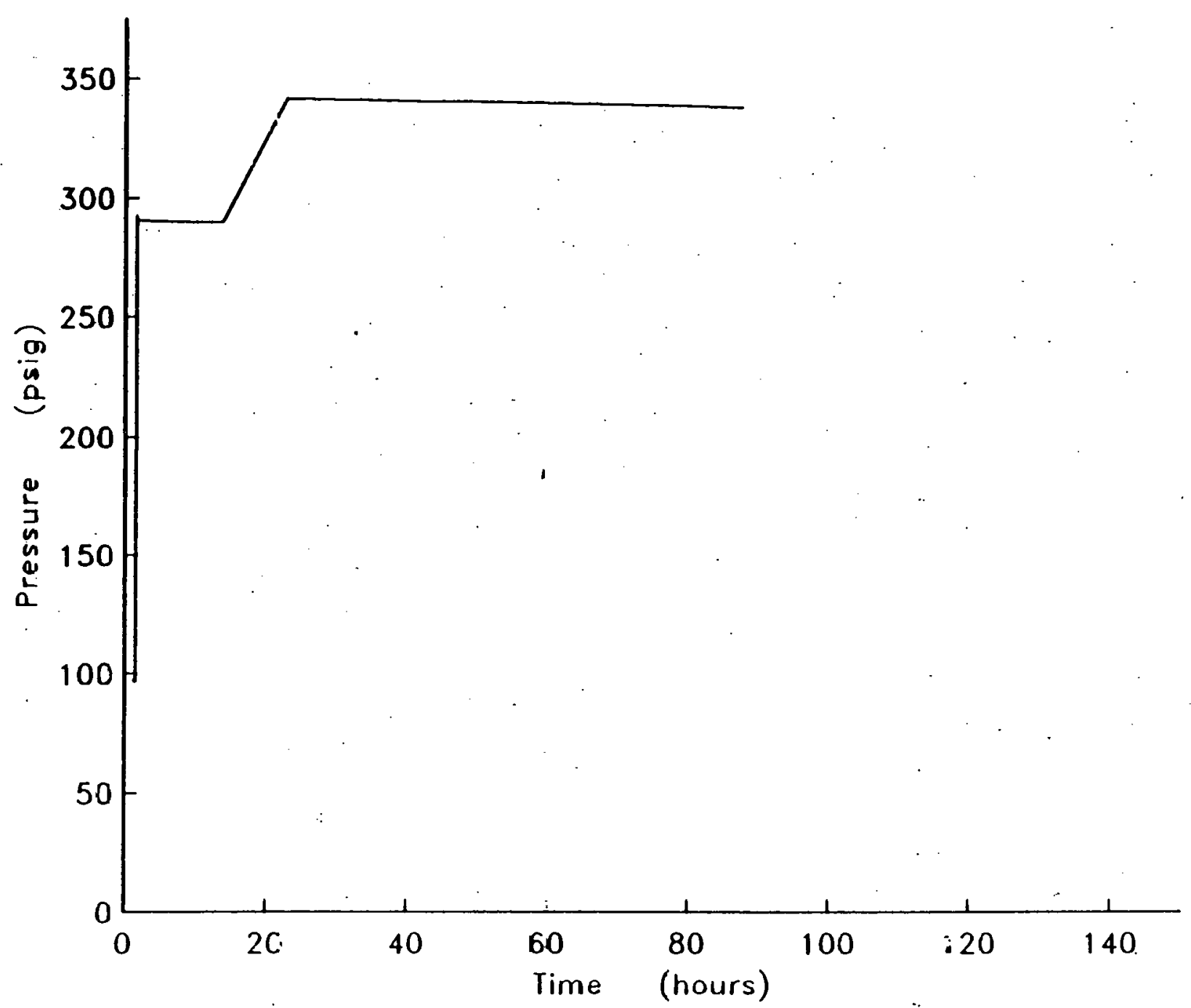

Figure A-1. Test region pressure history measured during the MAE11 gas flow test. 


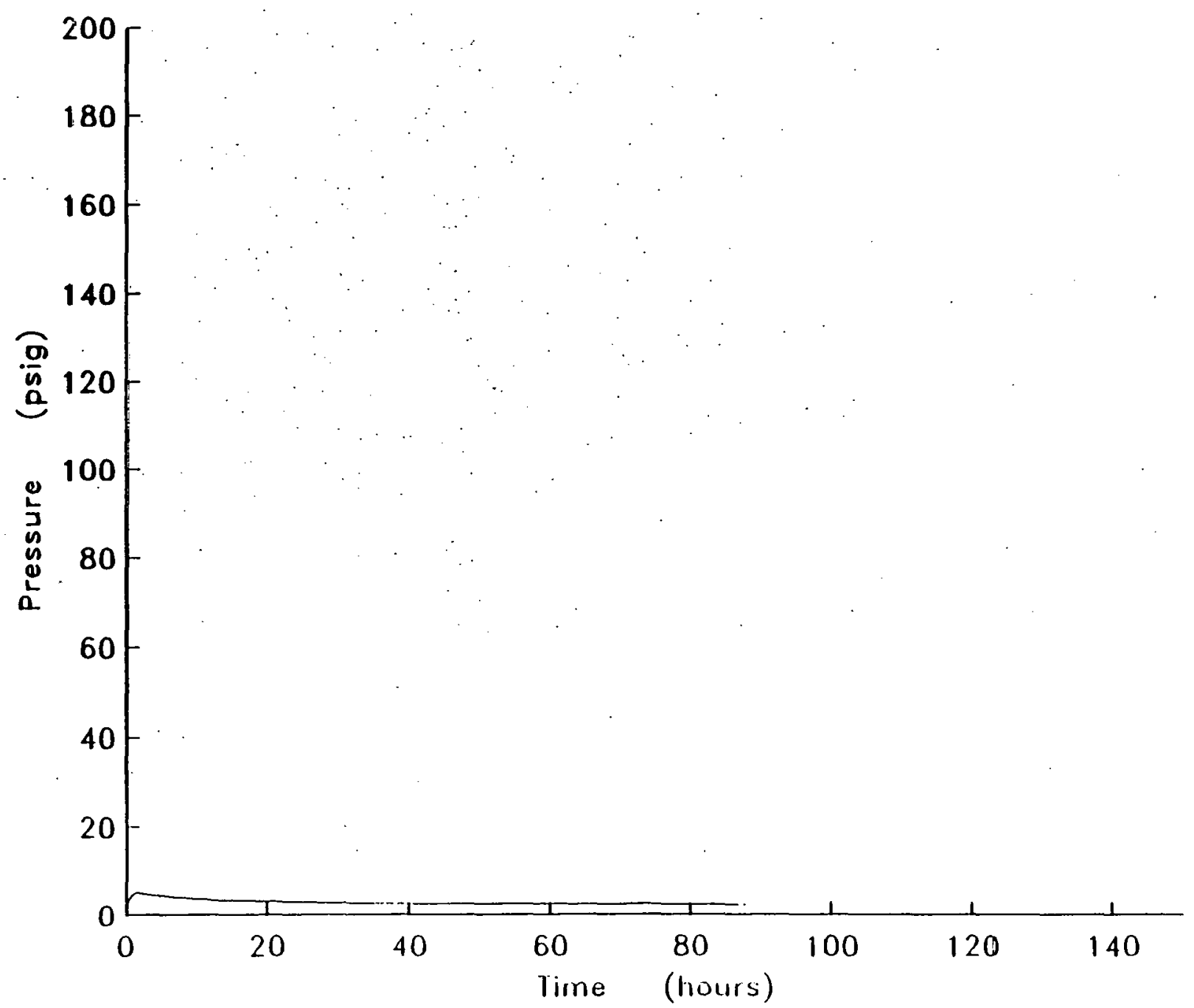

Figure A-2. Guard region pressure history measured during the MAE11 gas flow test. 


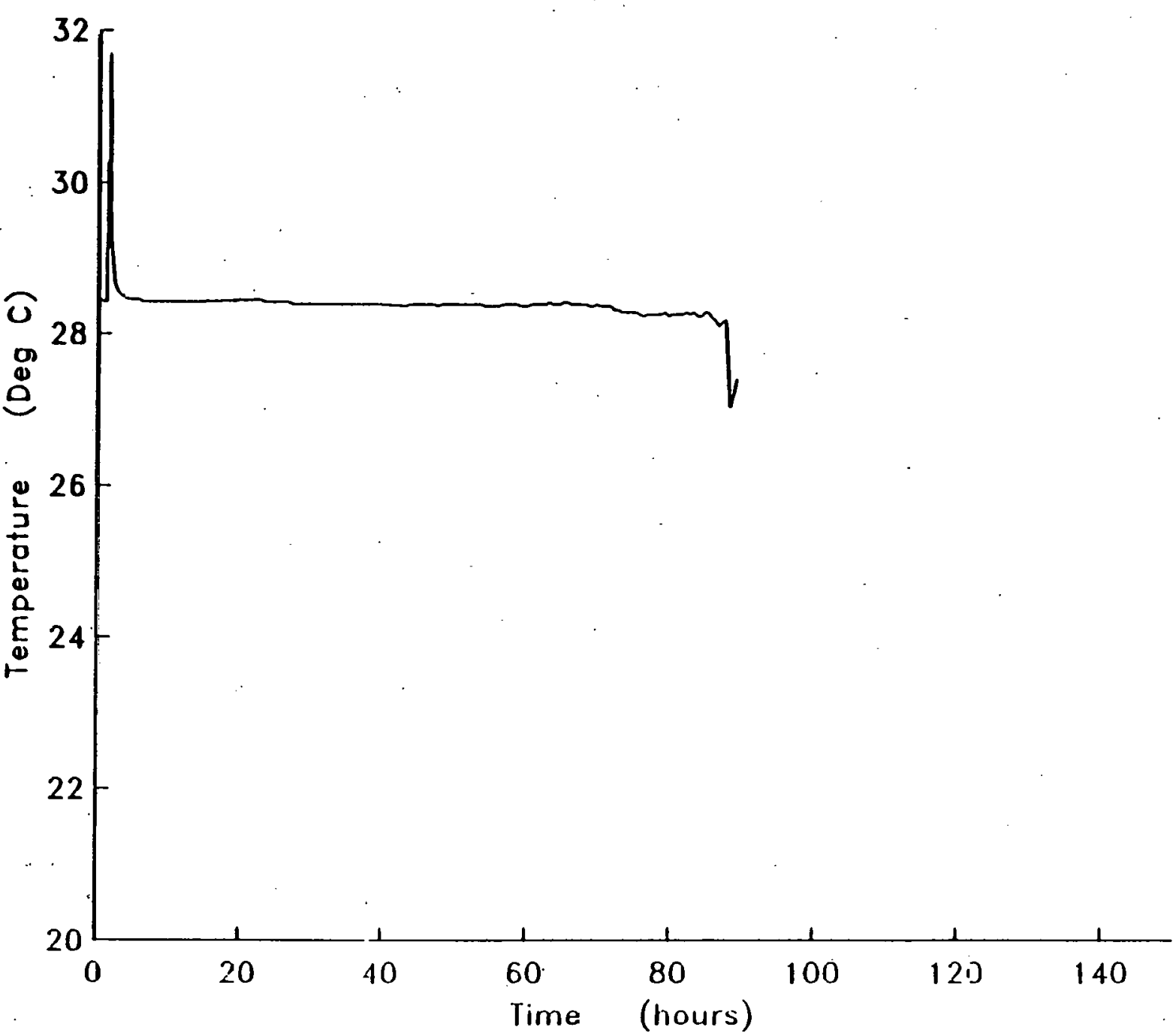

Figure A-3. Test region temperature history measured during the MAE11 gas flow test. 


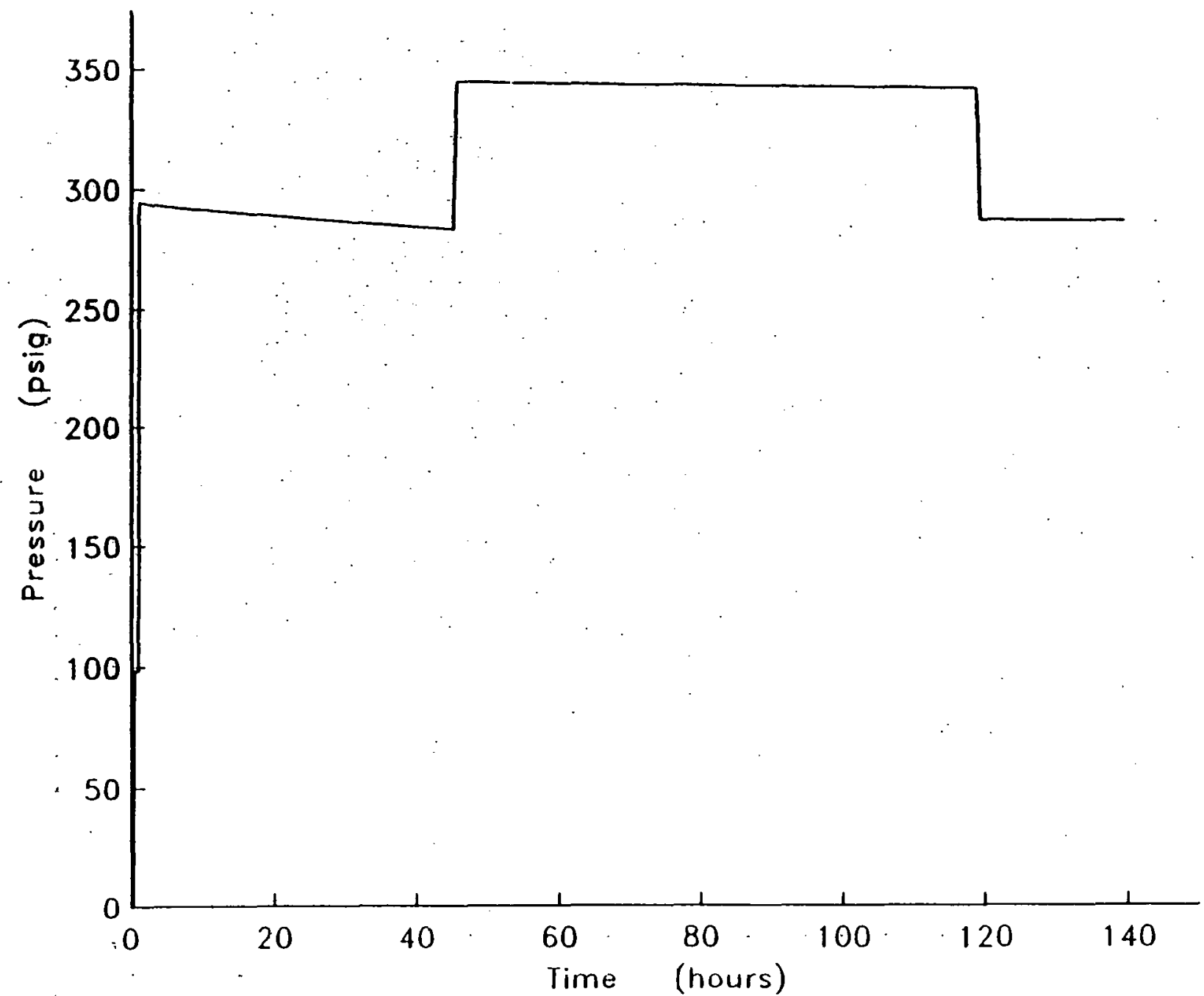

Figure A-4. Test regicn pressure history measured during the MAE12 gas flow test. 


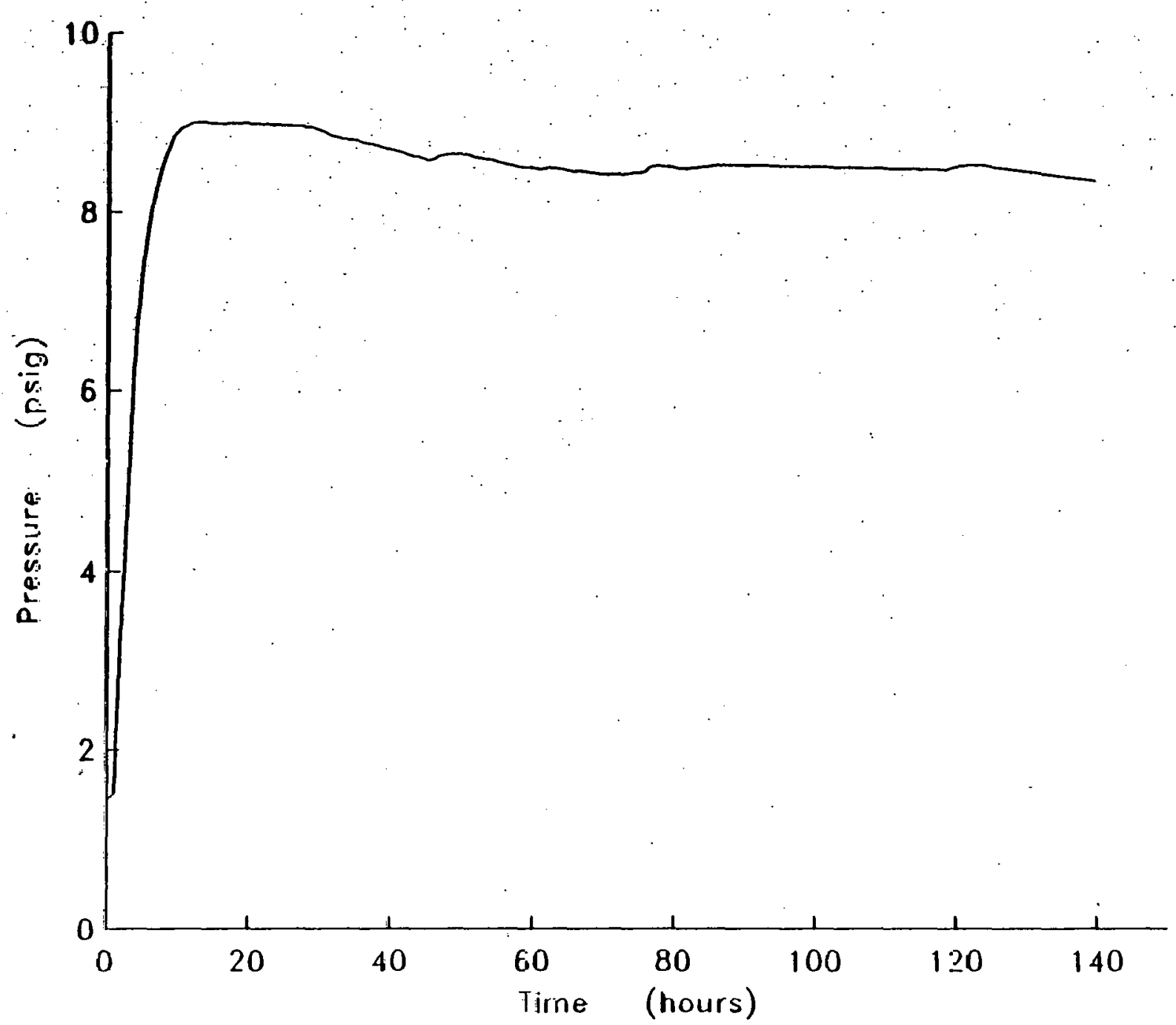

Figure A-5. Guard region pressure history measured during the MAE12 gas flow test. 


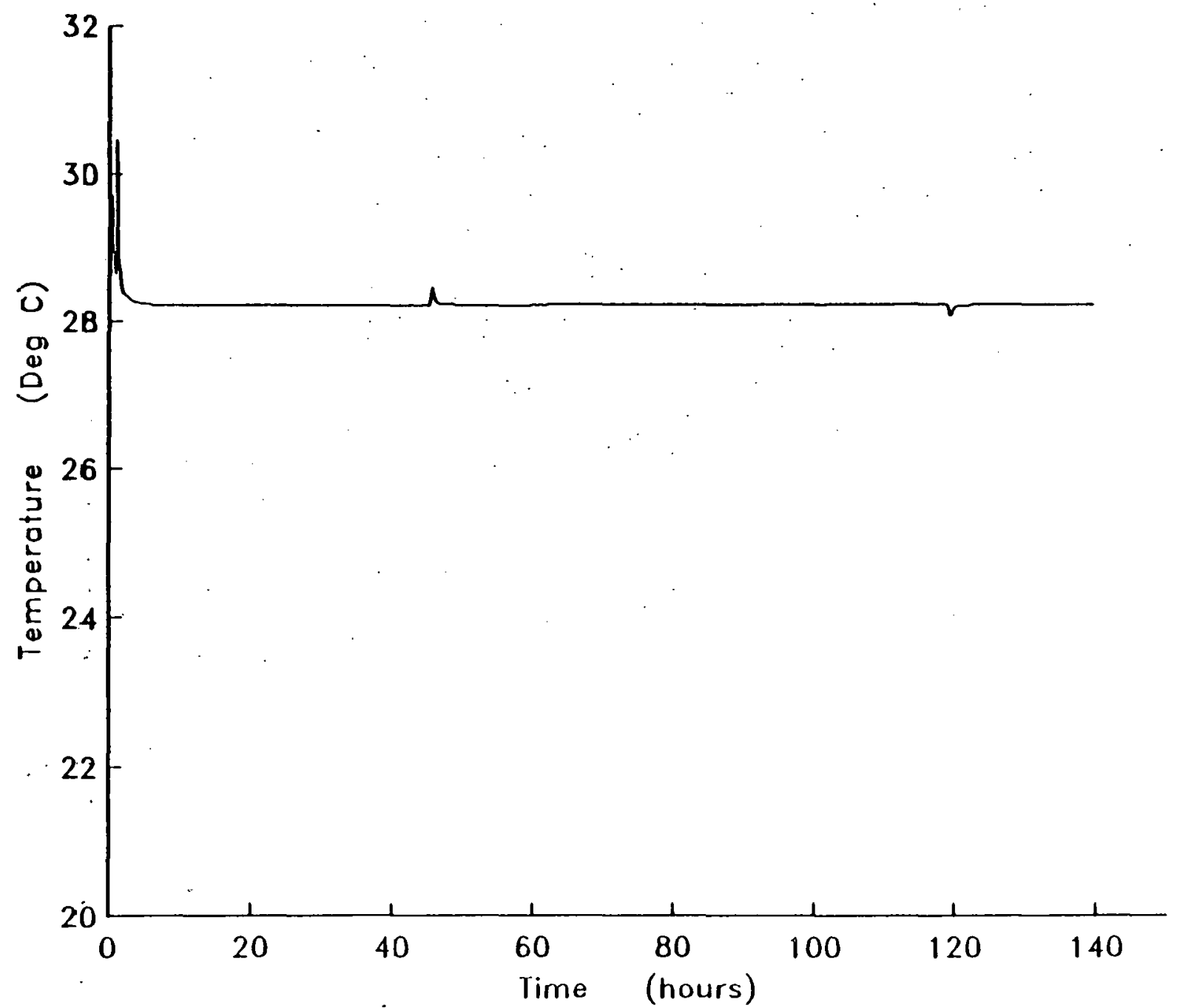

Figure A-6. Test region temperature history measured during the MAE12 gas flow test. 


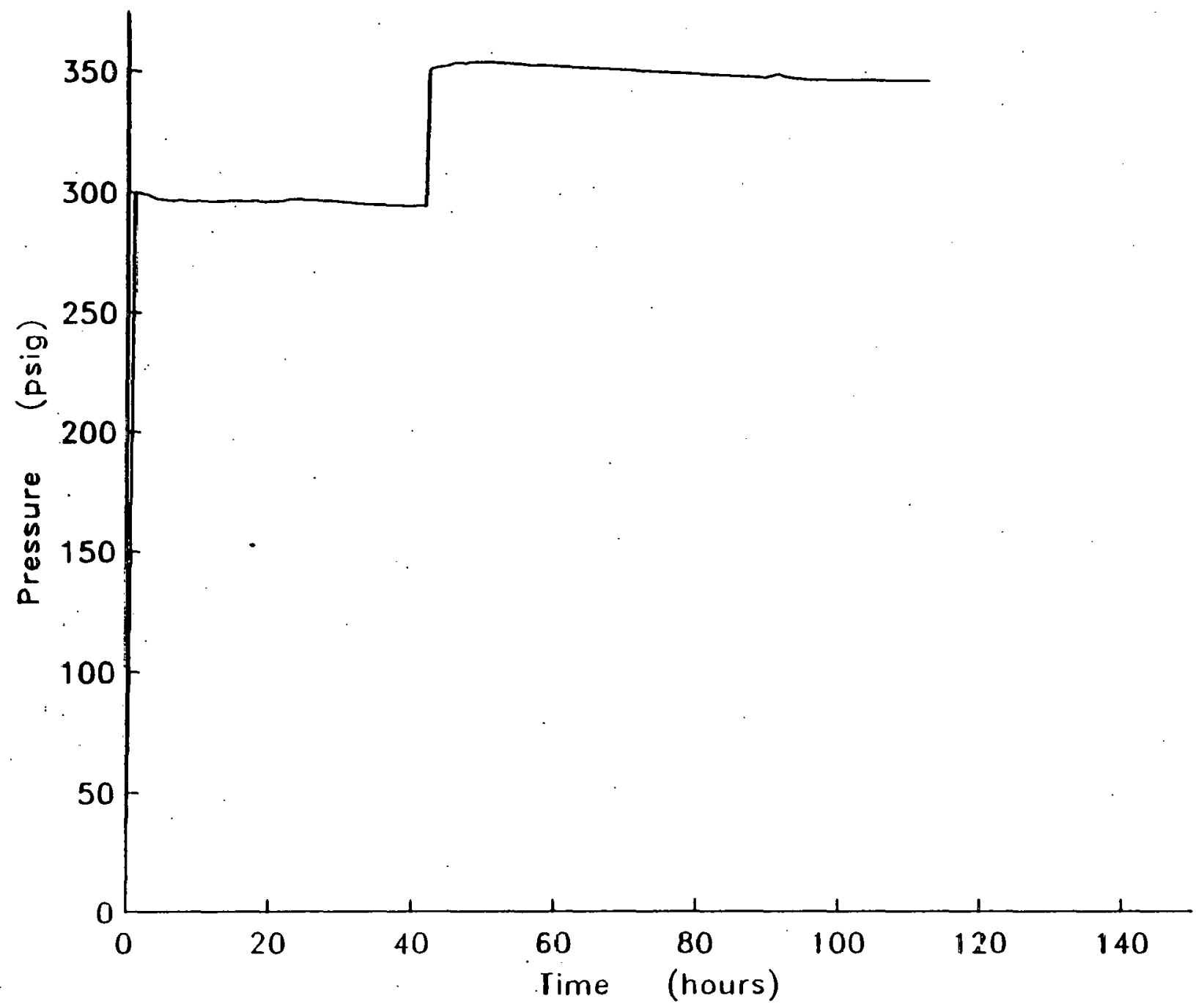

Figure A-7. Test region pressure history measured during the MAE?1 gas flow test. 


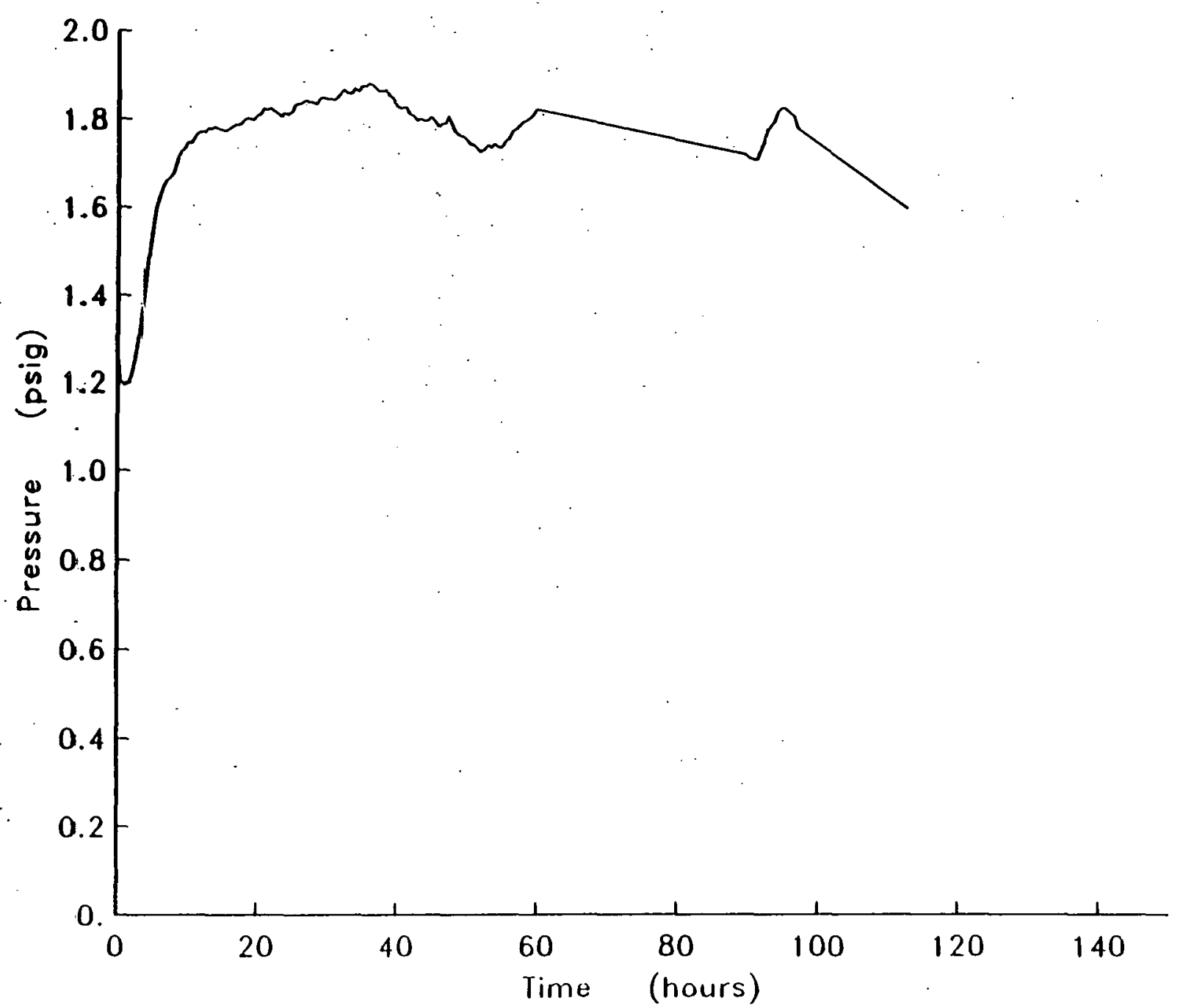

Figure A-8. Guard region pressure history measured during the MAE21 gas flow test. 


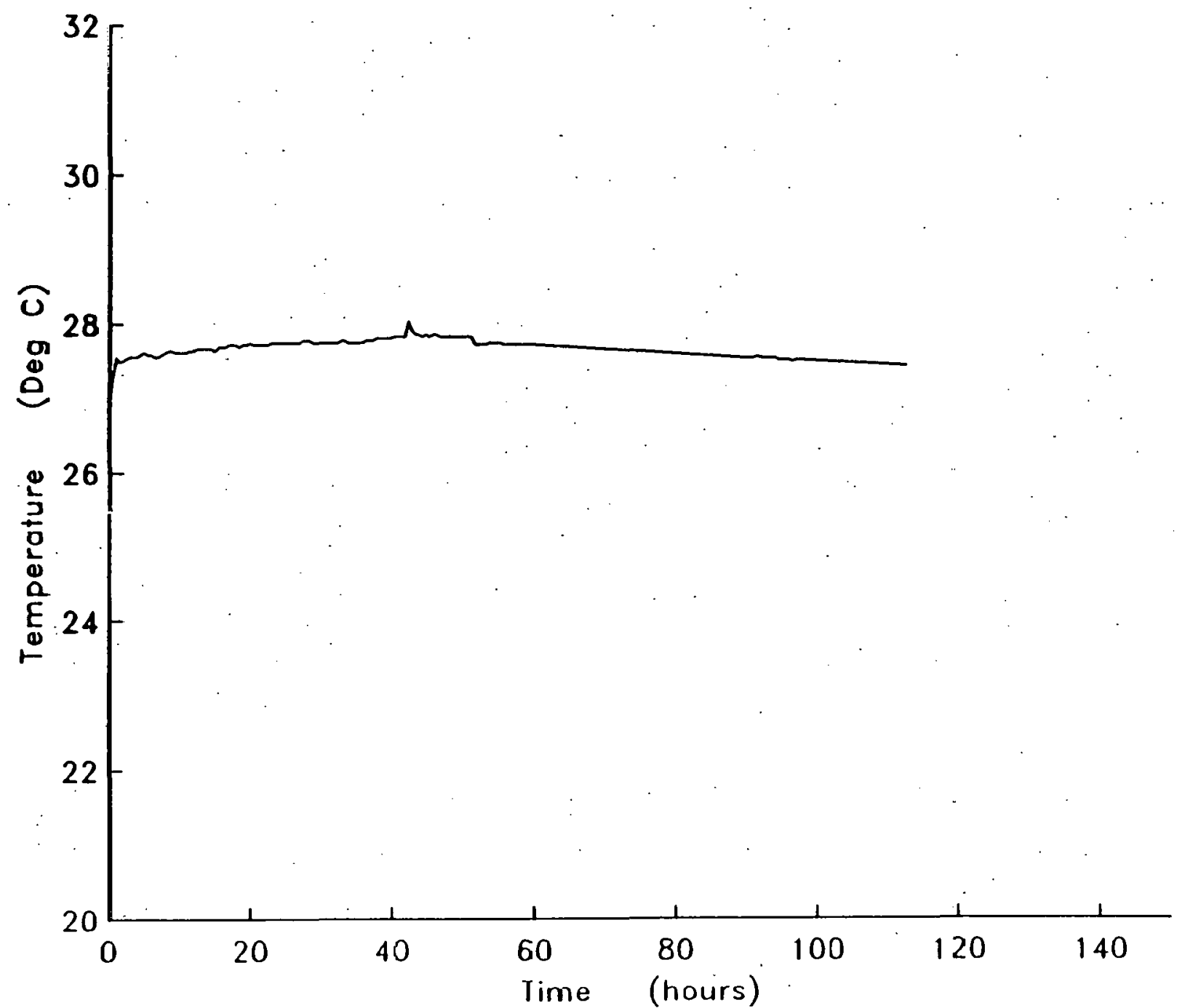

Figure A-9. Test region temperature history measured during the M.AE21 gas flow test. 


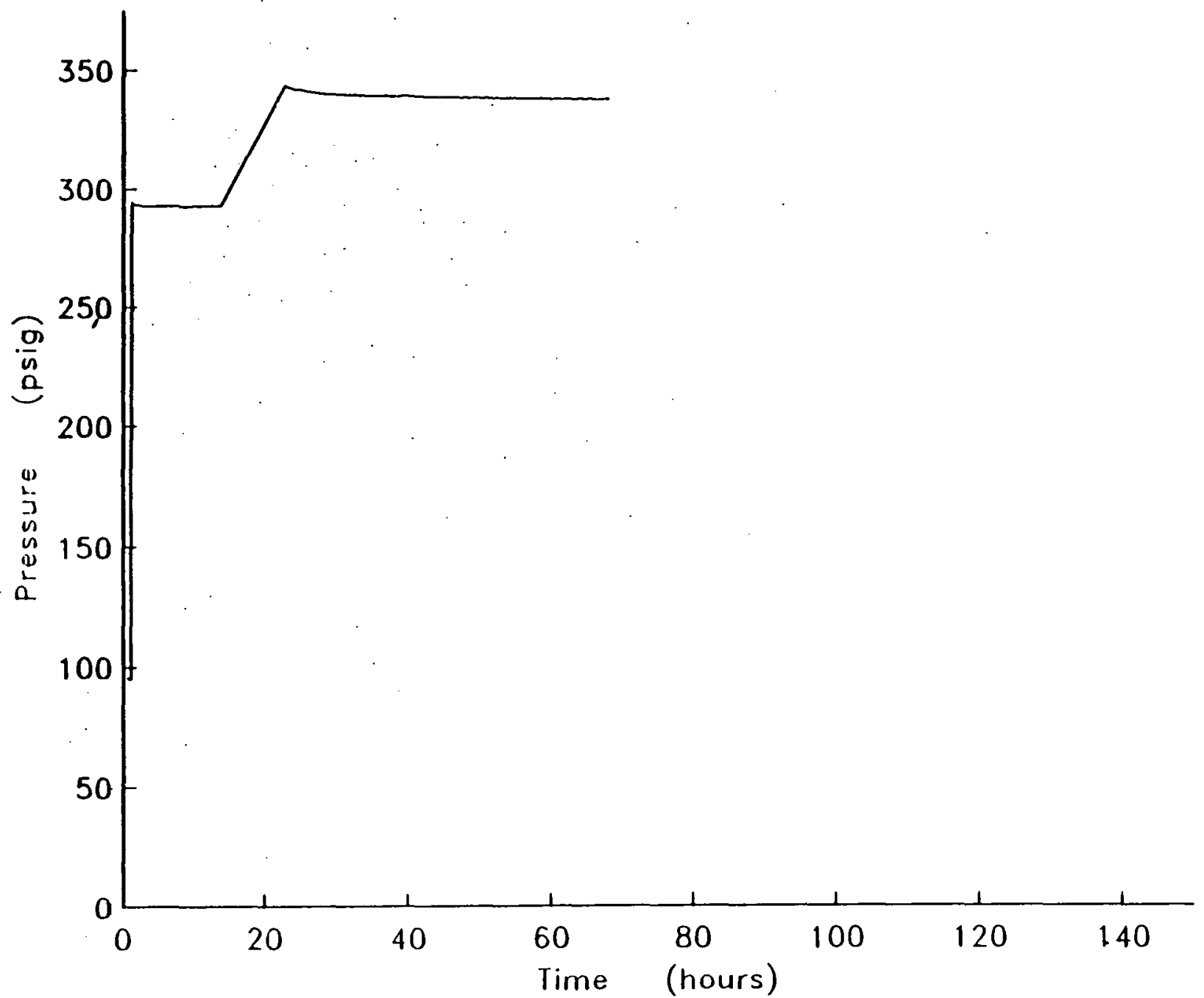

Figure A-10. Test region pressure history measured during the MAE22 gas flow test. 


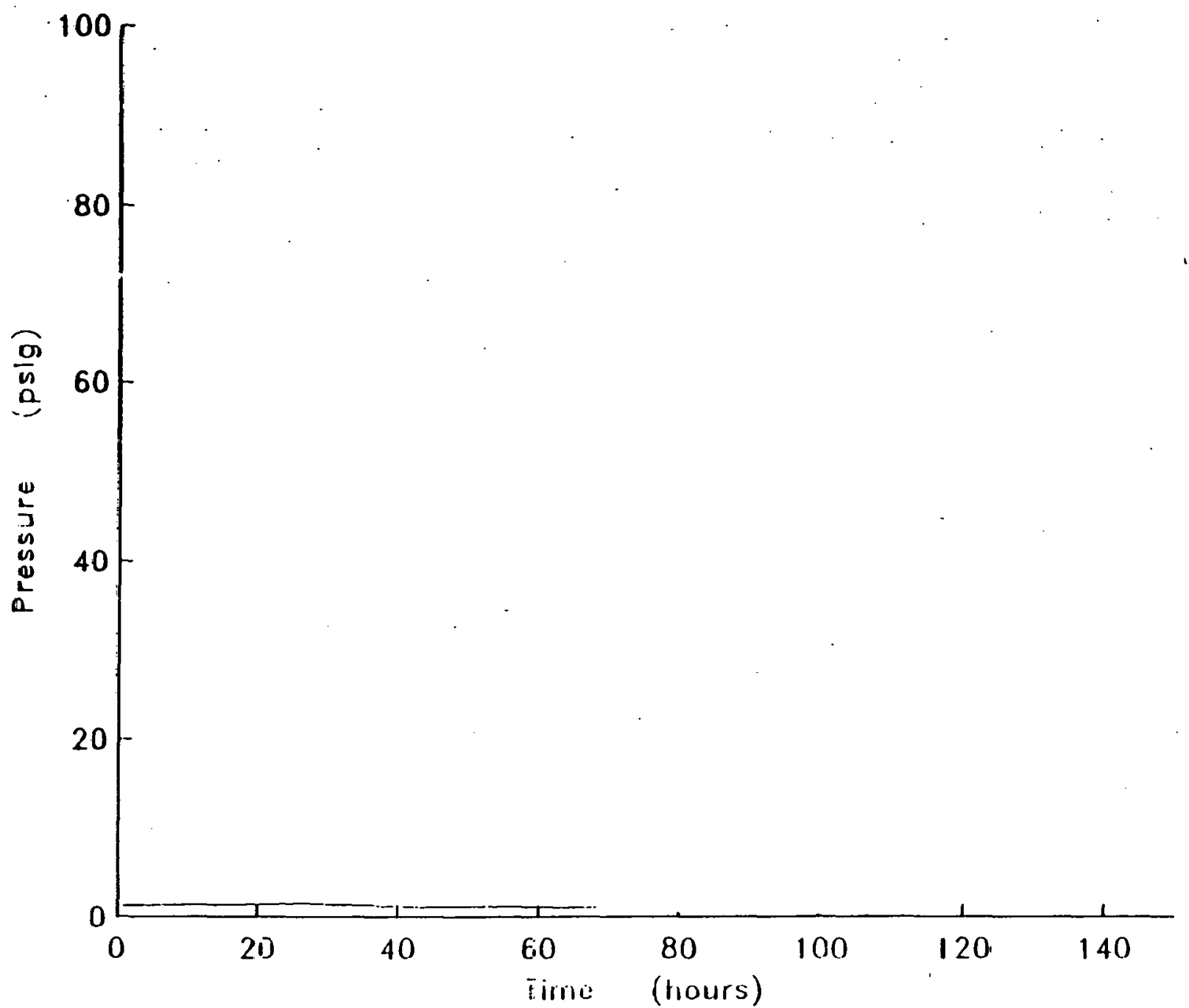

Figure A-11. Guard region pressure history measured during the MAE22 gas flow test. 


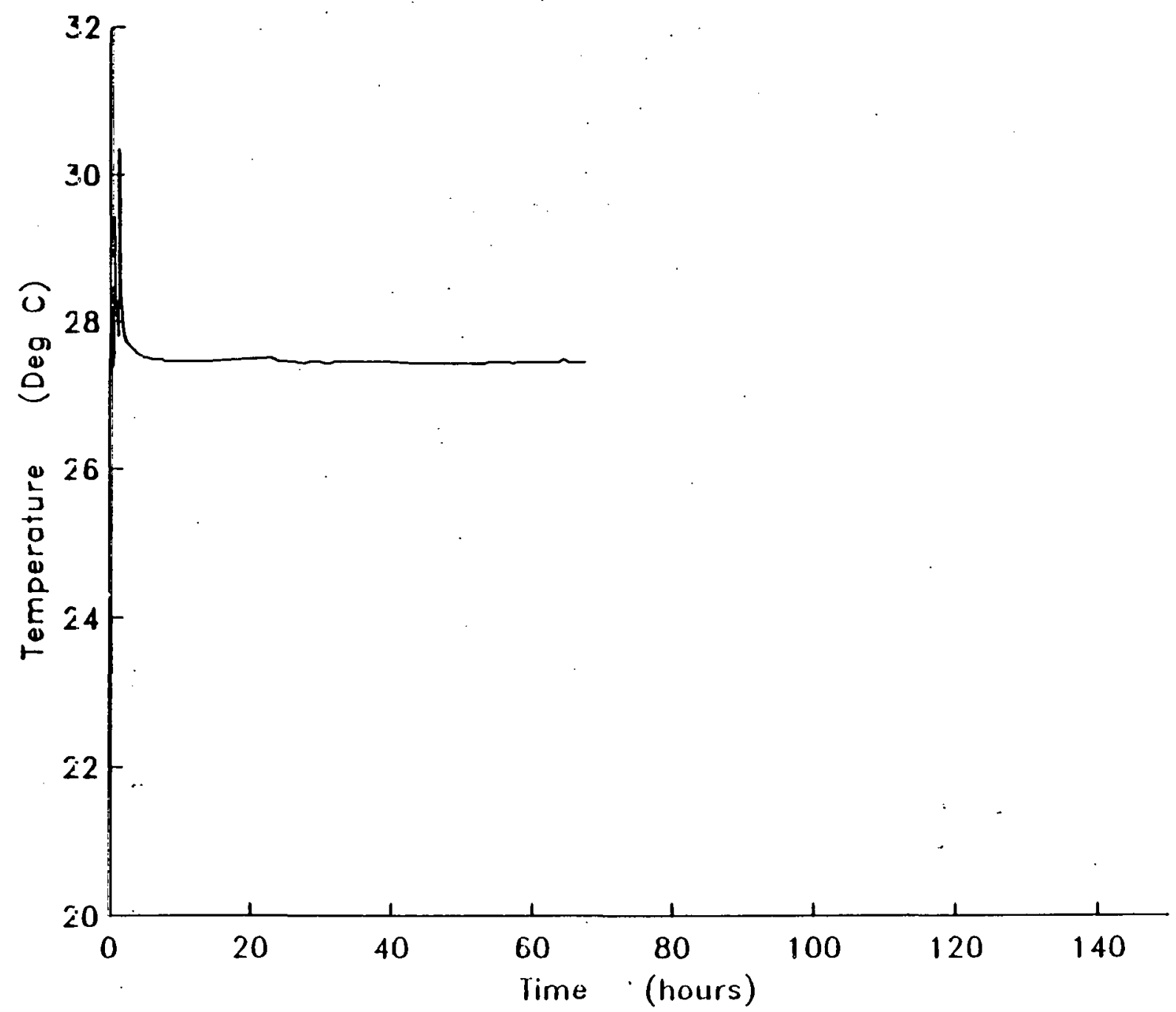

Figure A-12. Test region temperature history measured during the MAE22 gas flow test. 


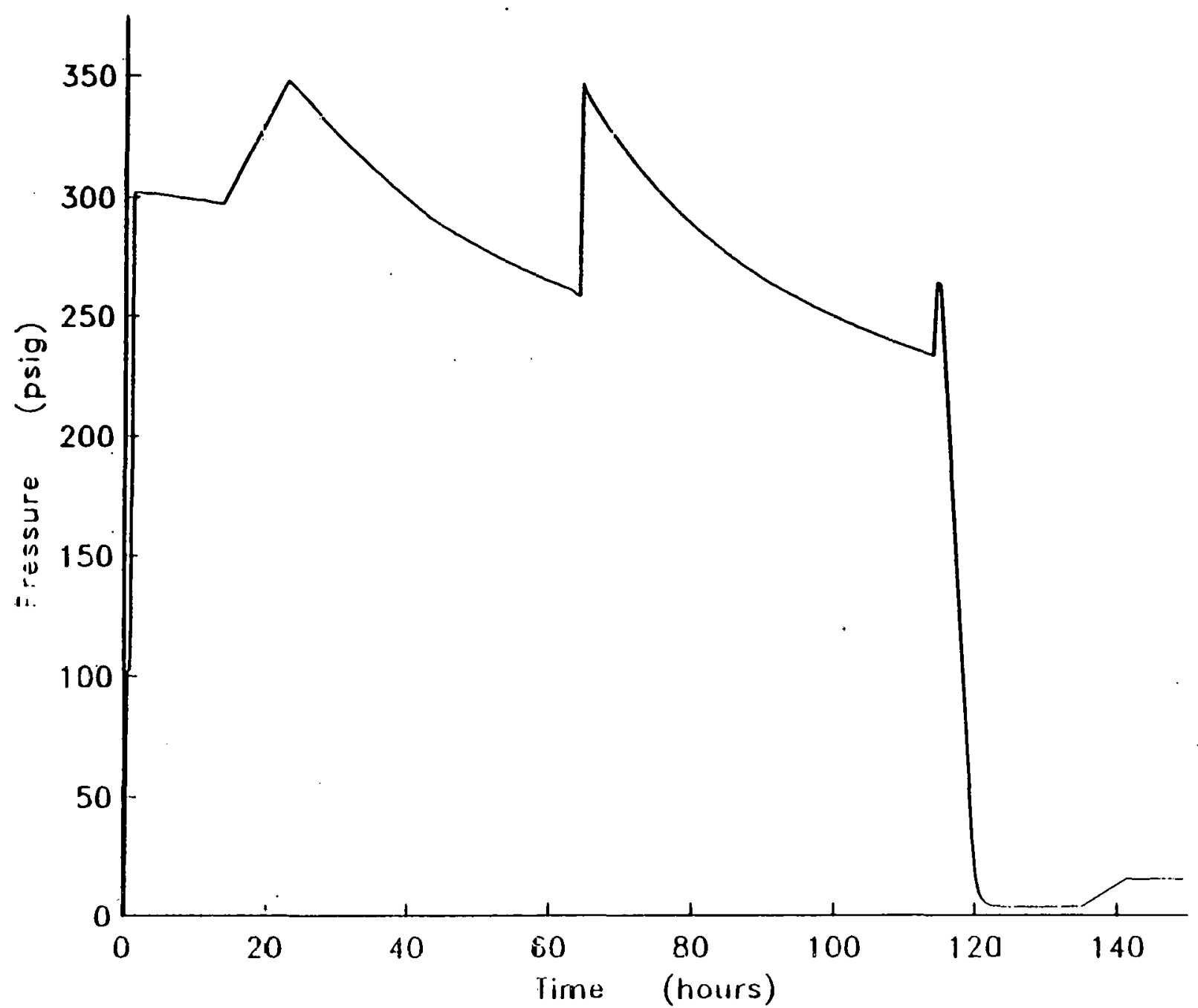

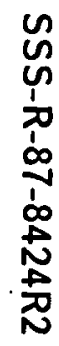

Figure A-13. Test region pressure history measured during the MAE31 gas flow test. 


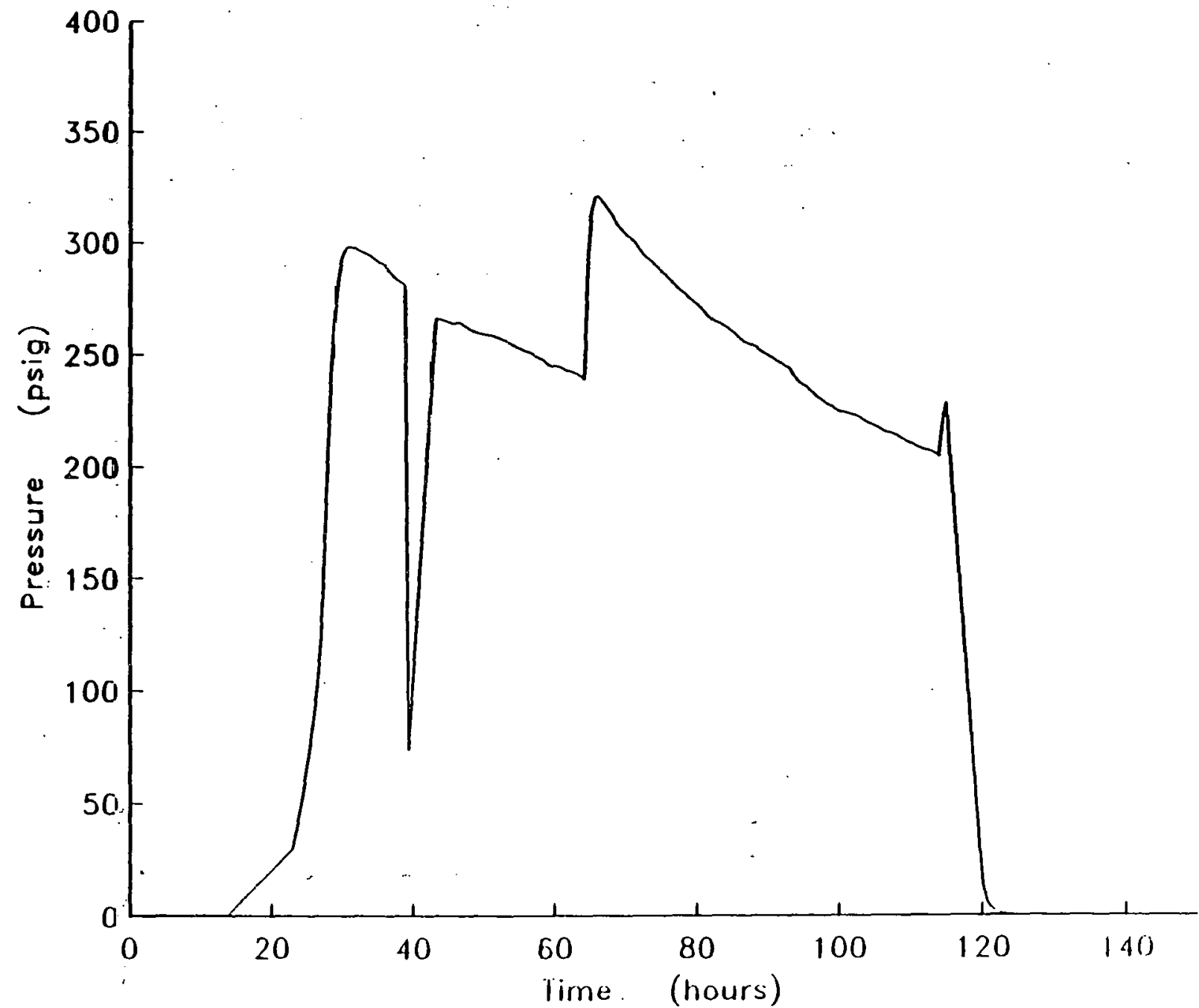

Figure A-14. Guard region pressure history measured during the MAE31 gas flow test. 


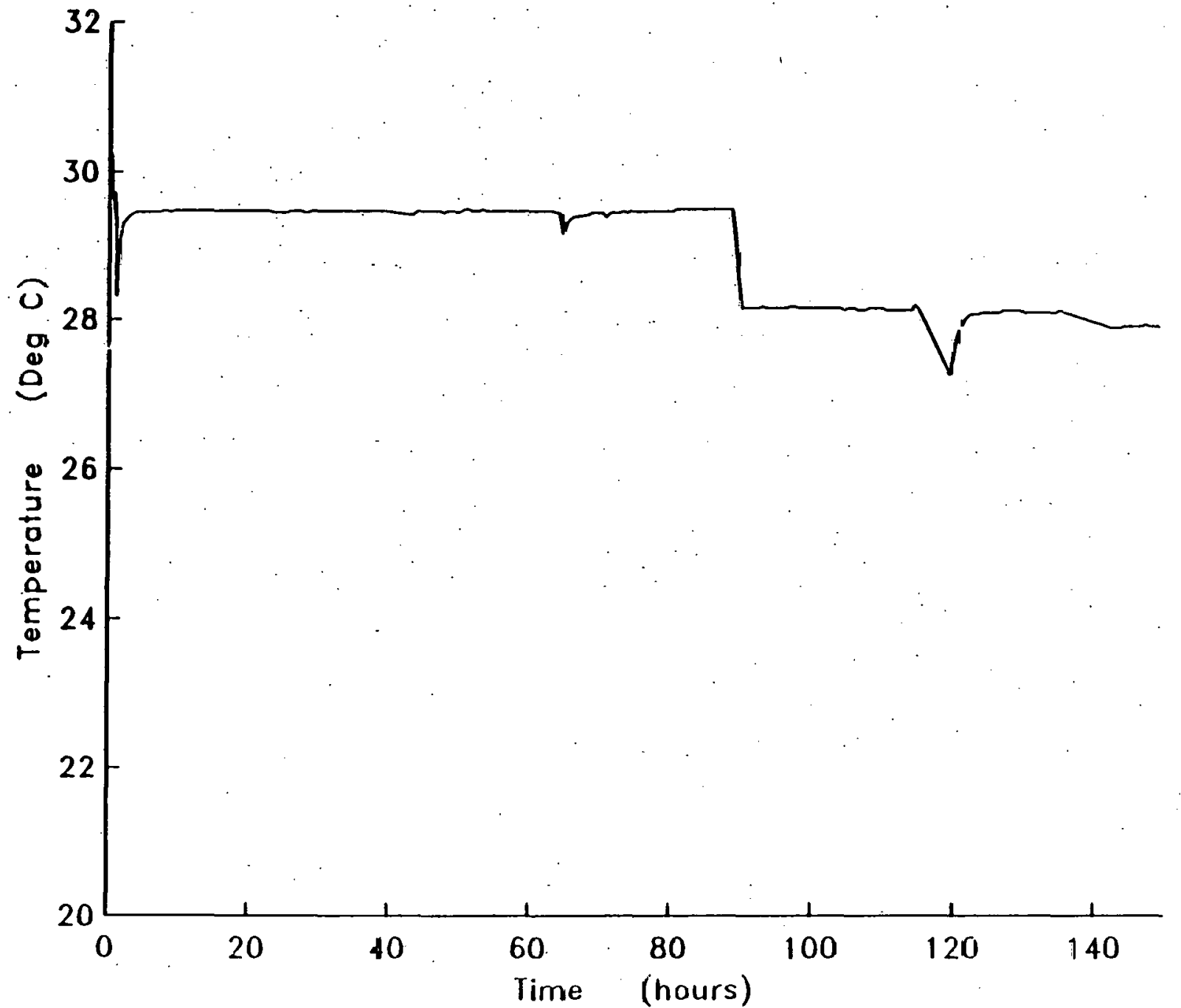

Figure A-15. Test region temperature history measured during the MAE31 gâs flow test. 


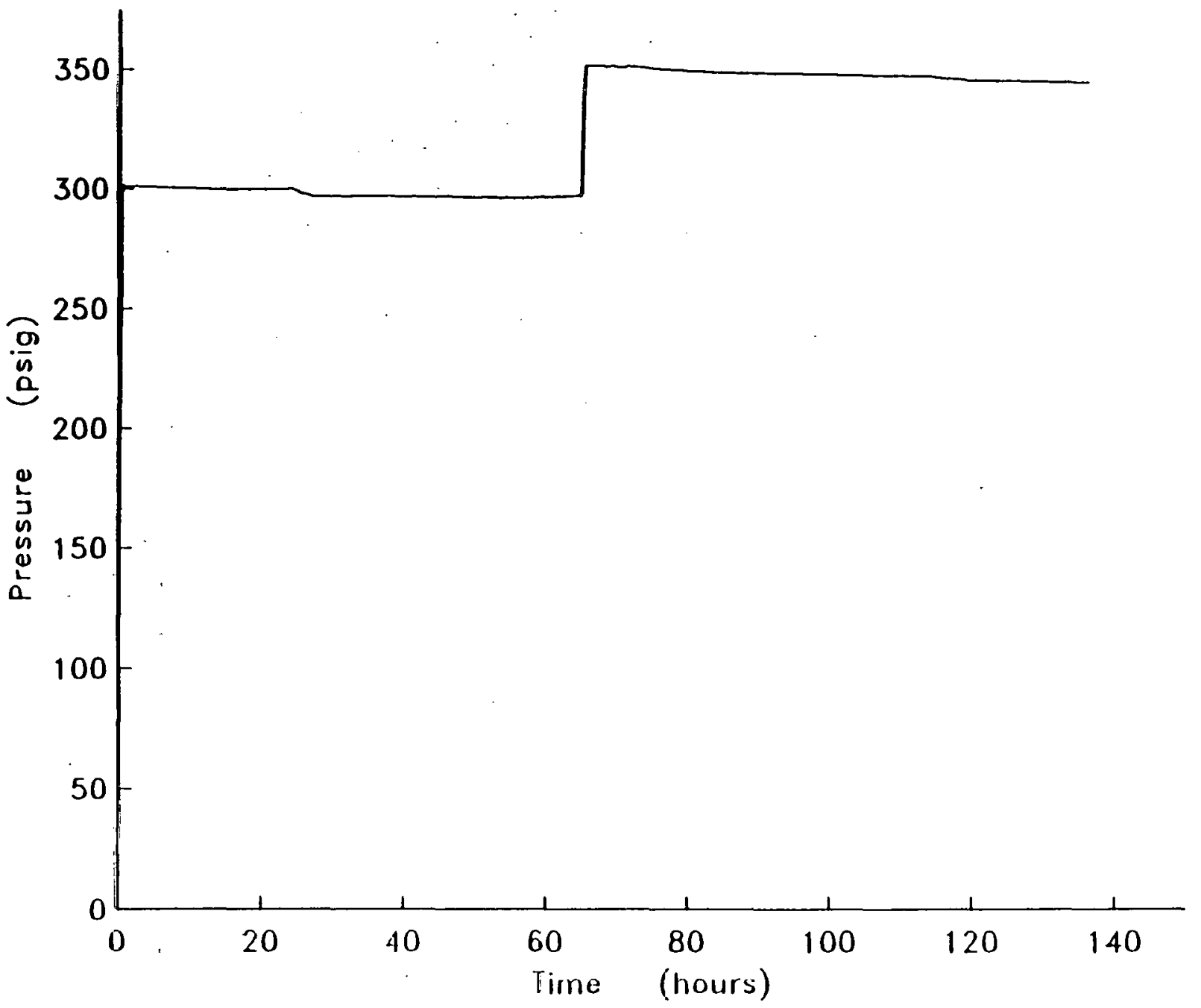

Figure A-16. Test region pressure history measured during the MAE32 gas flow test. 
$\infty$

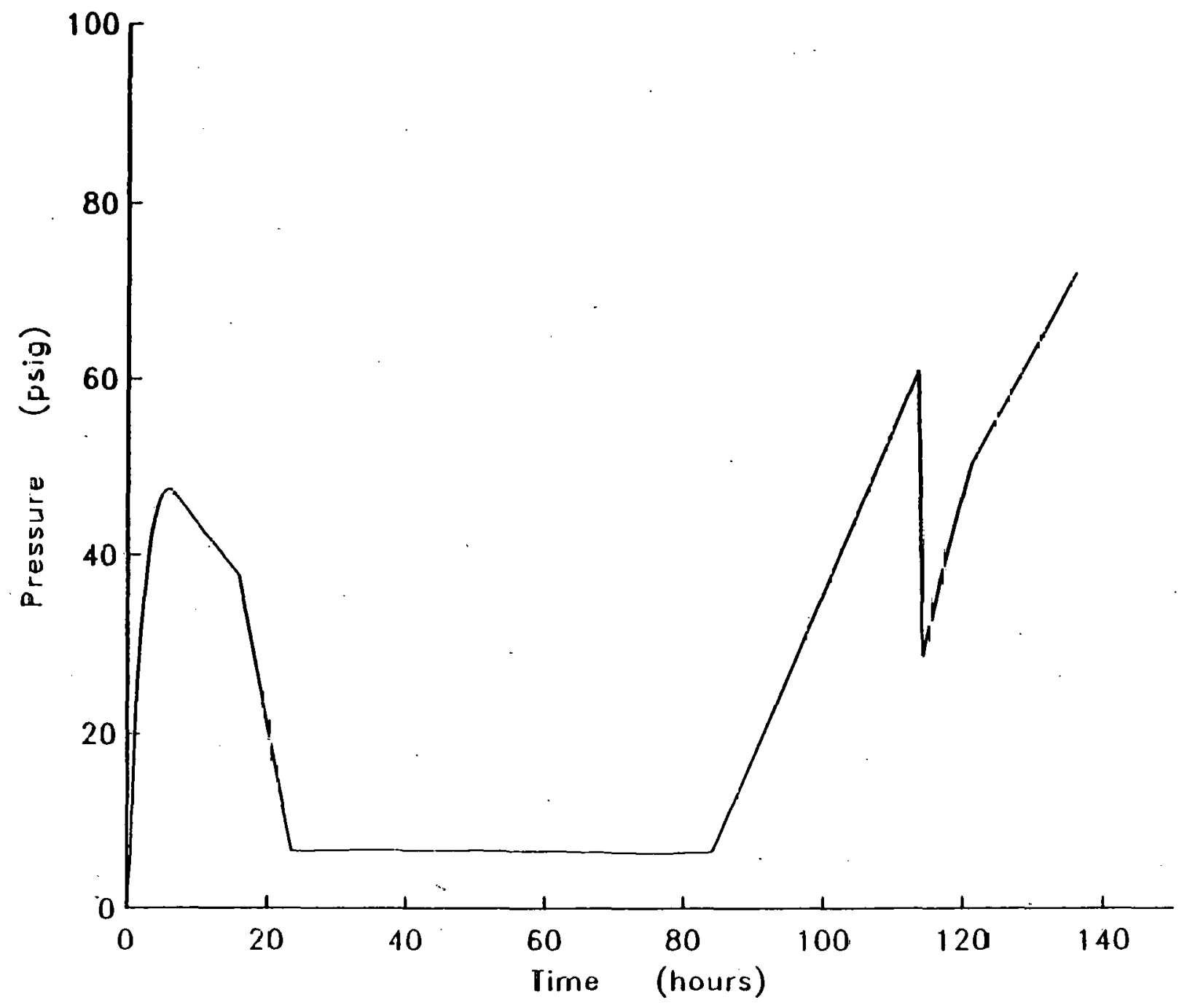

Figure A-17. Guard region pressure history measured during the MAE32 gas flow test. 


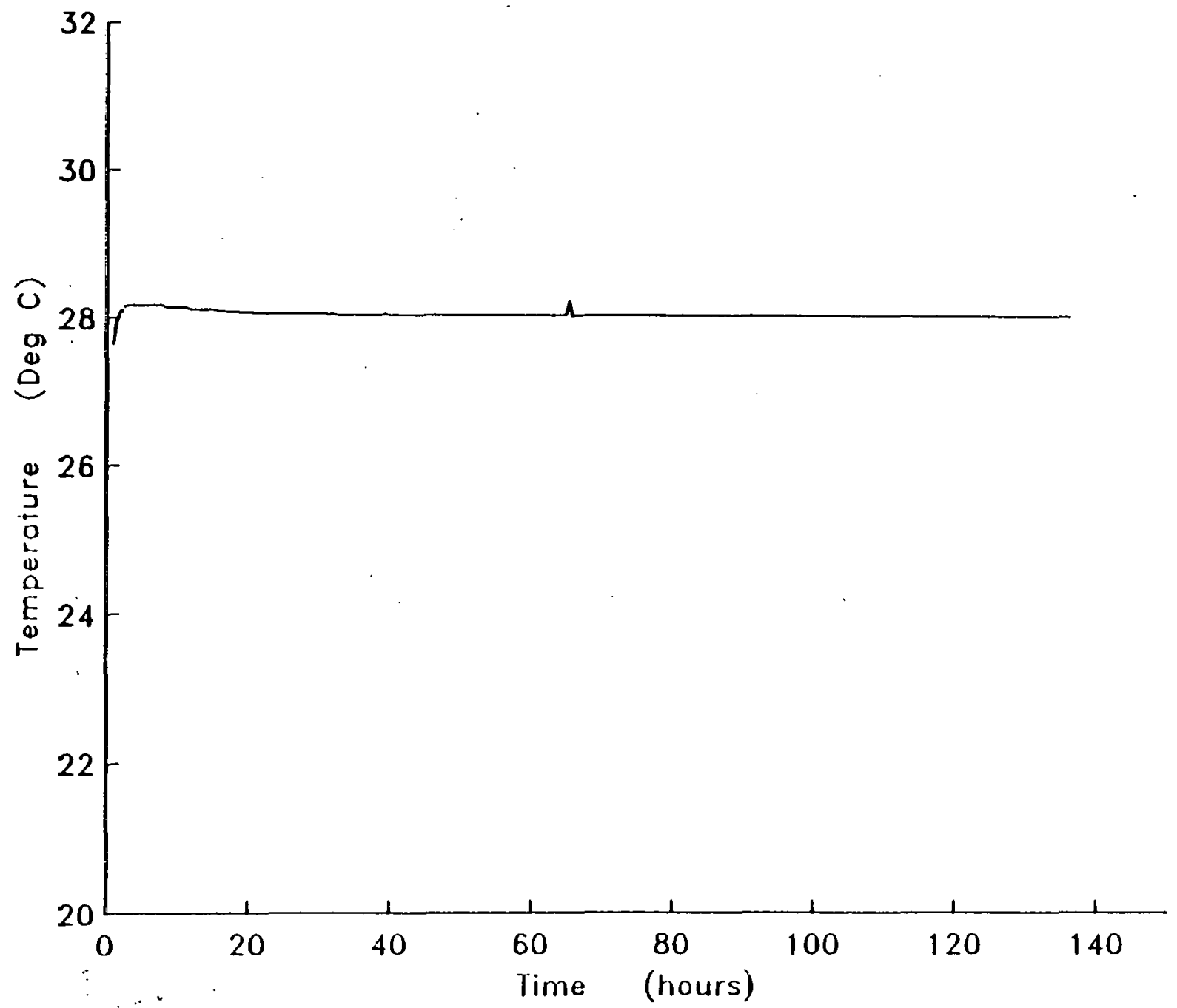

Figure A-18. Test region temperature history measured during the MAE32 gas flow test. 


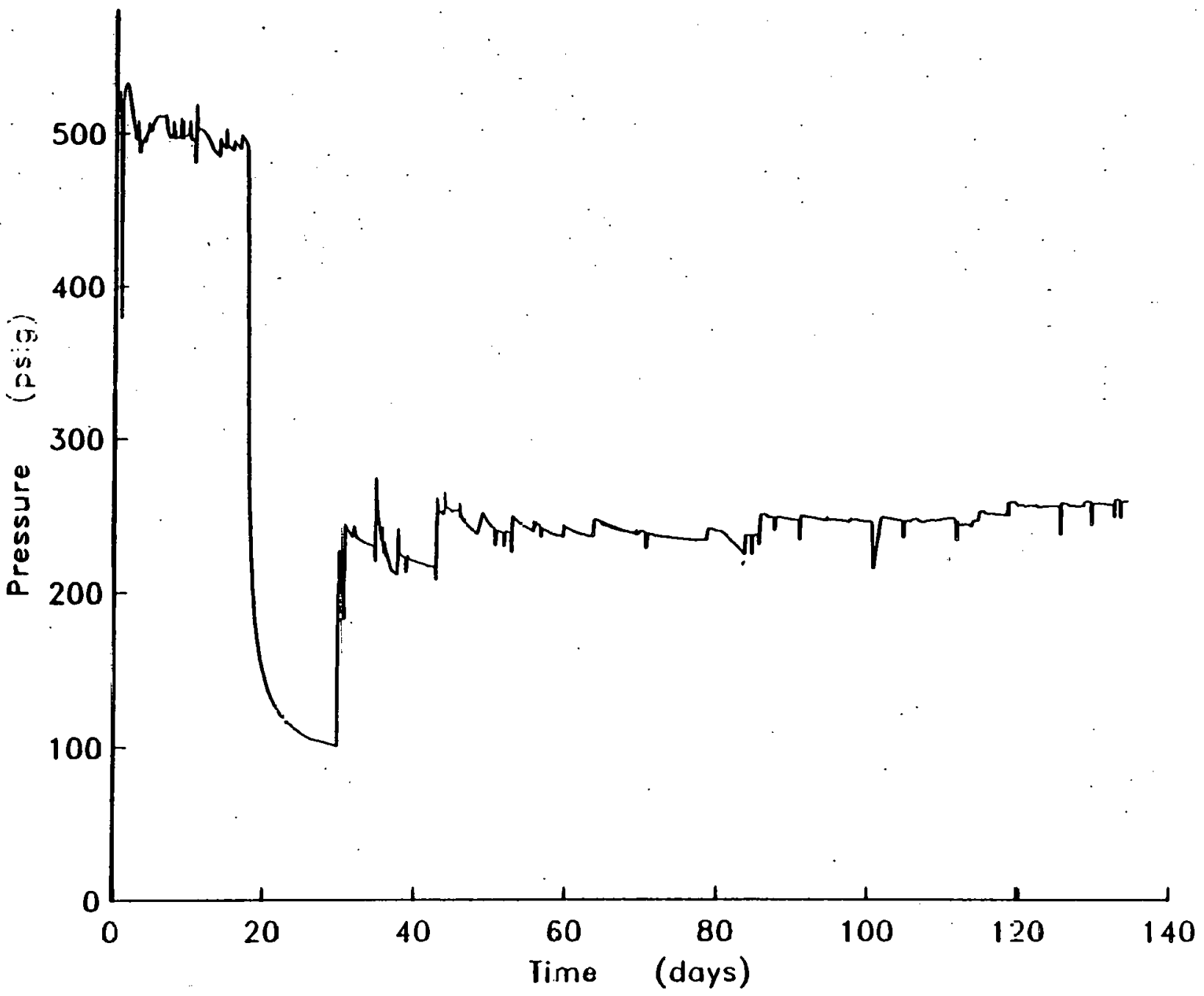

Figure A-19. Test region pressure histcry measured during the MAE12 brine flow test. 


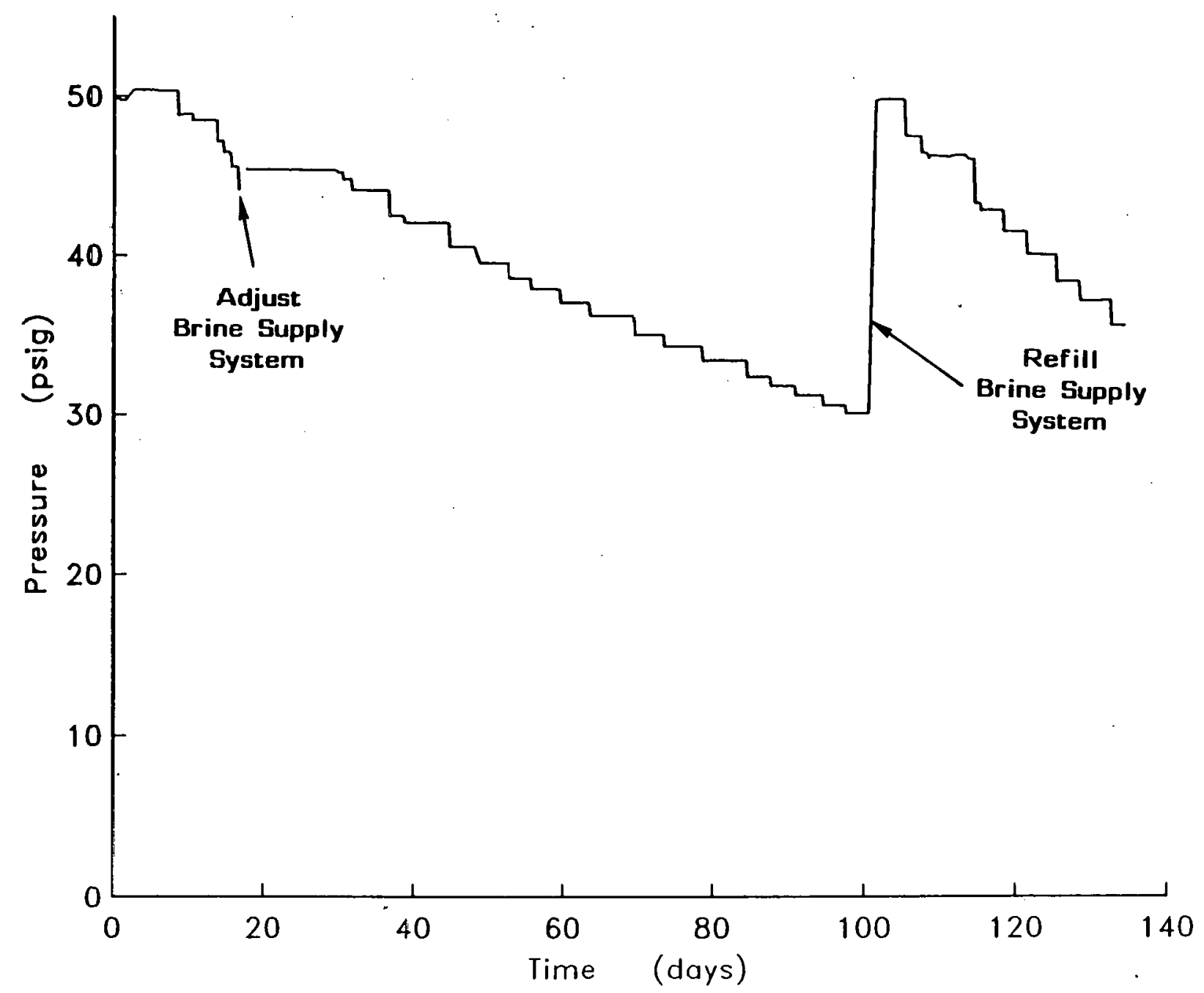

Figure A-20. Brine supply pressure history measured during the MAE12 brine flow test. 


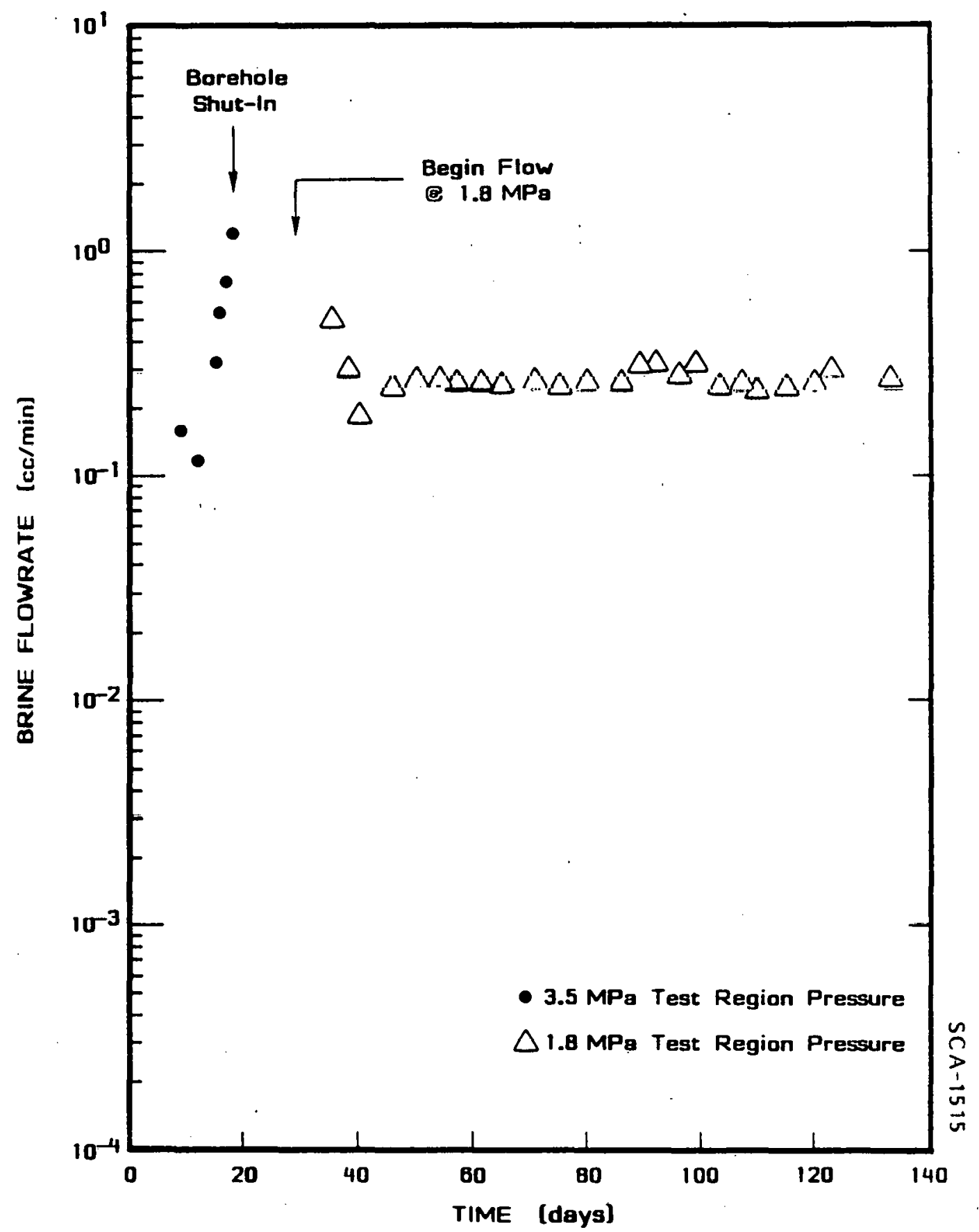

Figure A-21. MAE12 brine flowrate calculated from the brine supply pressure history shown on Figure A-20. 


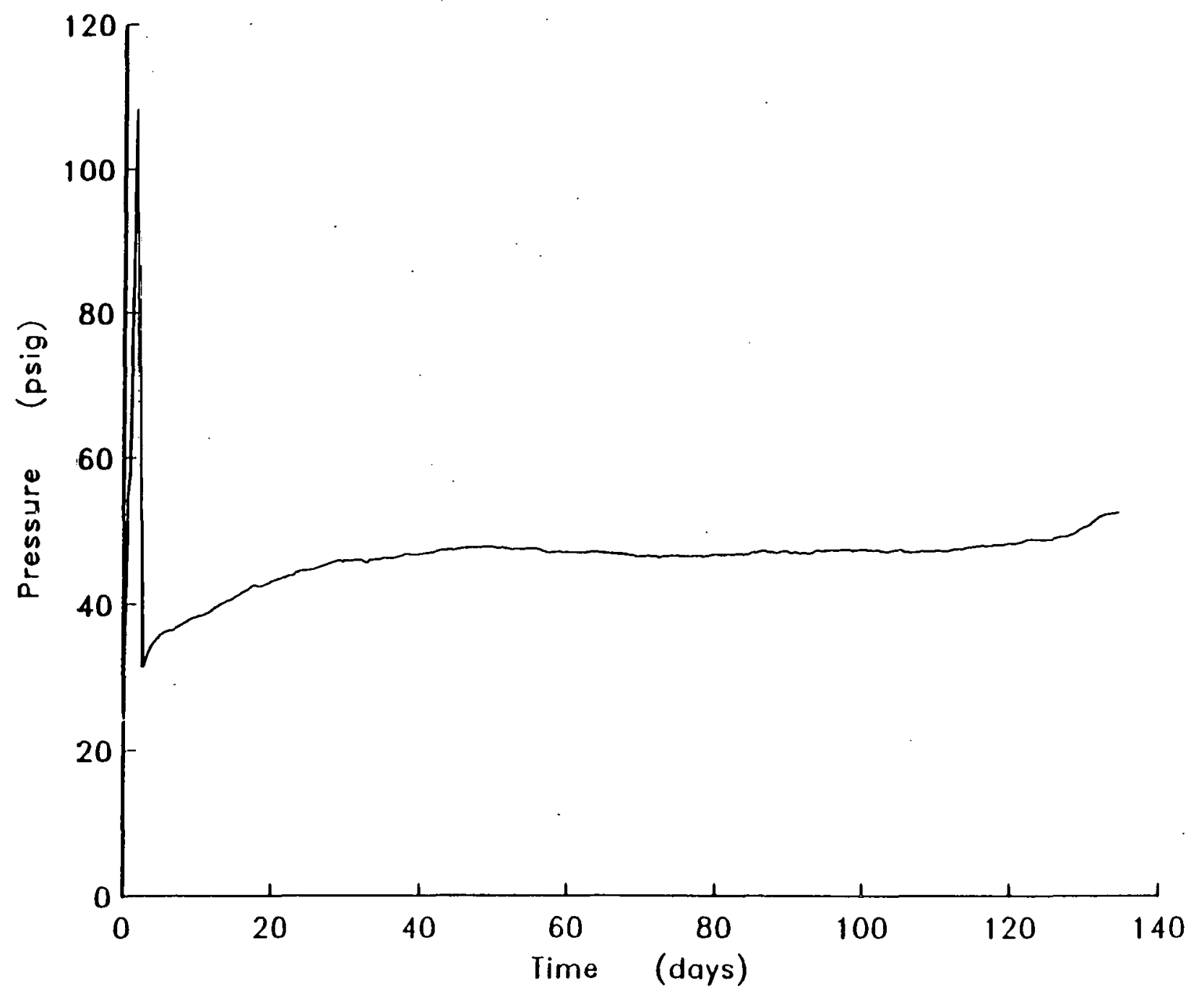

Figure A-22. Guard region pressure history measured during the MAE12 brine flow test. 


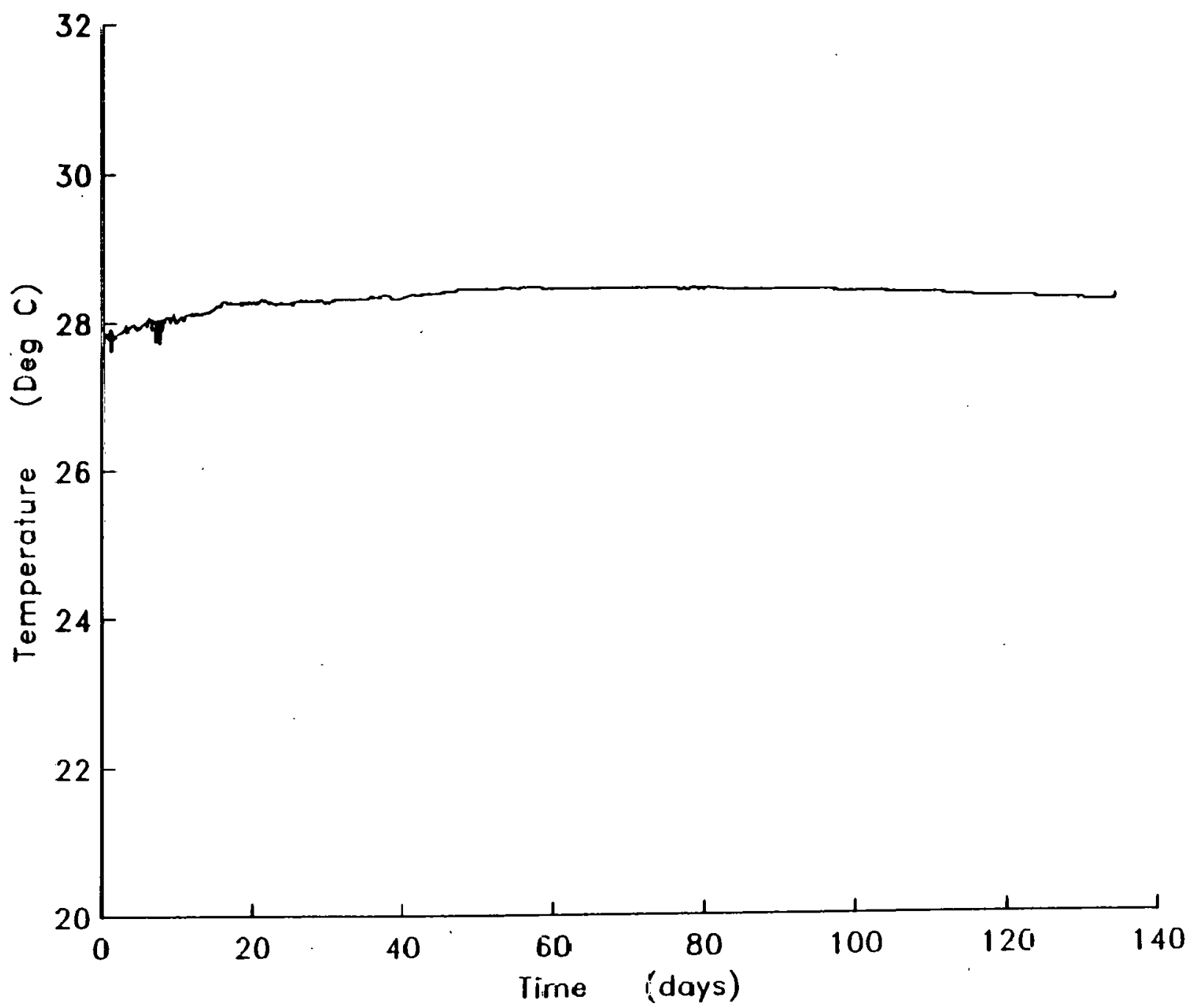

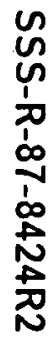

Figure A-23. Test region pressure history measured during the MAE12 brine flow test. 


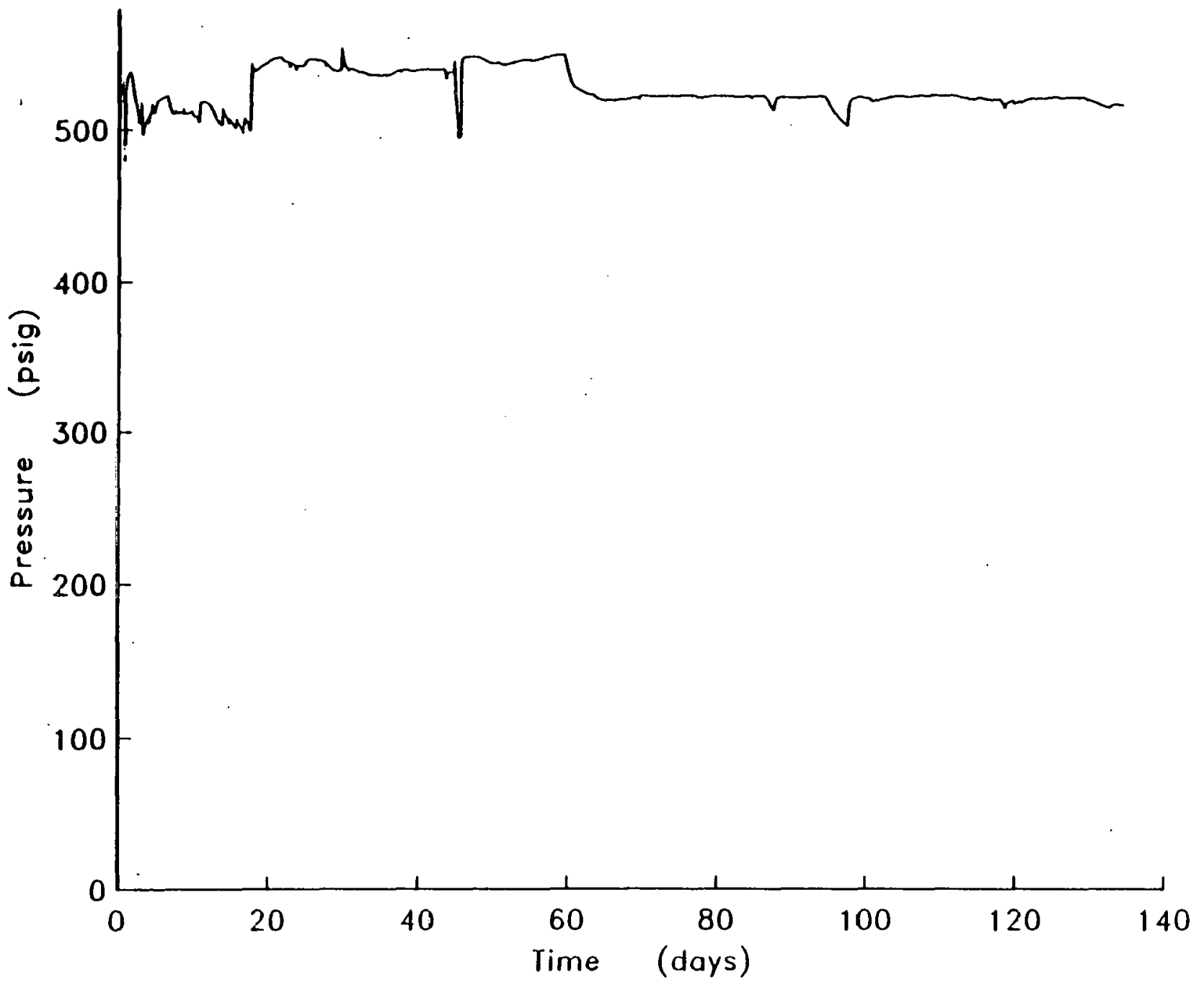

Figure A-24. Test region pressure history measured during the MAE22 brine flow test. 


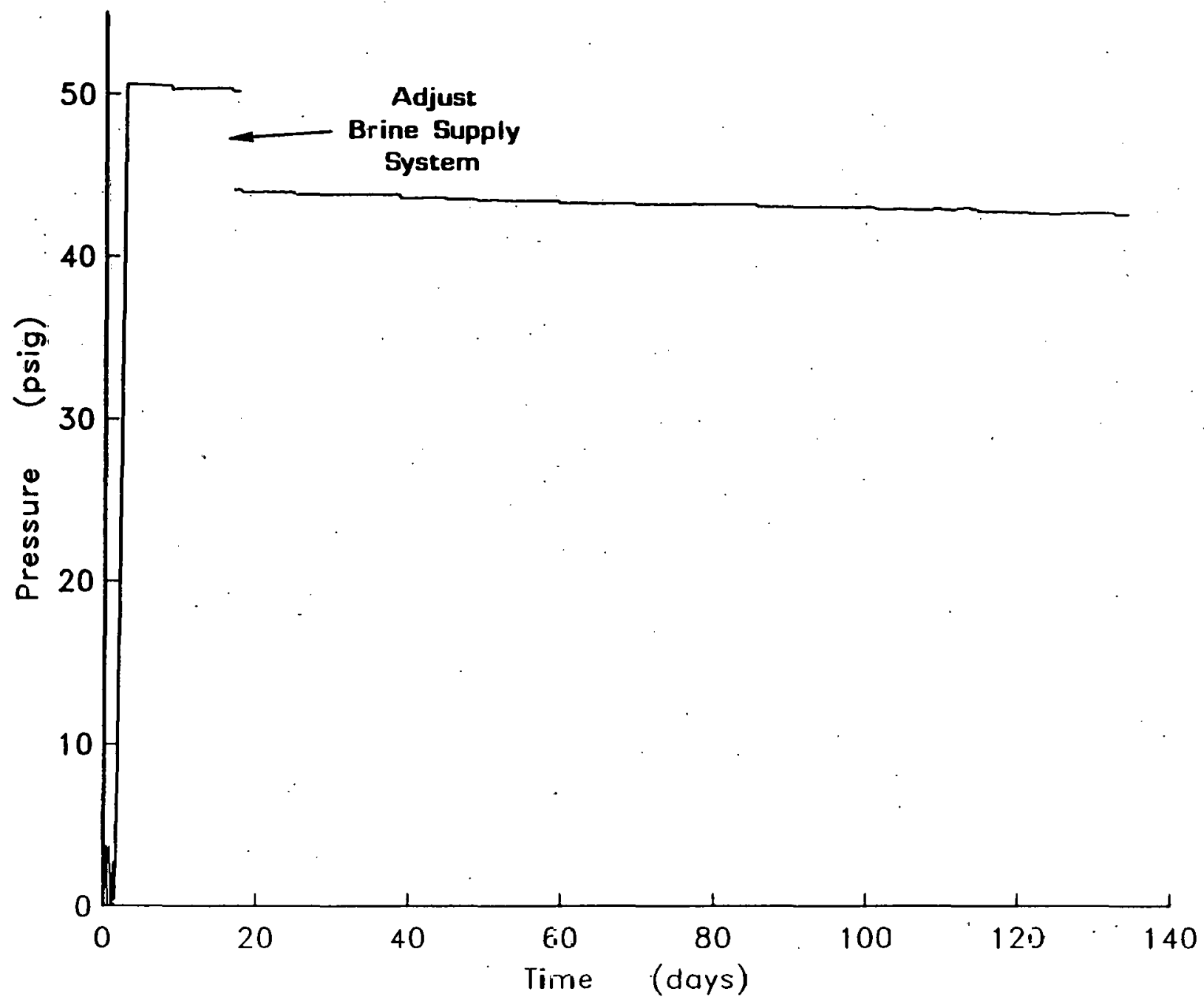

Figure A-25. Brine supply pressure history measured during the MAE22 brine flow test. 


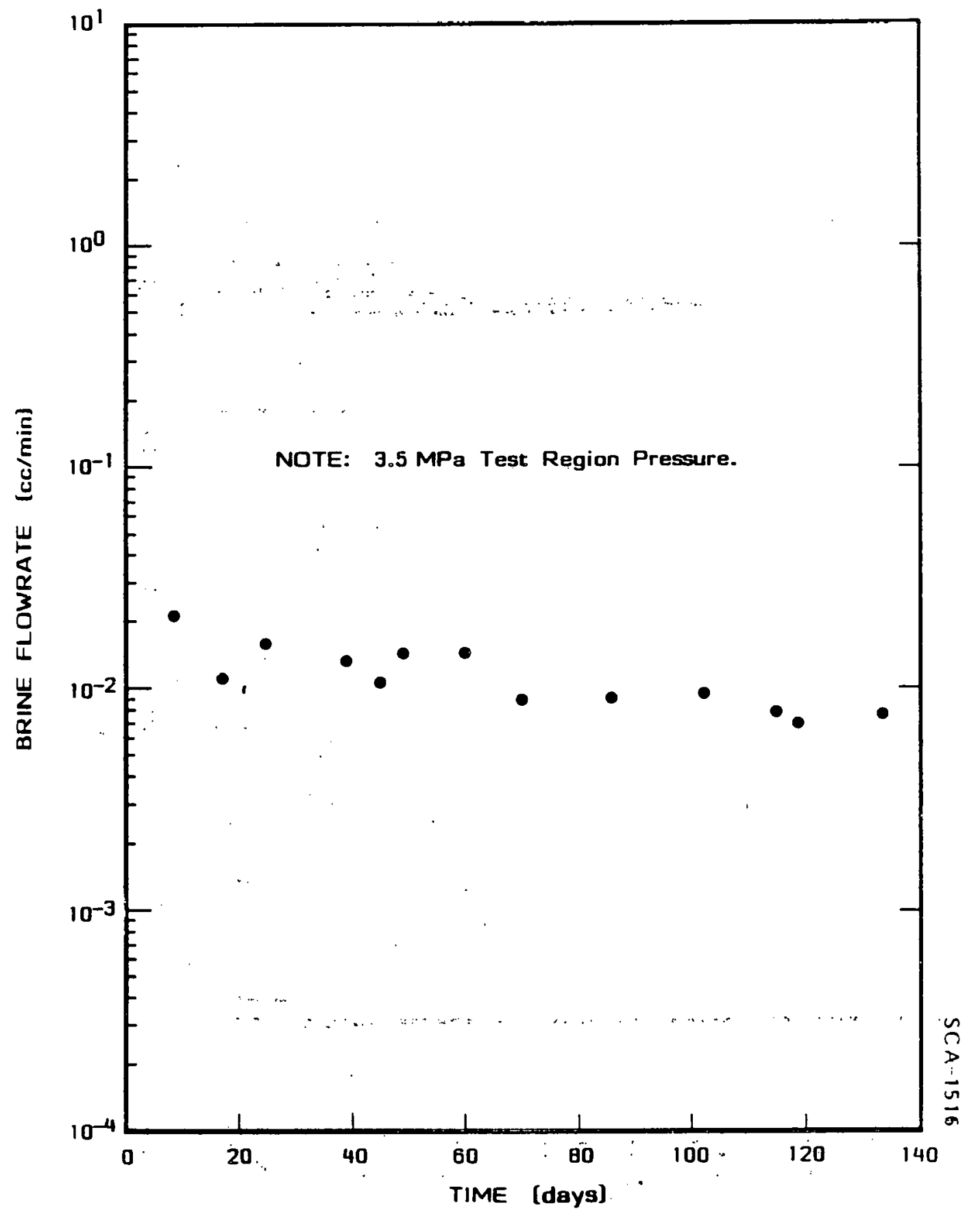

Figure A-26. MAE22 brine flowrate calculated from the brine supply pressure history shown on Figure A-25. 


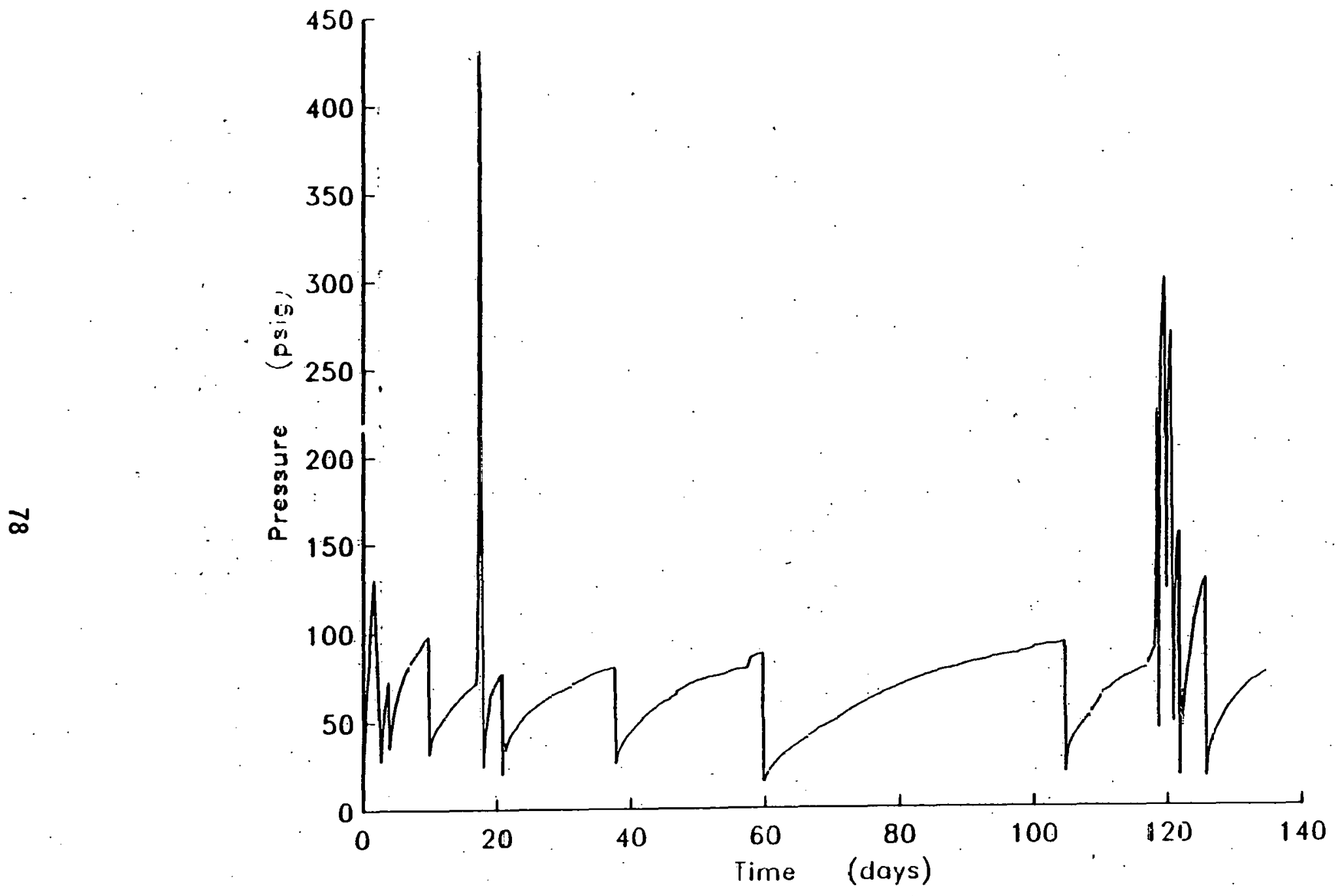

Figure A-27. Guard region pressure history measured during the MAE22 brine flow test. 


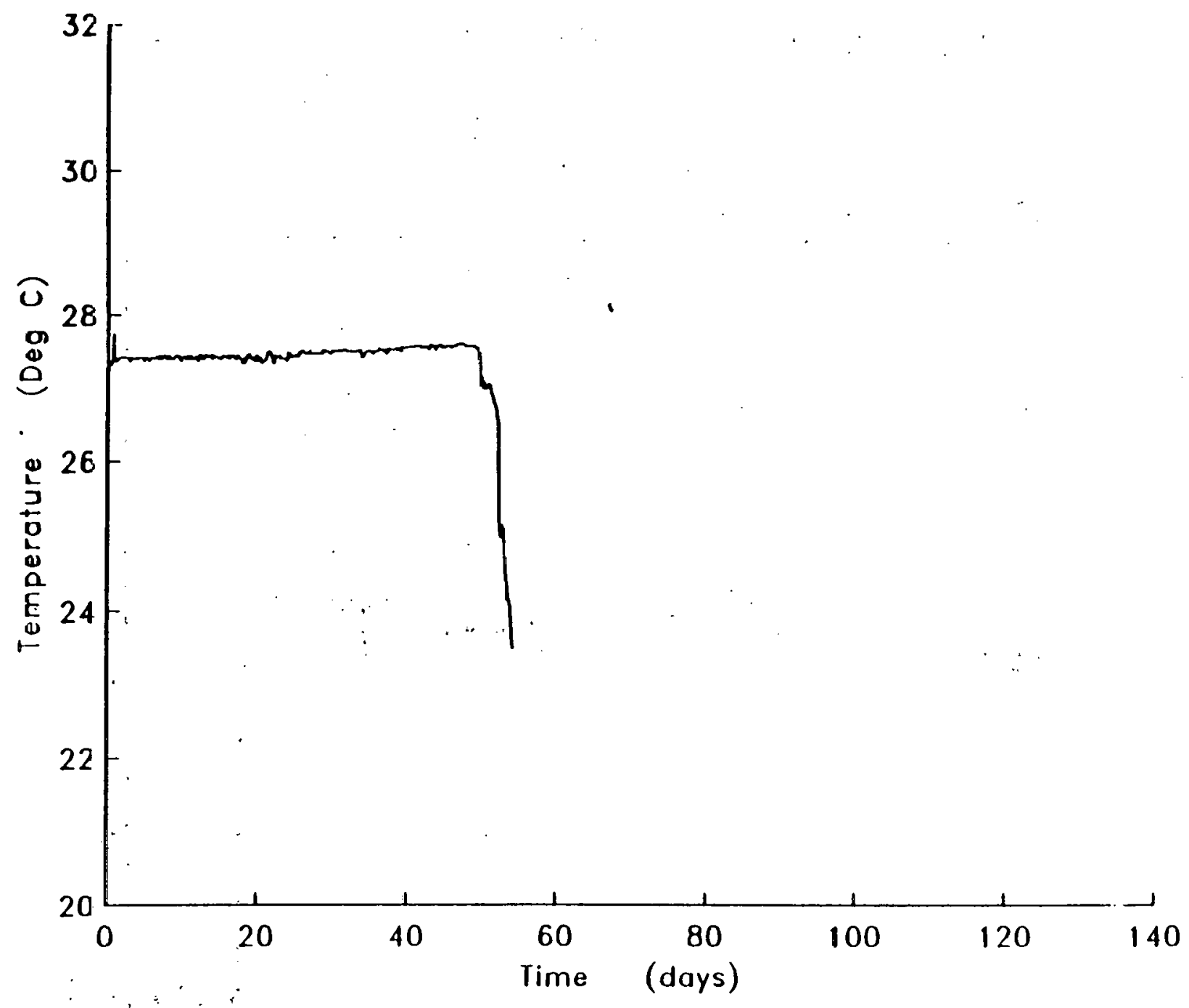

Figure A-28. Test region temperature history measured during the MAE22 brine flow test. 


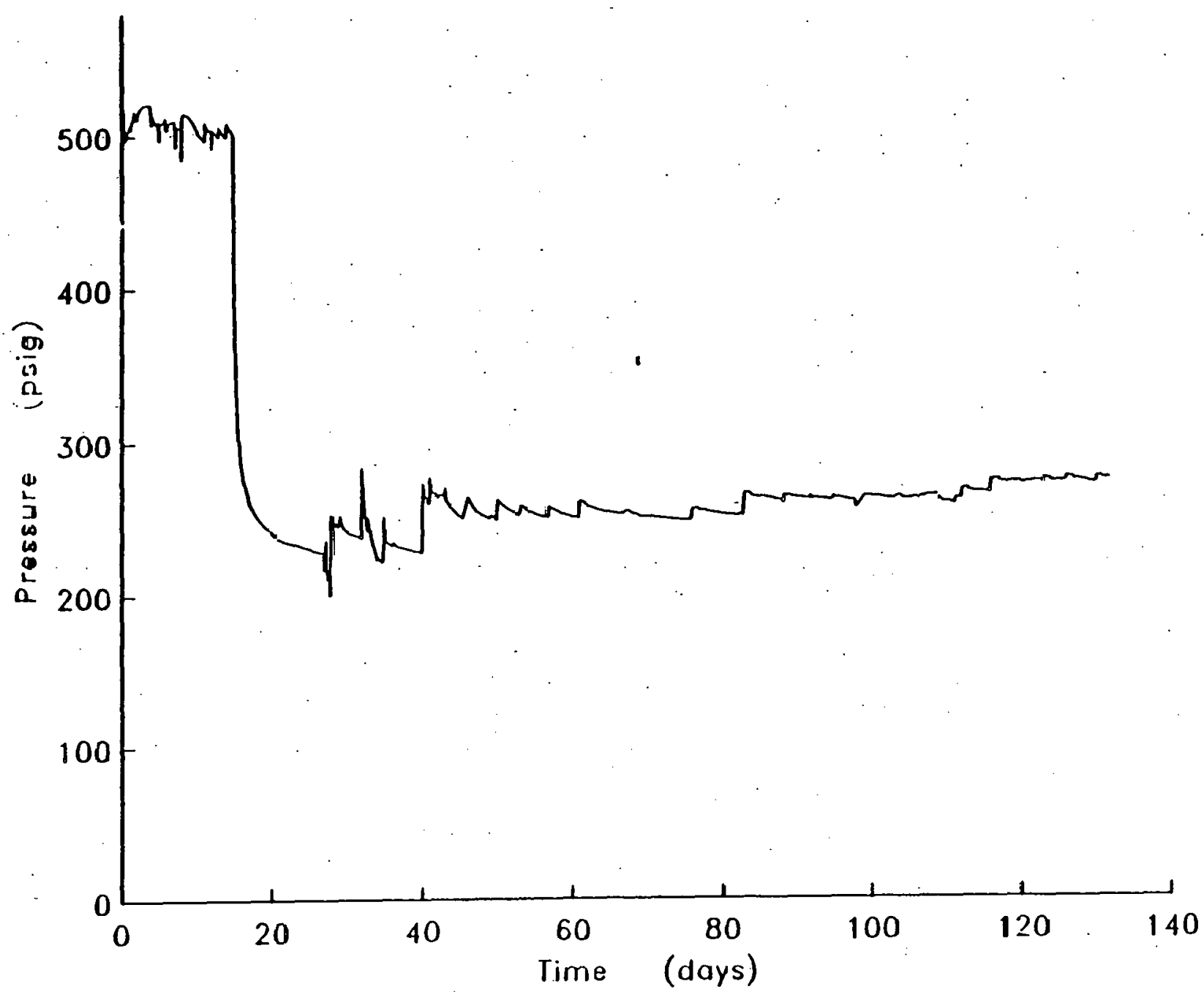

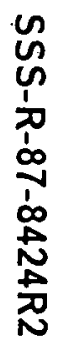

Figure A-29. Test region pressure history measured during the MAE32 brine flow test. 


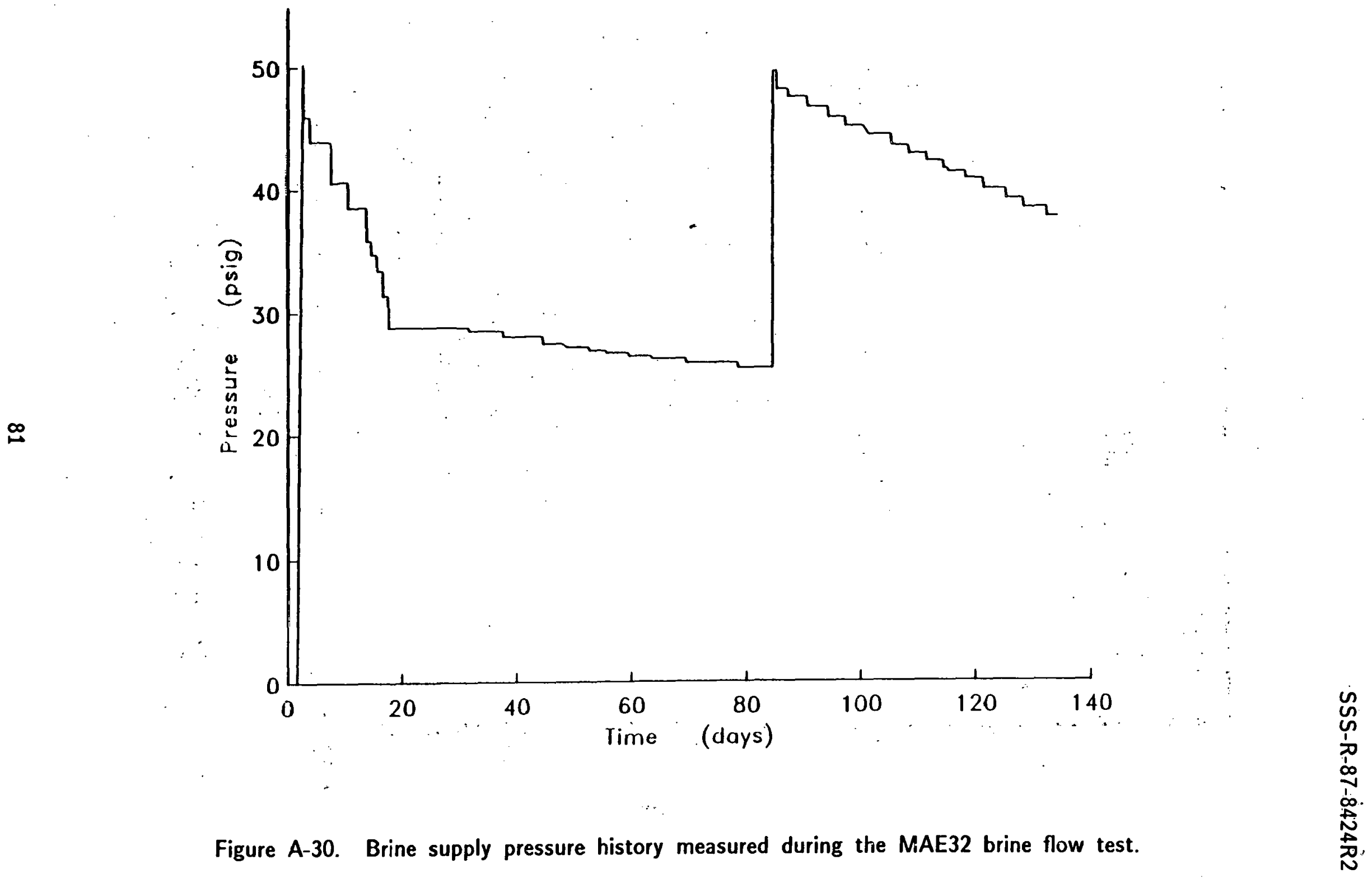




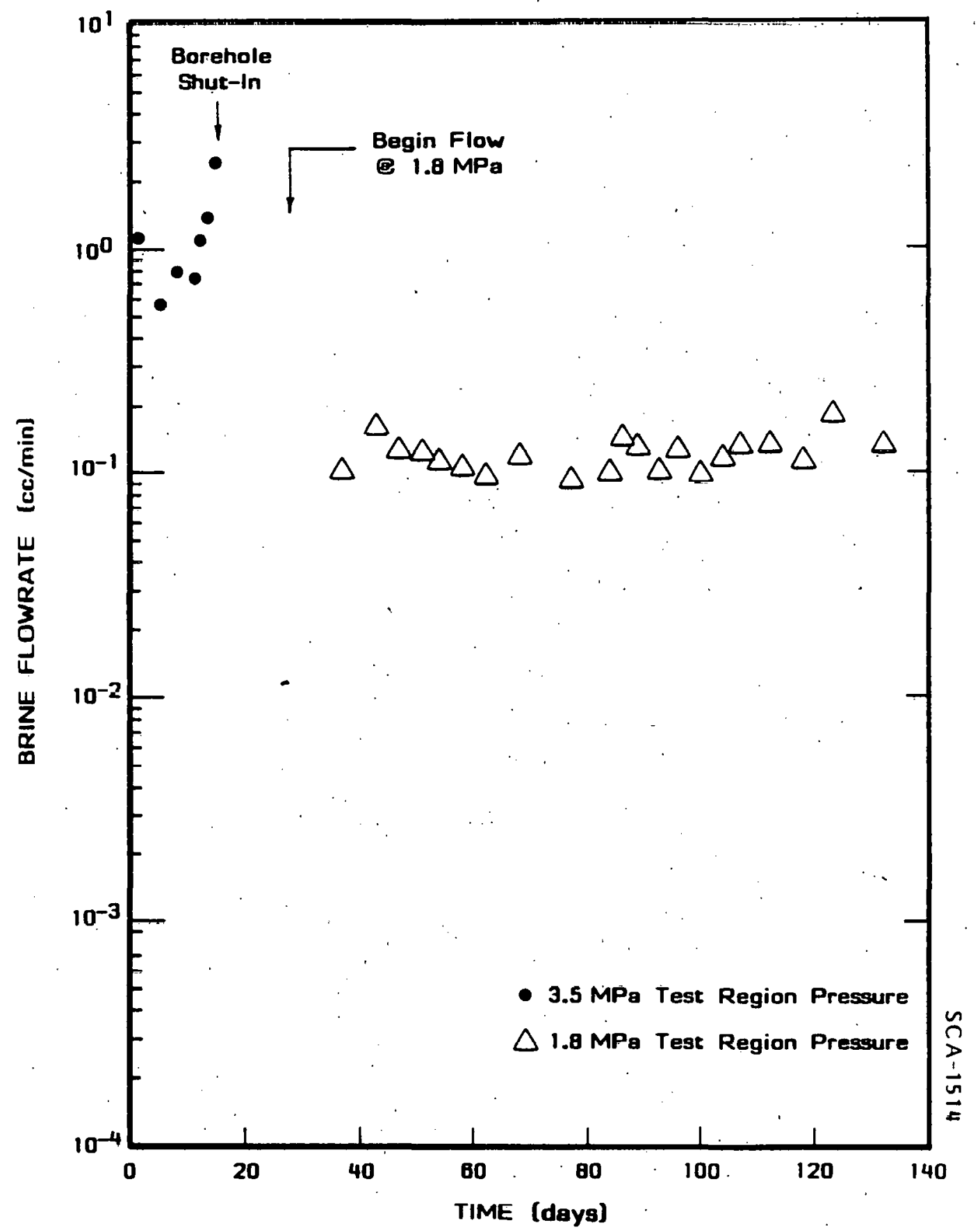

Figure A-31. MAE32 brine flowrate calculated from the brine supply pressure history shown on Figure A-30. 
$\stackrel{\infty}{\omega}$

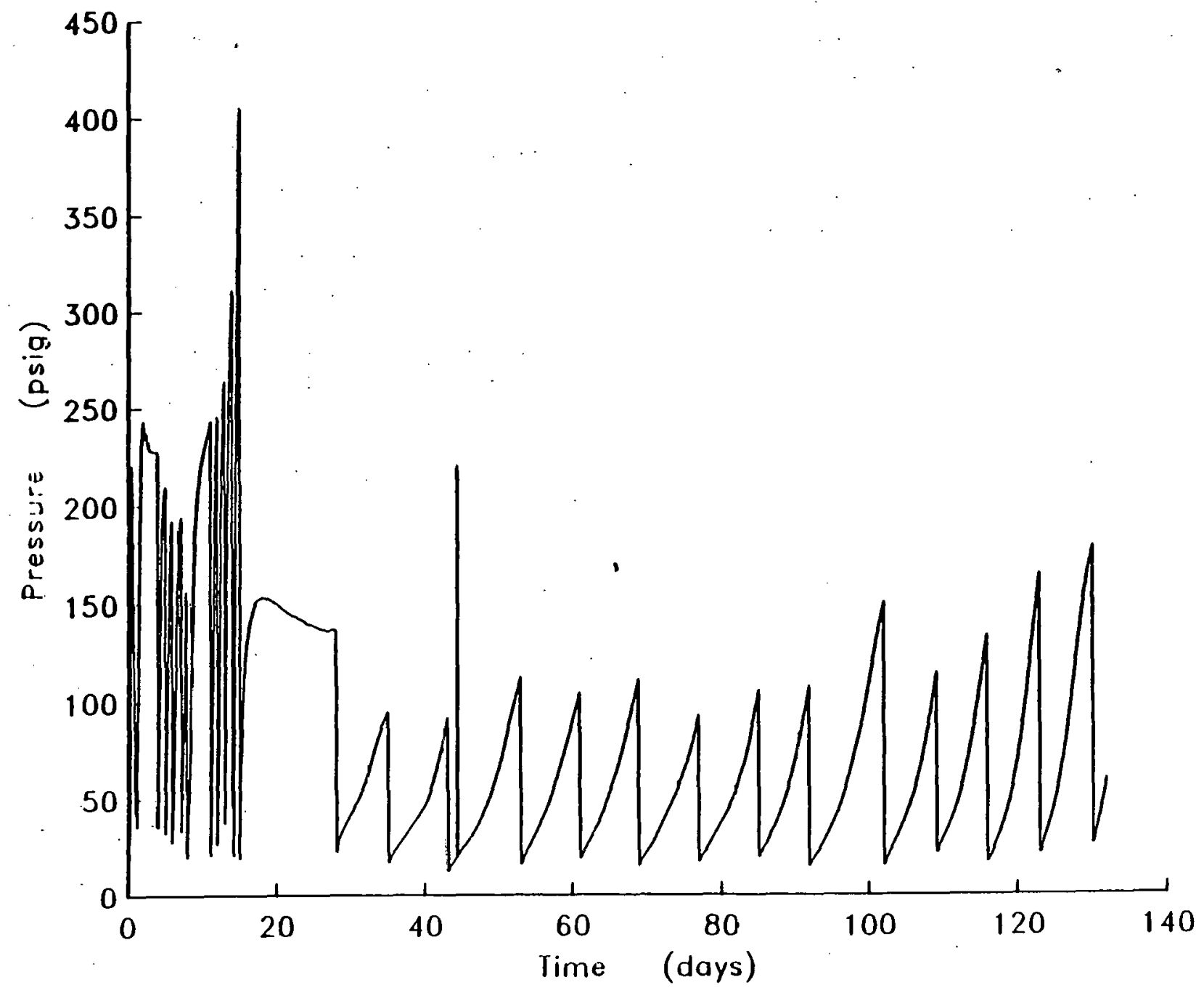

Figure A-32. Guard region pressure history measured during the MAE32 brine flow test.

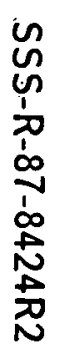




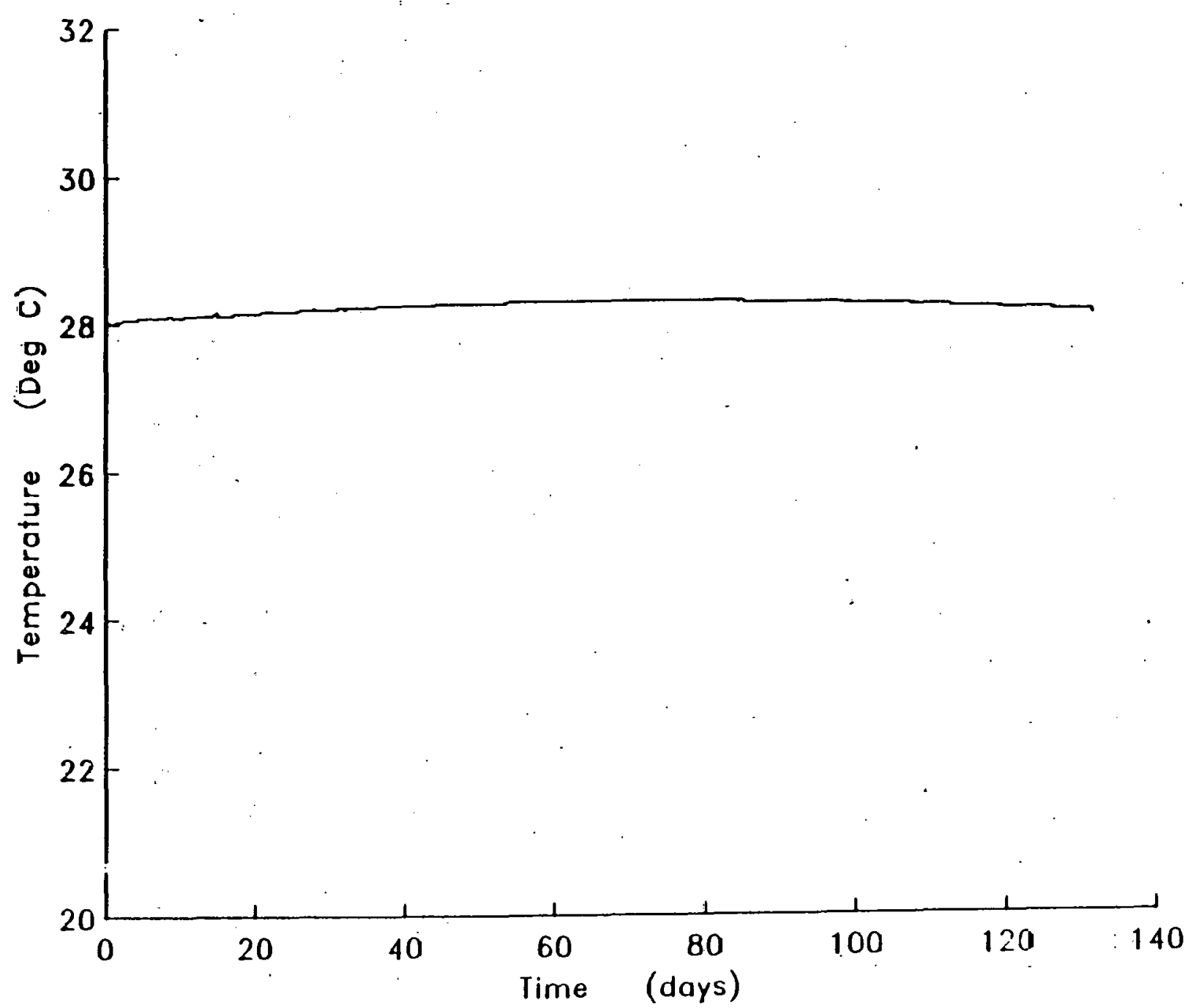

Figure A-33. Test region temperature history measured during the MAE32 brine flow test. 


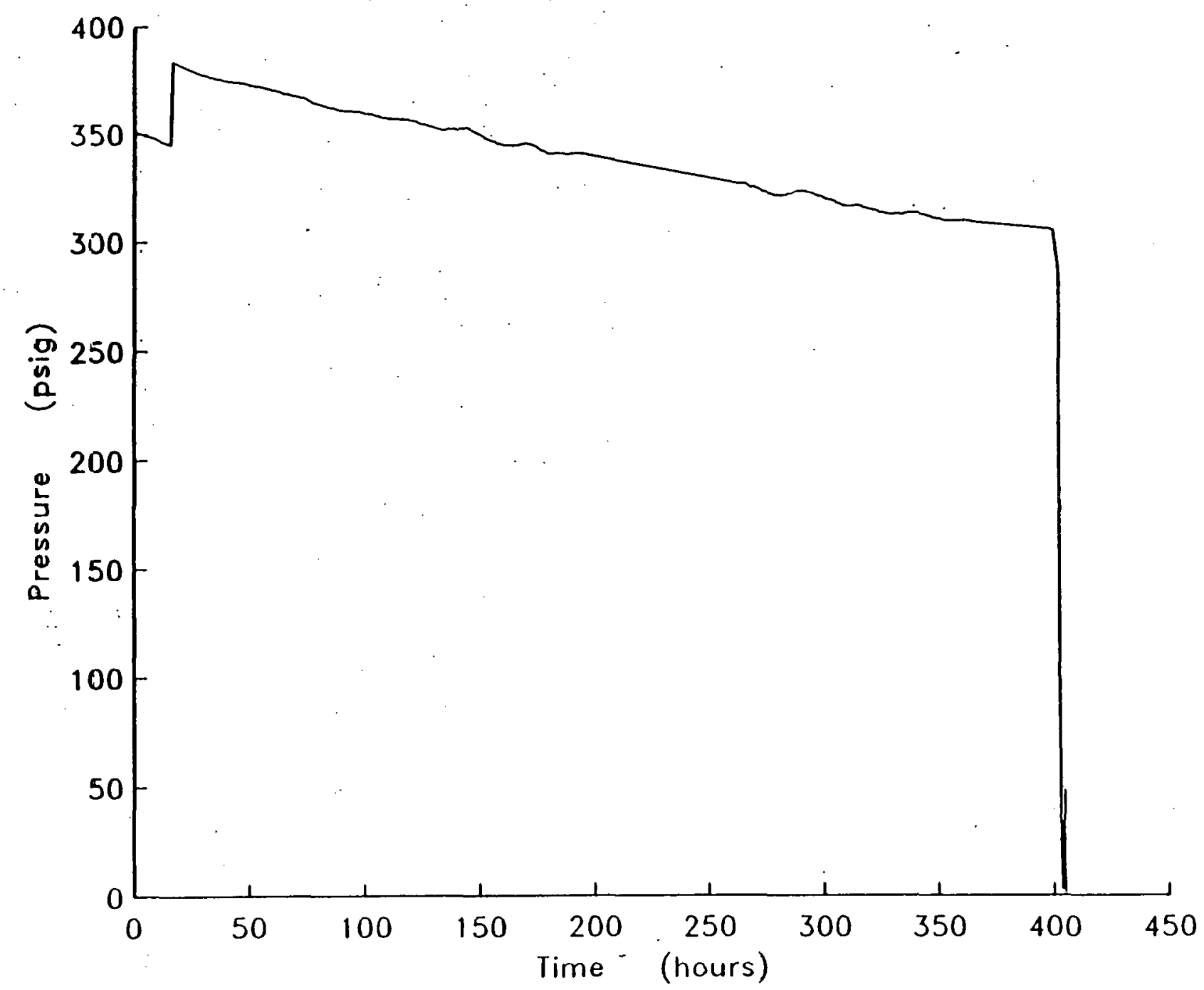

Figure A-34. Test region pressure history measured during the April 1986 MBE31 gas flow test. 


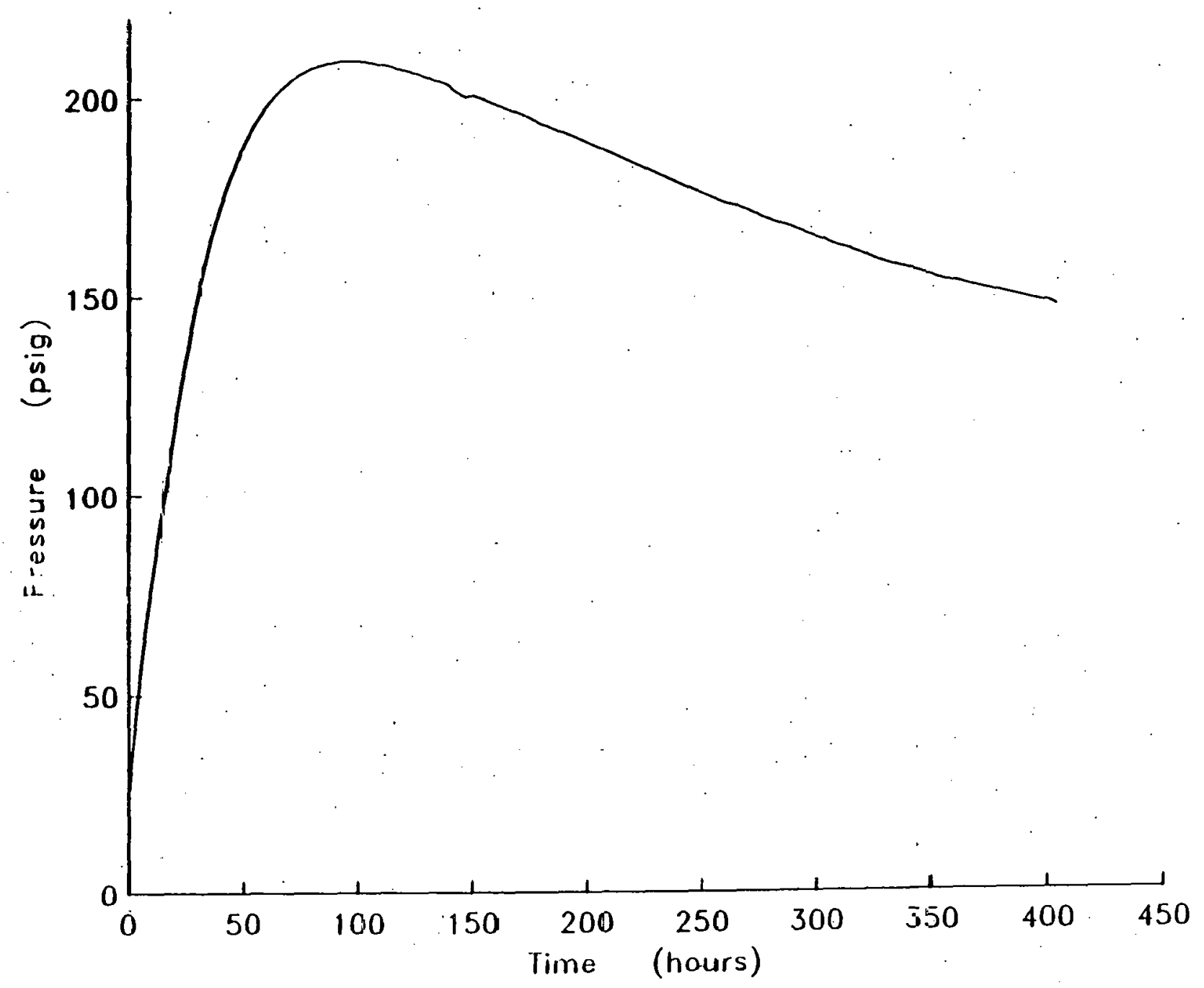

Figure A-35. Guard region pressure history measured during the April 1986 MBE31 gas flow test. 


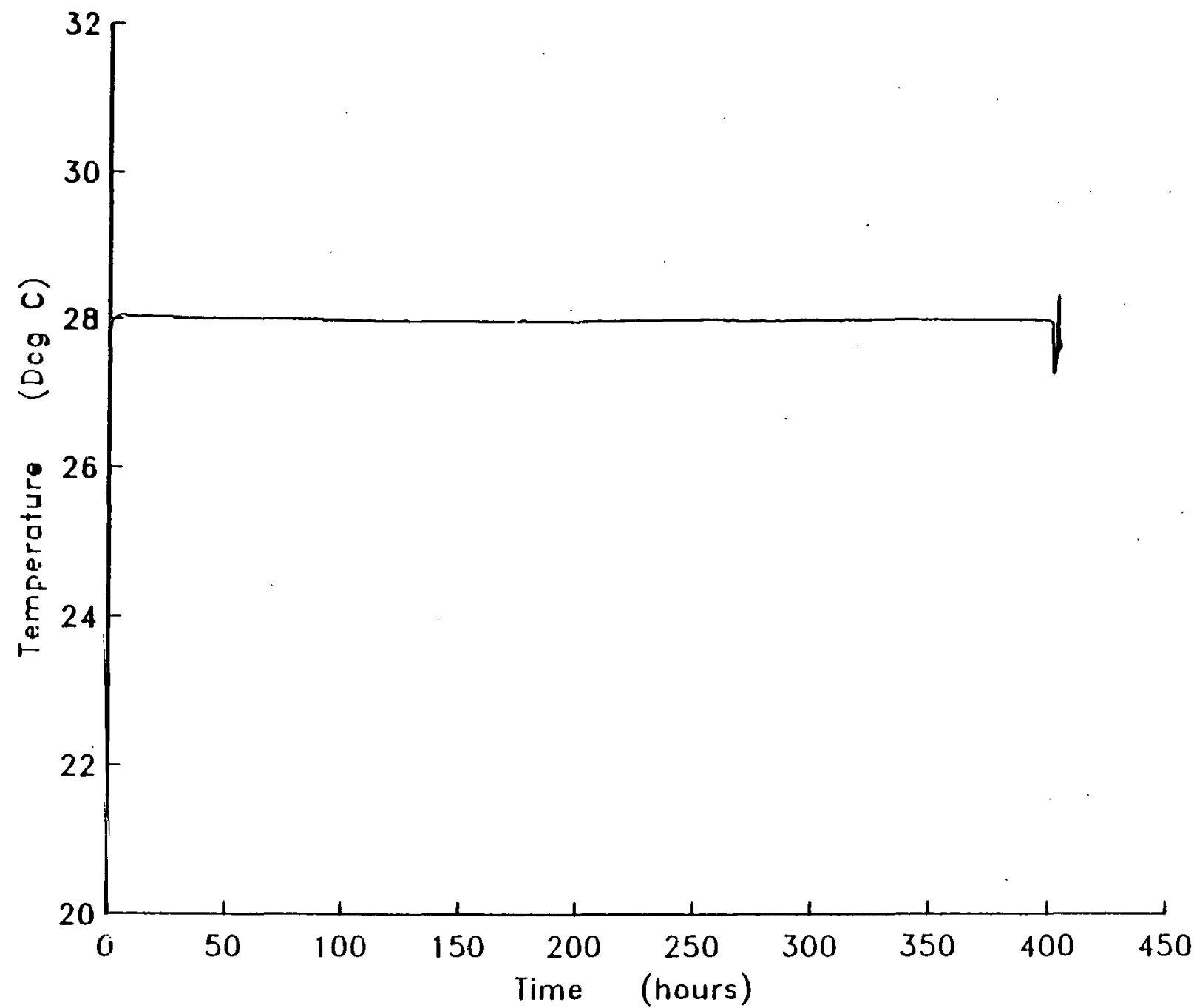

Figure A-36. Test region temperature history measured during the April 1986 MBE31 gas flow test. 


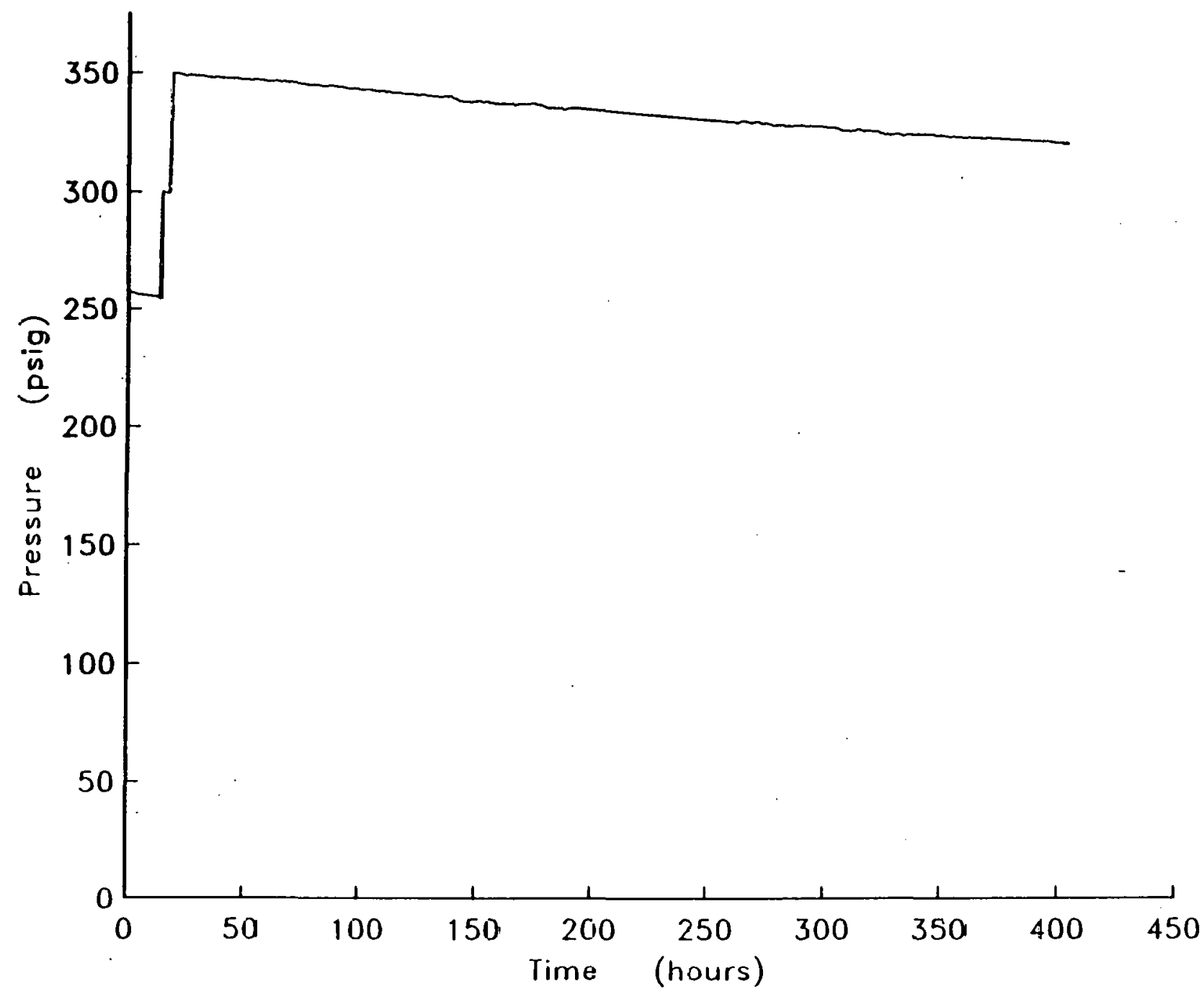

Figure A-37. Test region pressure history measured during the April 1986 MBE32 gas flow test. 


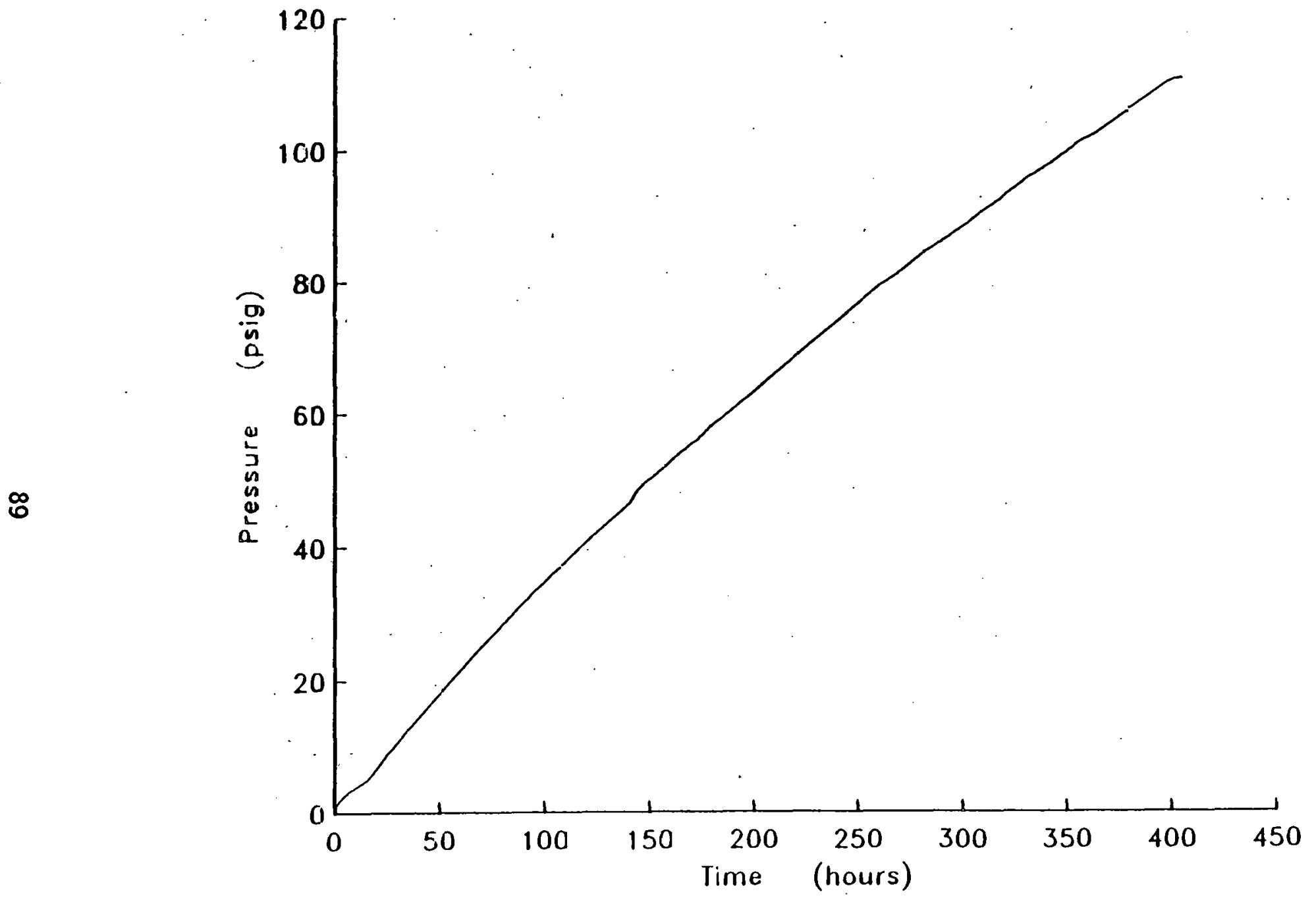

Figure A-38. Guard region pressure history measured during the April 1986 MBE32 gas flow test.

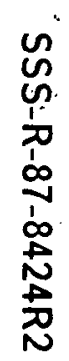




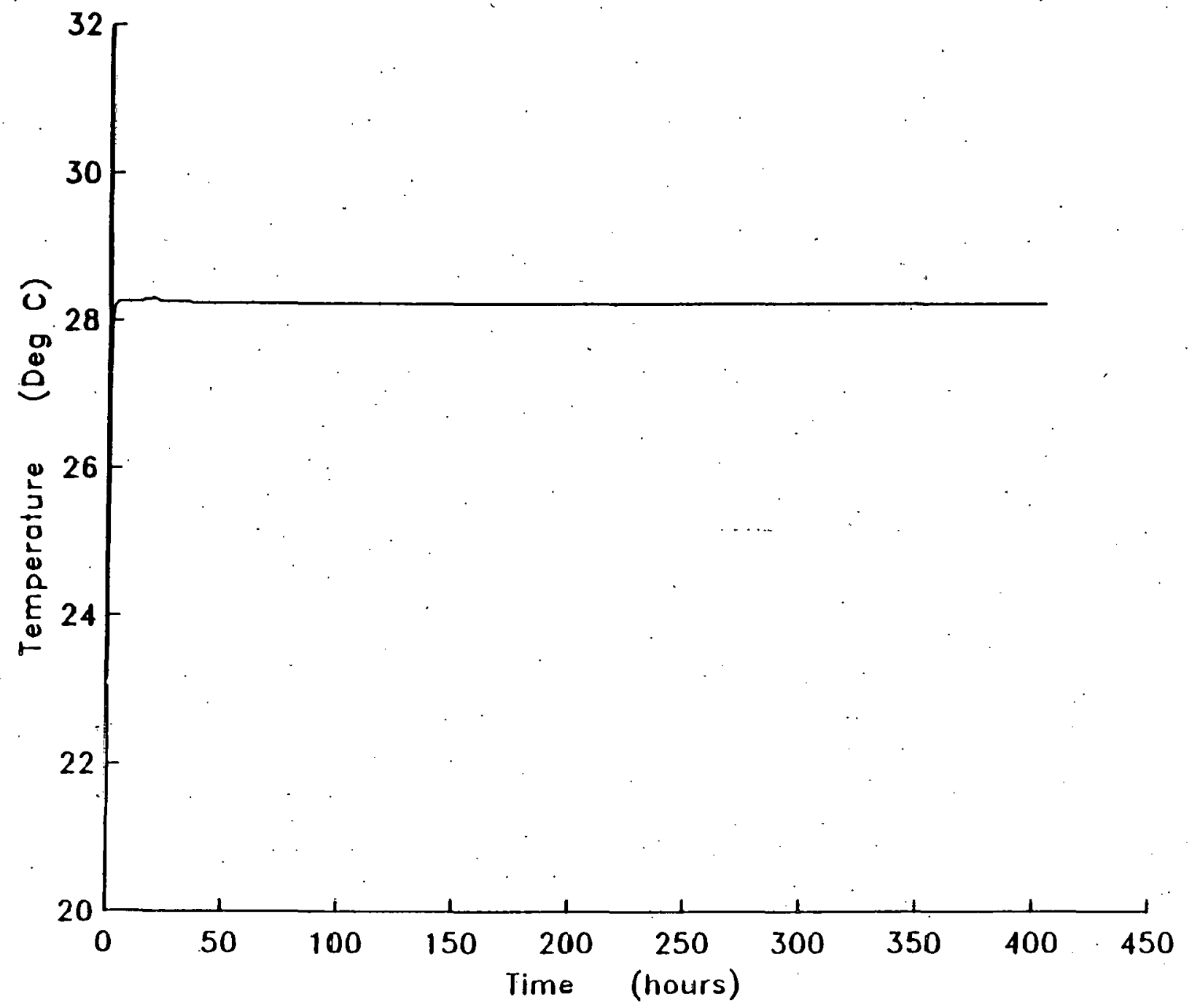

Figure A-39. Test region temperature history measured during the April 1986 MBE32 gas flow test. 


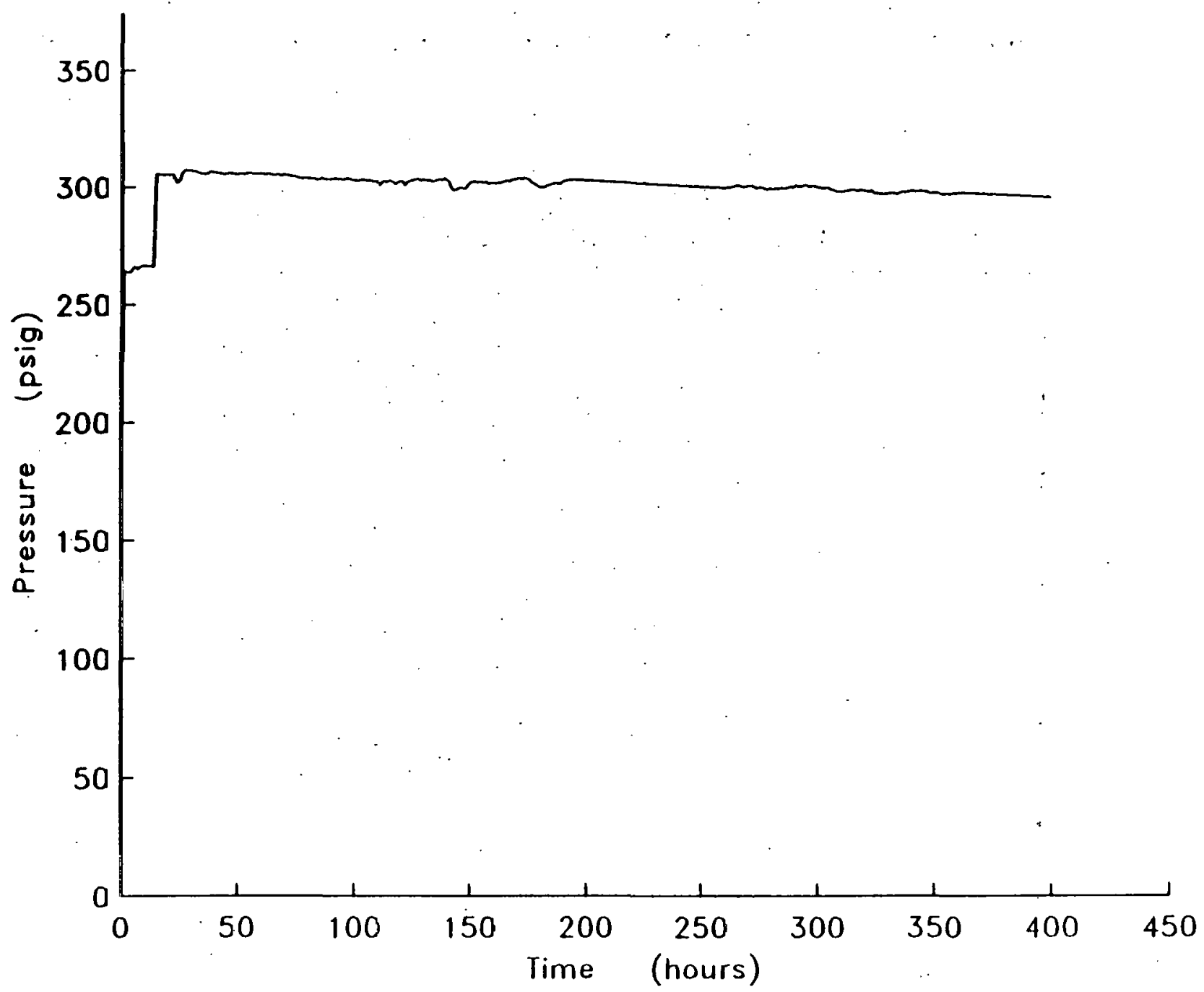

Figure A-40. Test region pressure history measured during the April 1986 MBE33 gas flow test. 


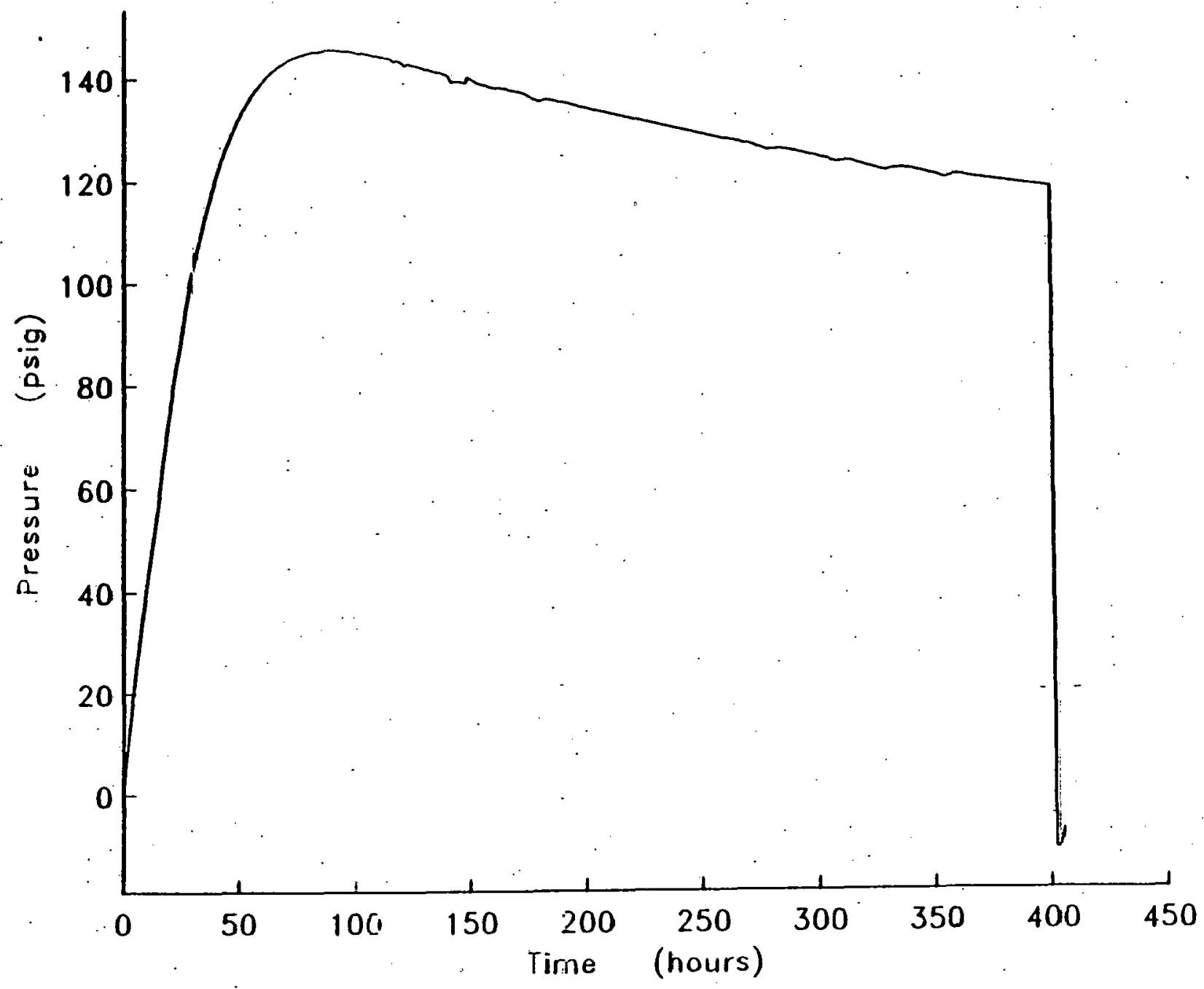

Figure A-41. Guard region pressure history measured during the April 1986 MBE33 gas flow test. 


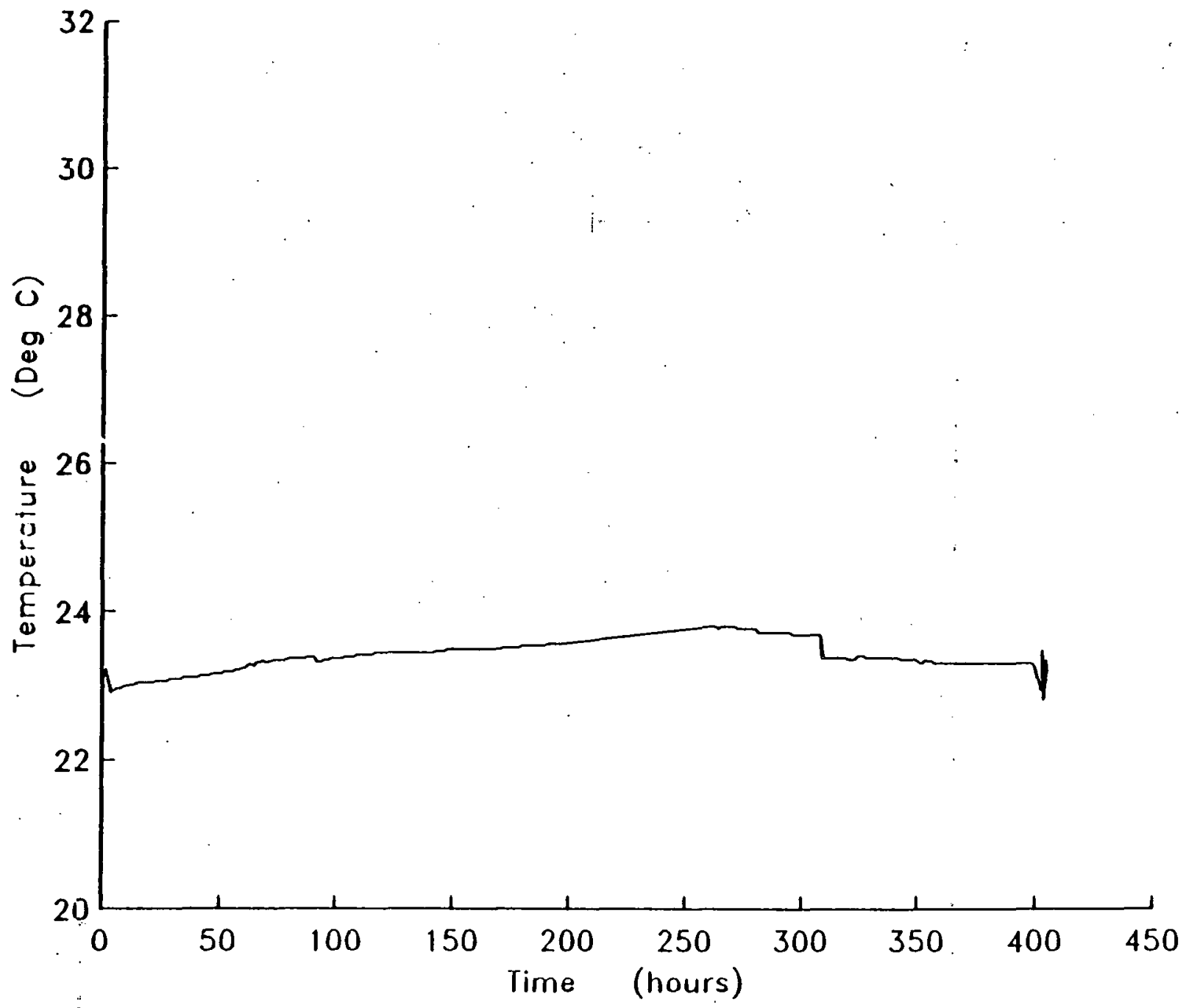

Figure A-42. Test region temperature history measured during the April 1986 MBE33 gas flow test. 


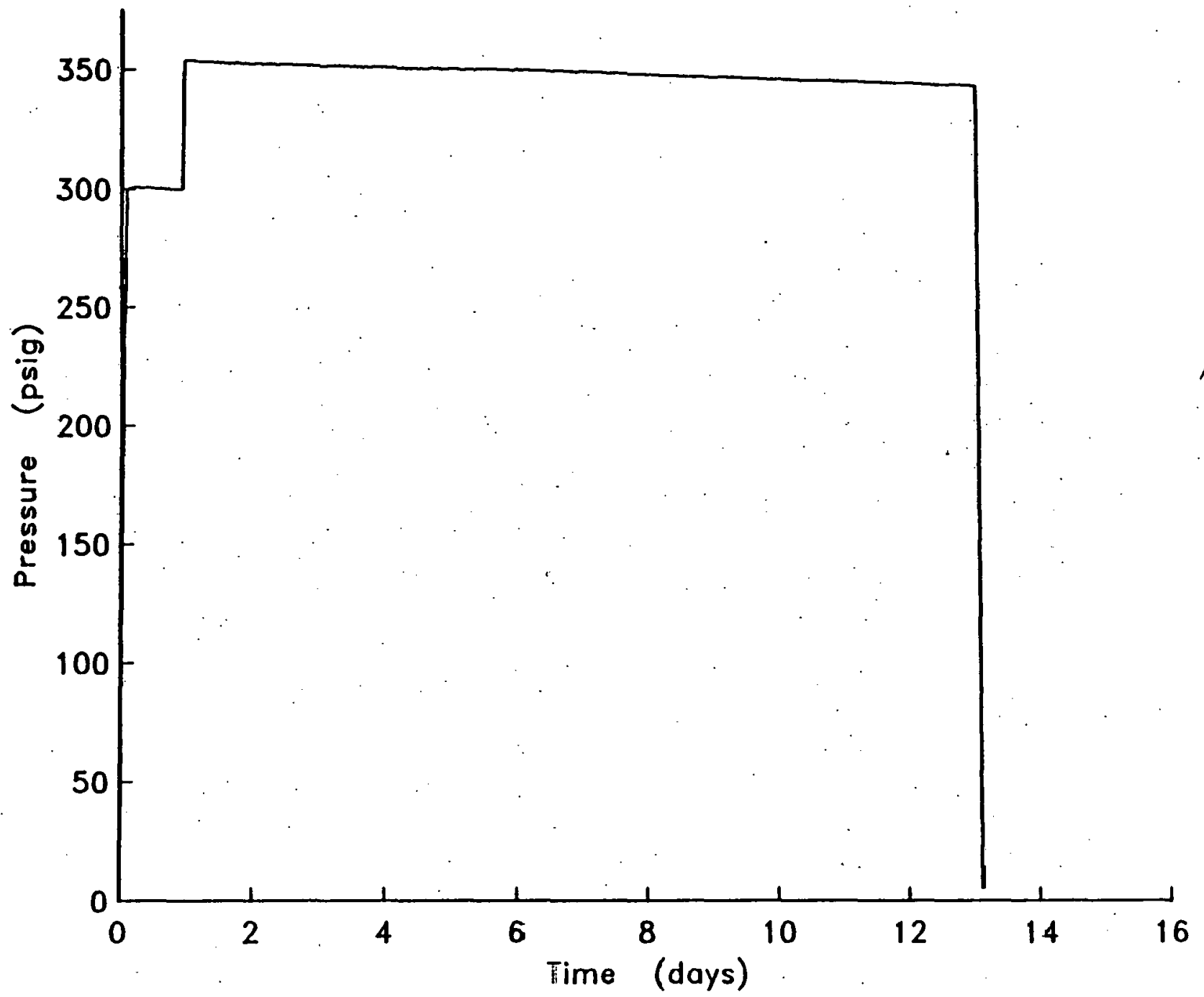

Figure A-43. Test region pressure history measured during the May 1987 MEE 31 gas flow test. 


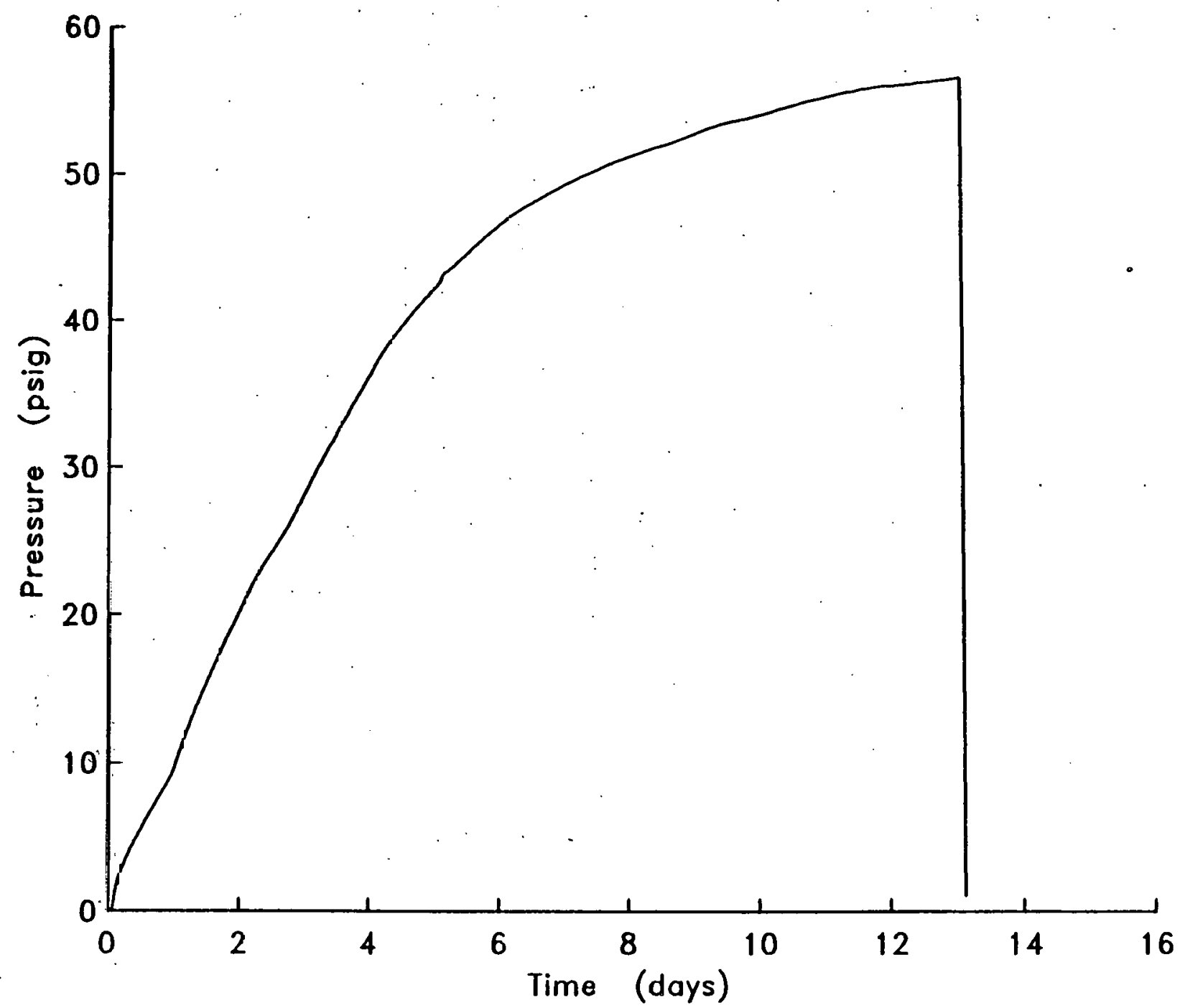

Figure A-44. Guard region pressure history measured during the May 1987 MBE 31 gas flow test. 


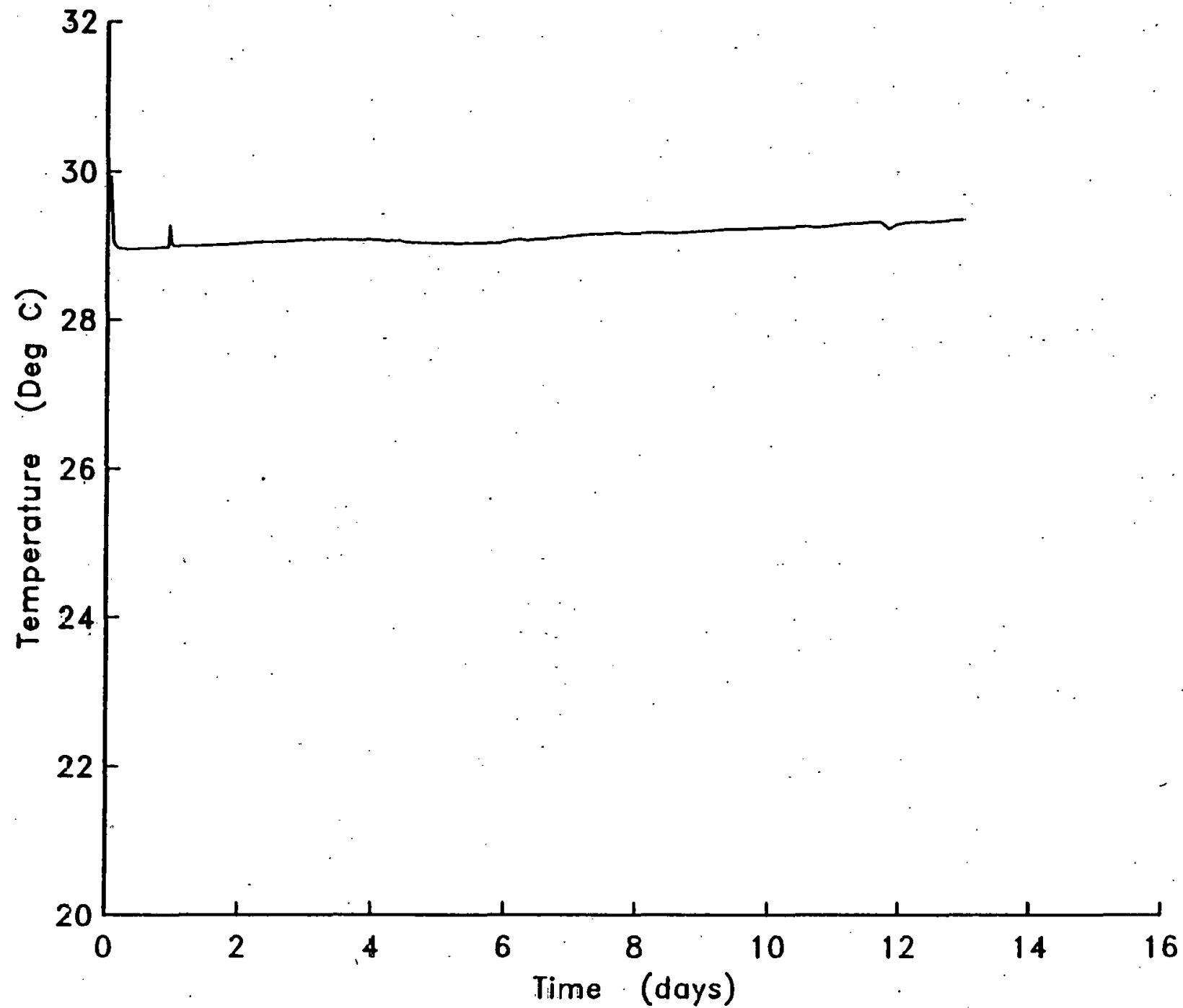

Figure A-45. Test region temperature history measured during the May 1987 MBE 31 gas flow test. 


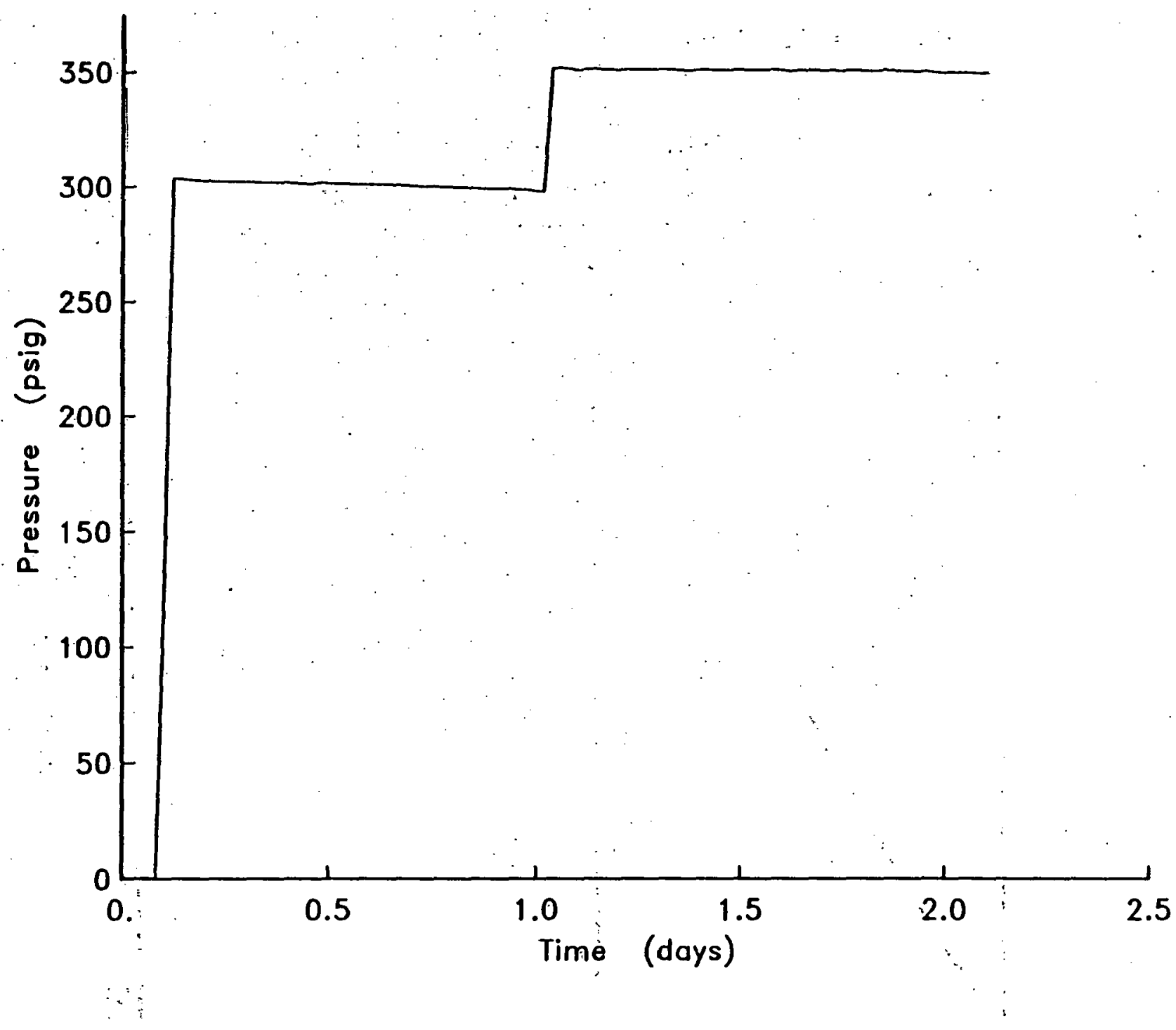

Figure A-46. Test region pressure history measured during the May 1987 MBE 32 gas flow test. 


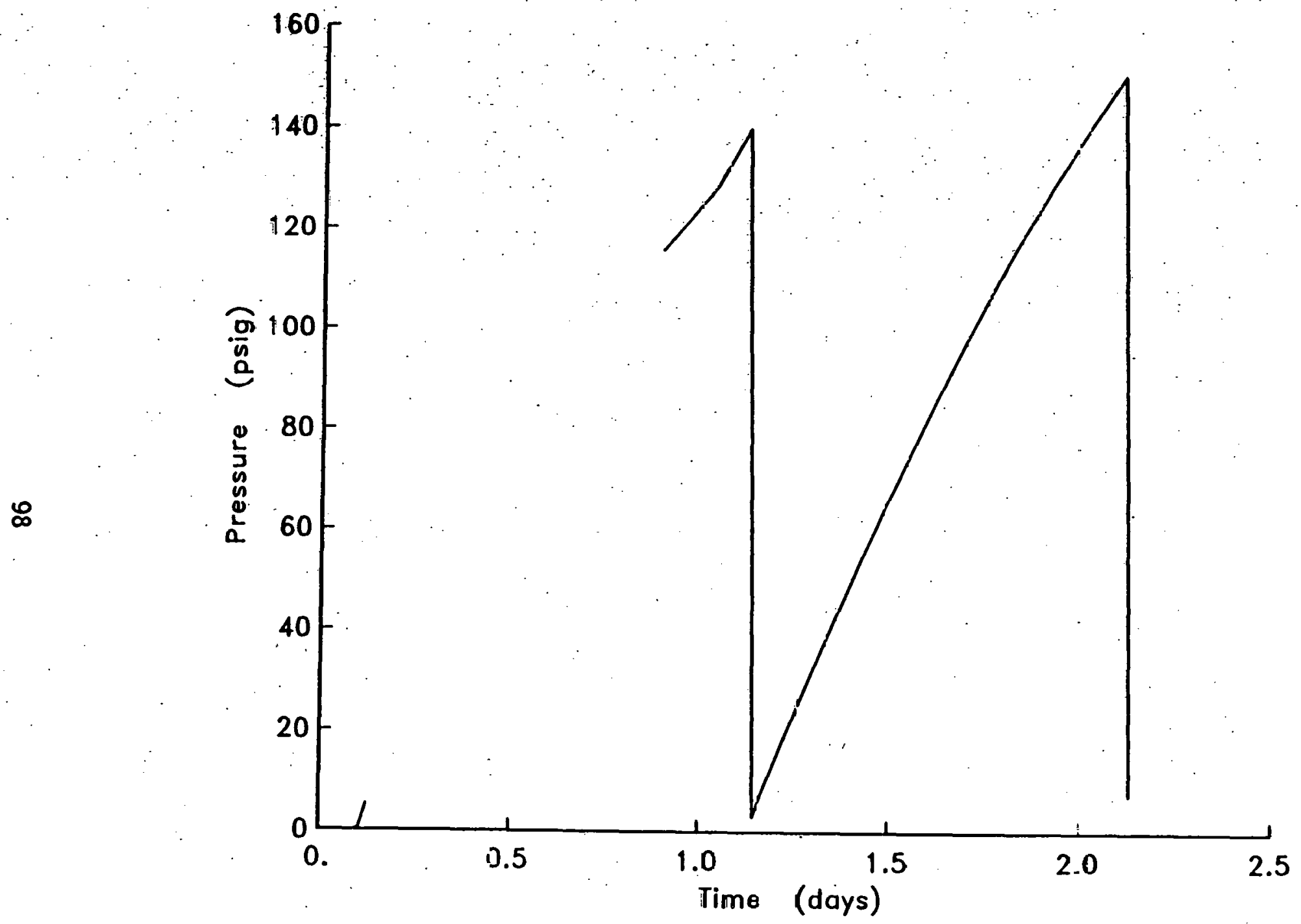

Figure A-47. Guard region pressure history measured during the May 1987 ME 32 gas flow test. 




Figure A-48. Test region temperature history measured during the May 1987 MBE 32 gas flow test. 


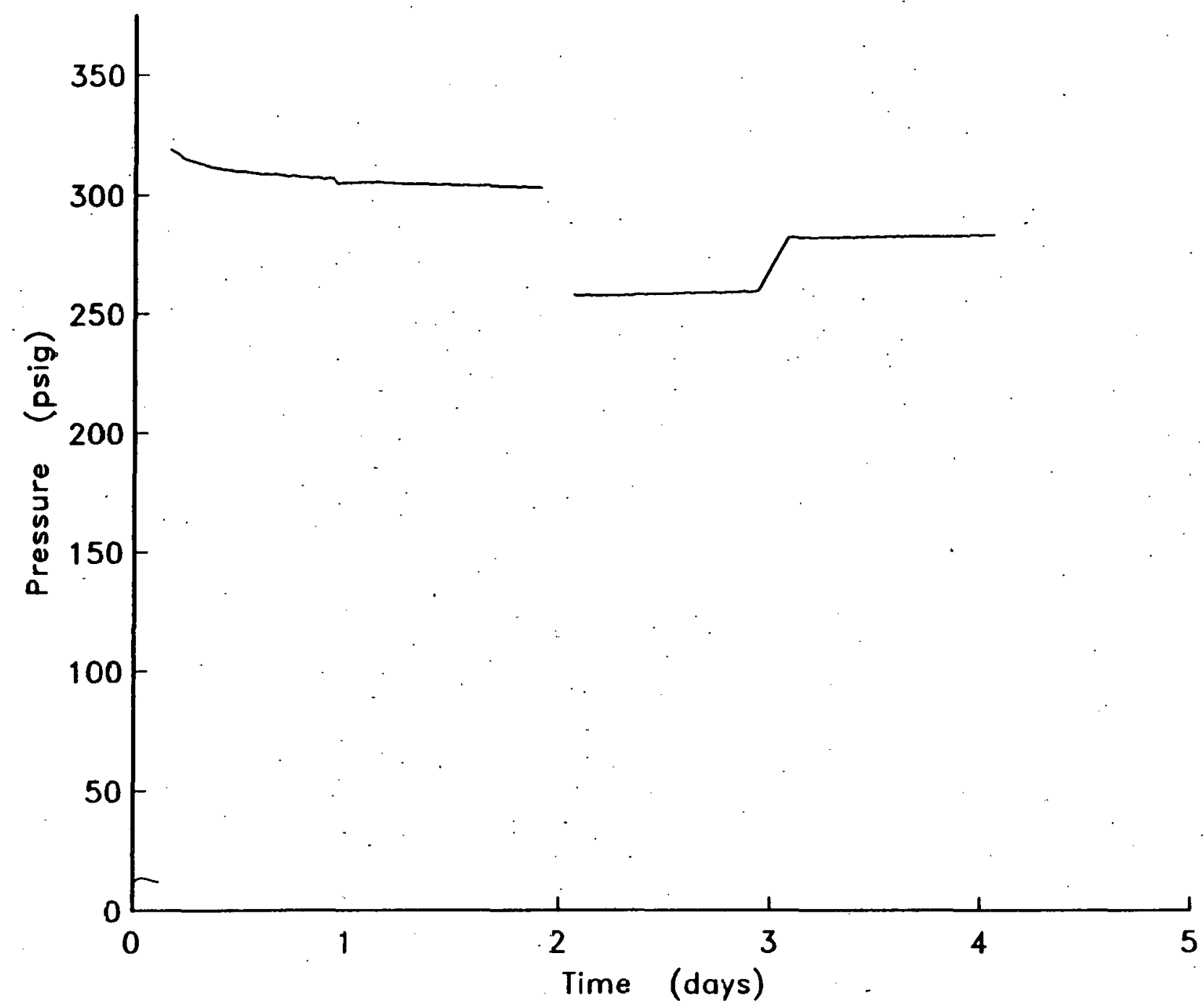

Figure A-49. Test region prassure history measured during the May 1987 MBE 33 gas flow test. 


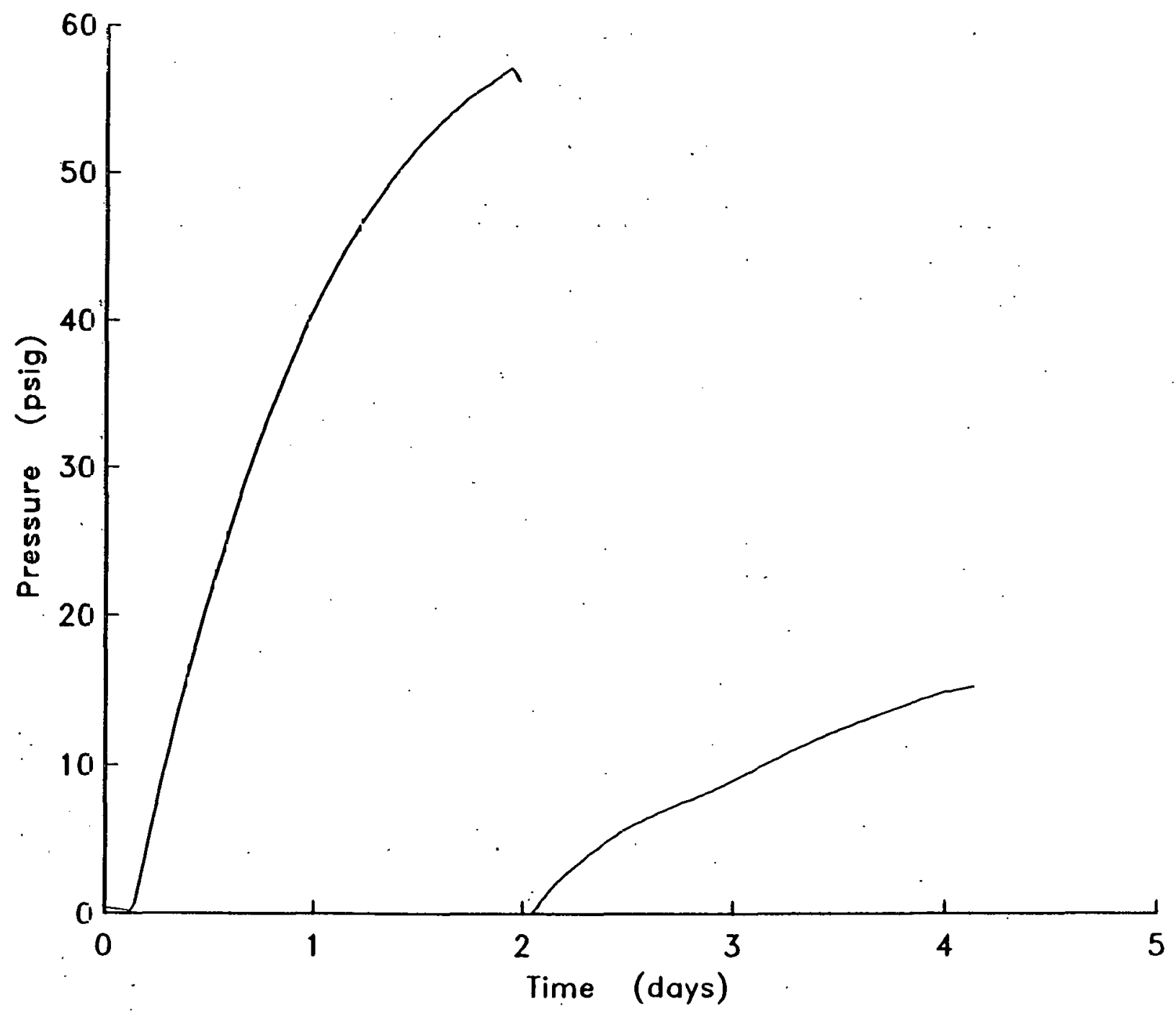

Figure A-50. Guard region pressure history measured during the May 1987 MBE 33 gas flow test. 


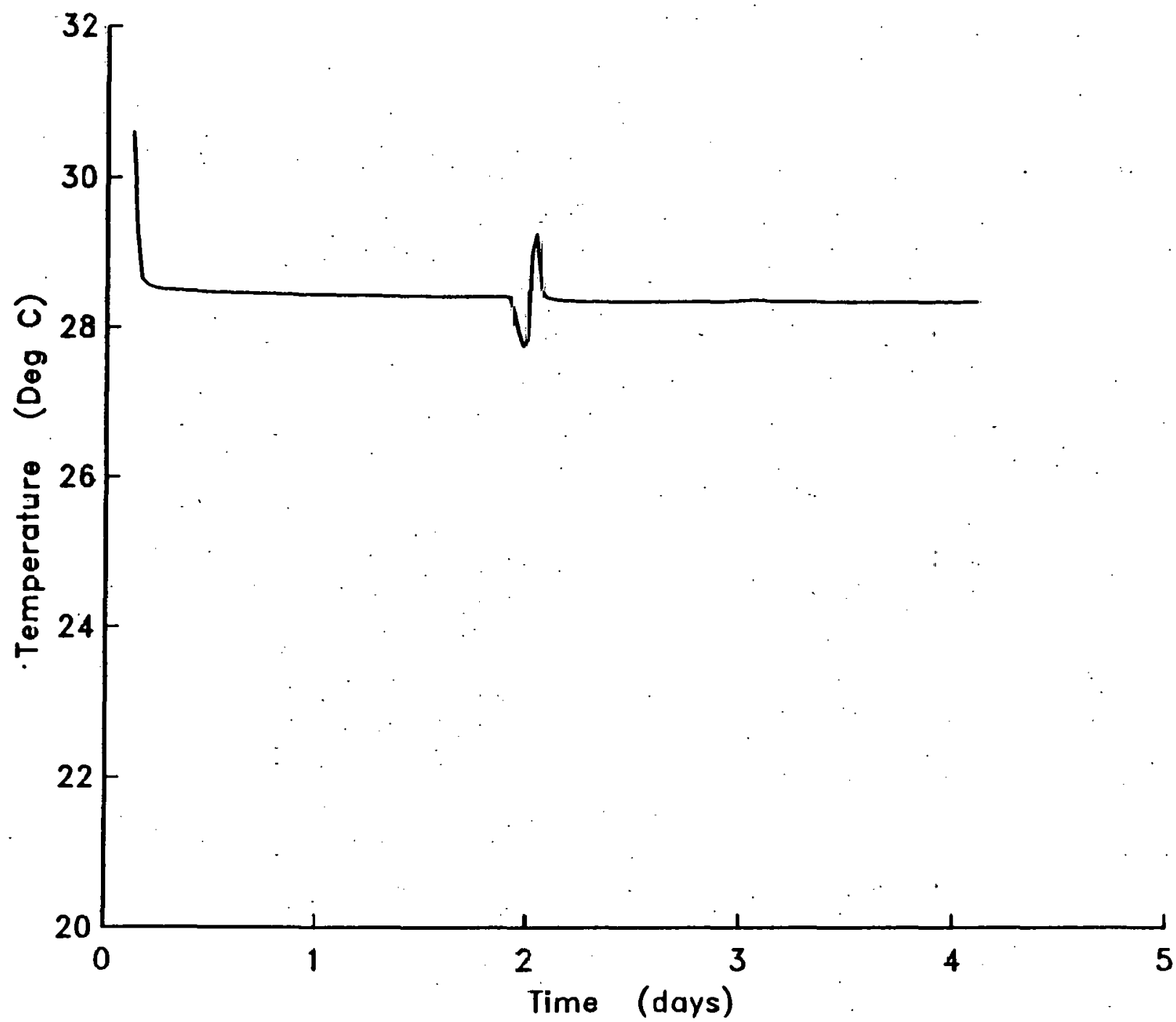

$n$
4
1
0
0
0
1
$\infty$
1
$N$
0
0
$N$

Figure A-51. Test region tempenature history measured during the May 1987 MEE 33 gas flow test. 


\section{APPENDIX B \\ PARAMETER SENSITIVITY}

This Appendix contains plots which compare calculated pressure and flow histories with measured data. The sensitivity of the data interpretation to the selected seal and formation permeability and porosity values can be determined by comparing the results shown on these Figures.

Notes

- The "Time" shown on Figures B-1 through B-10 is measured beginning from the time the calculated and measured pressures are compared on Figures 14 and 15.

- The calculations for Figures B-16 through B-20 assume a transmissive outer boundary at $r=5$ meters. 


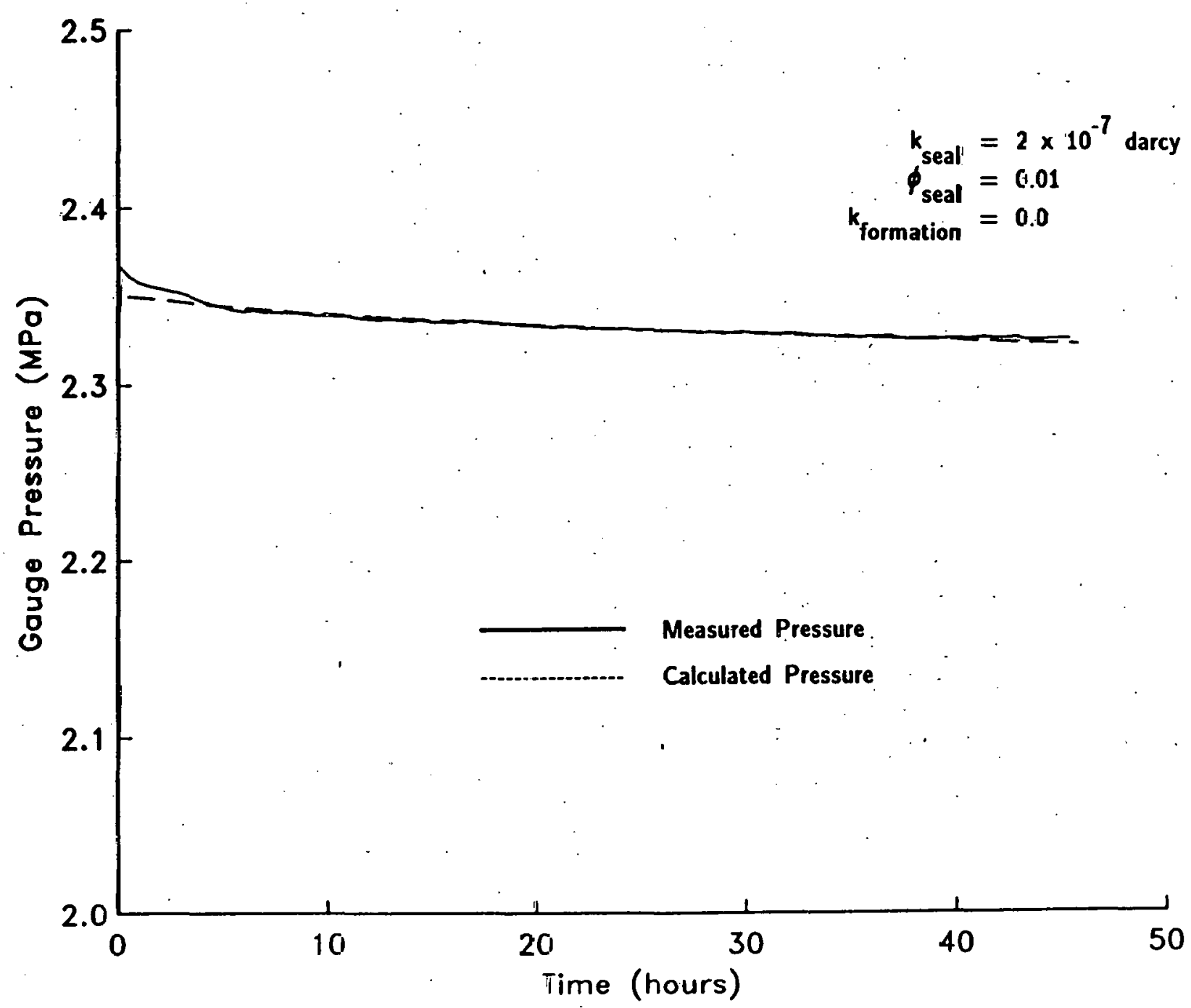

Figure B-1. Comparison of calculated and measured MAE22 pressure decay histories assuming gas flow through the seal (see Figure 14). 


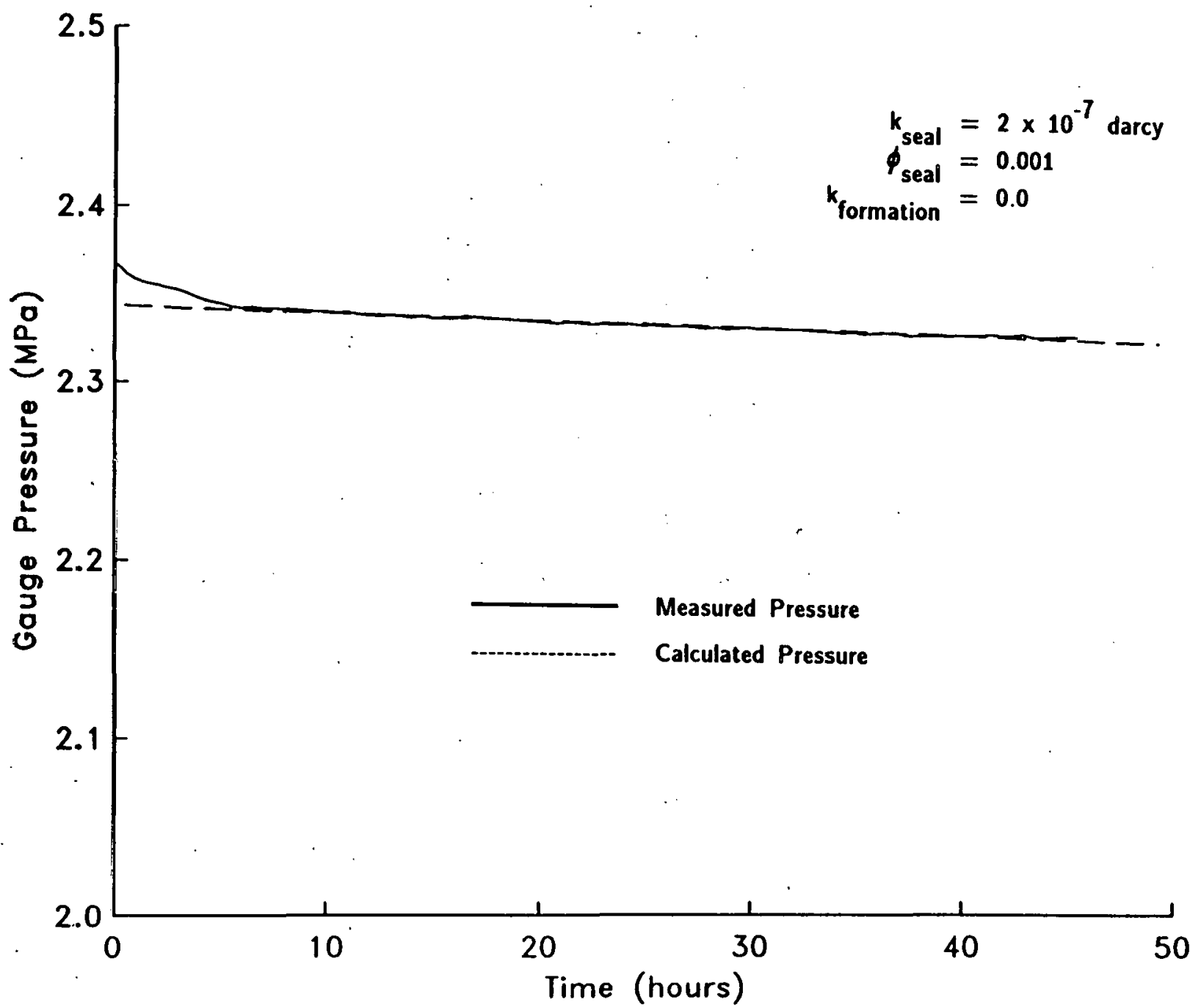

Figure B-2. Comparison of calculated and measured MAE22 pressure decay histories assuming gas flow through the seal. (Compare with Figure B-1 to determine the effect of changing the seal porosity from 0.01 to 0.001 .) 


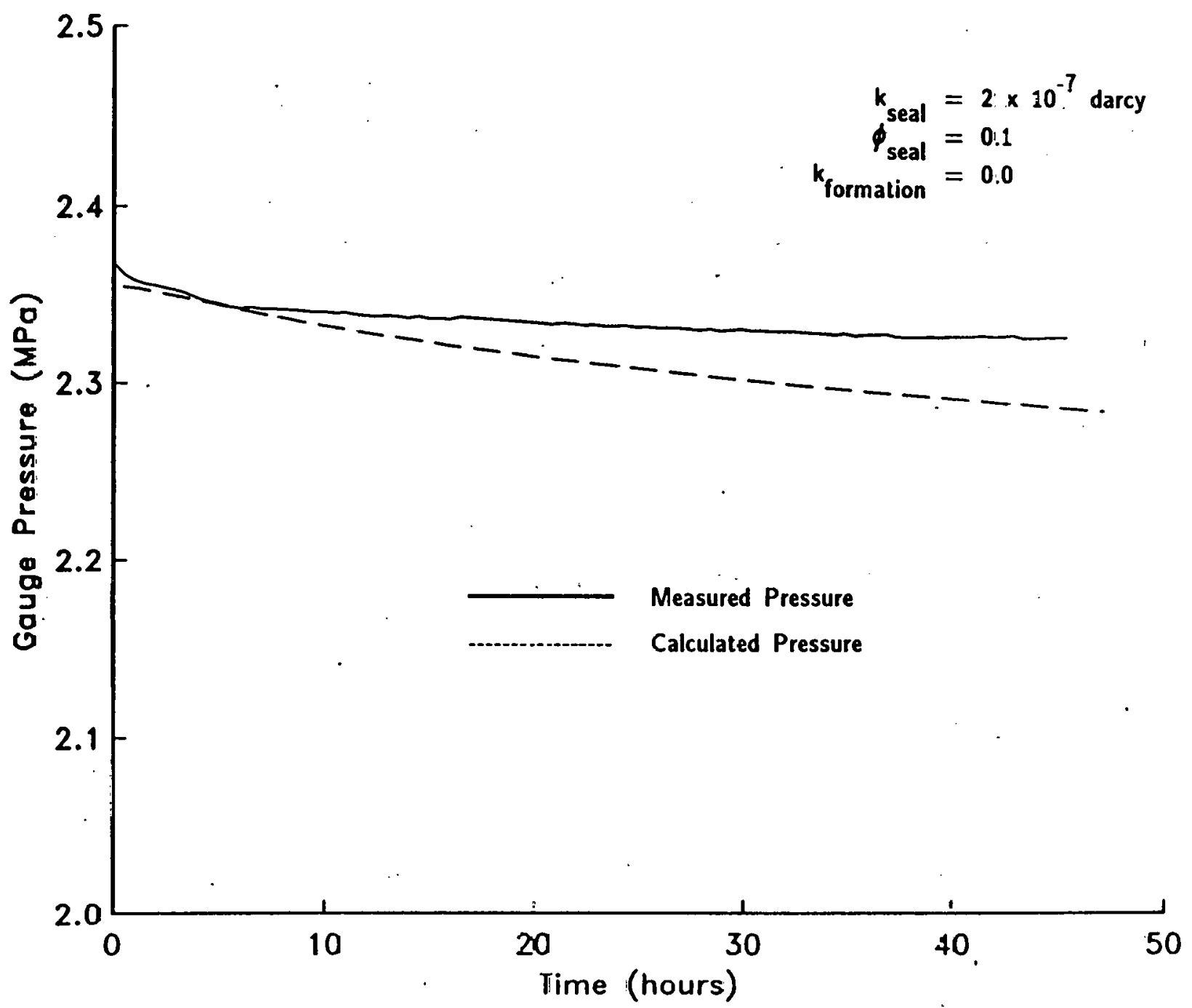

Figure B-3. Comparison of calculated and measured MAE22 pressure decay histories assuming gas flow through the seal. (Compare with Figure B-1 to determine the effect of changing the seal porosity from 0.01. to 0.1.) 


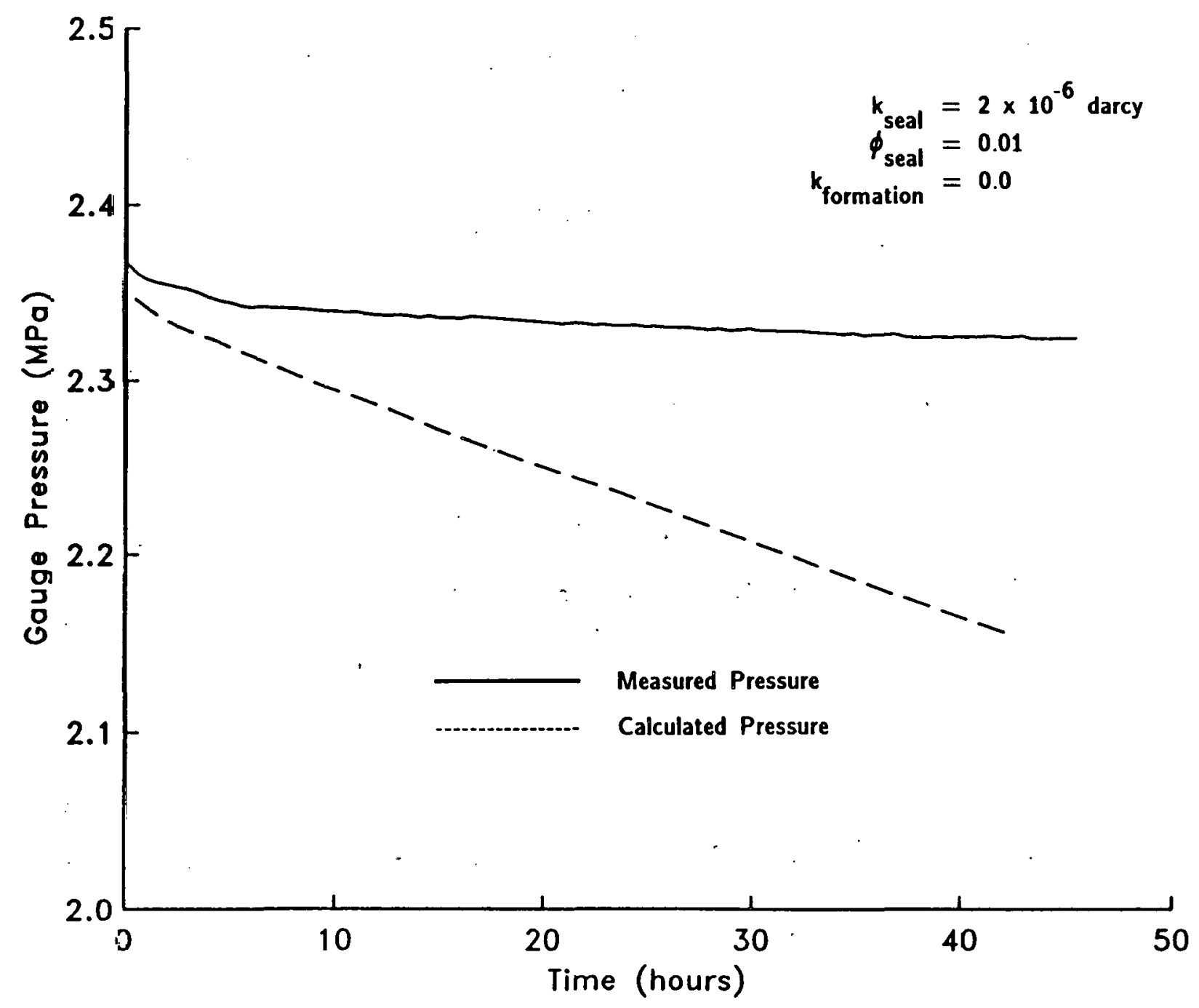

Figure B-4. Comparison of calculated and measured MAE22 pressure decay histories assuming gas flow through the seal. (Compare with Figure B-1 to determine the effect of changing the seal permeability from $2 \times 10^{-7}$ darcy to $2 \times 10^{-6}$ darcy.) 


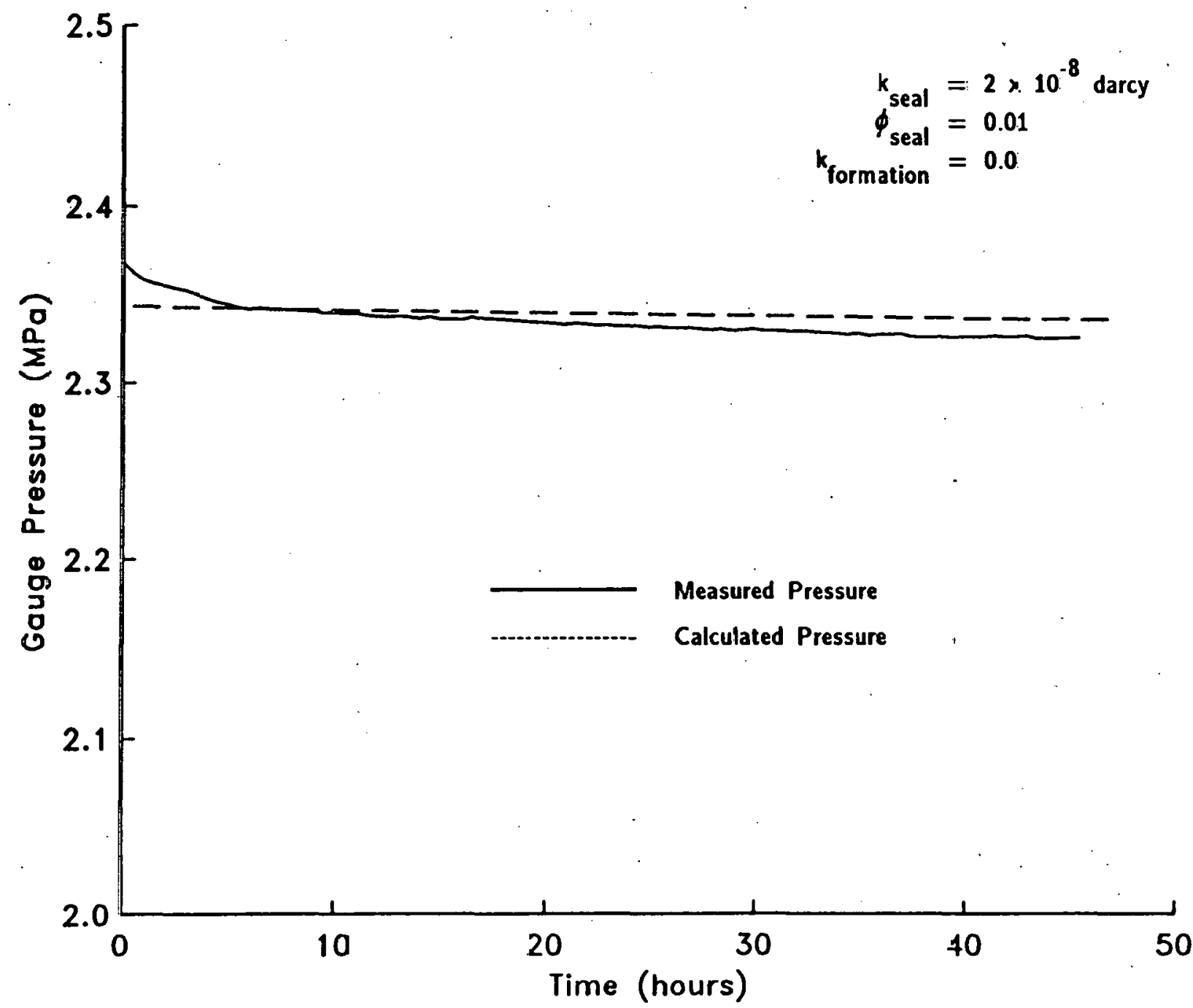

Figure B-5. Comparison of calculated and measured MAE22 pressure decay histories assuming gas flow through, the seal. (Compare with Figure B-1 to determirie the effect of changing the seal permeability from $2 \times 10^{-7}$ darcy to $2 \times 10^{-8}$ darcy.) 


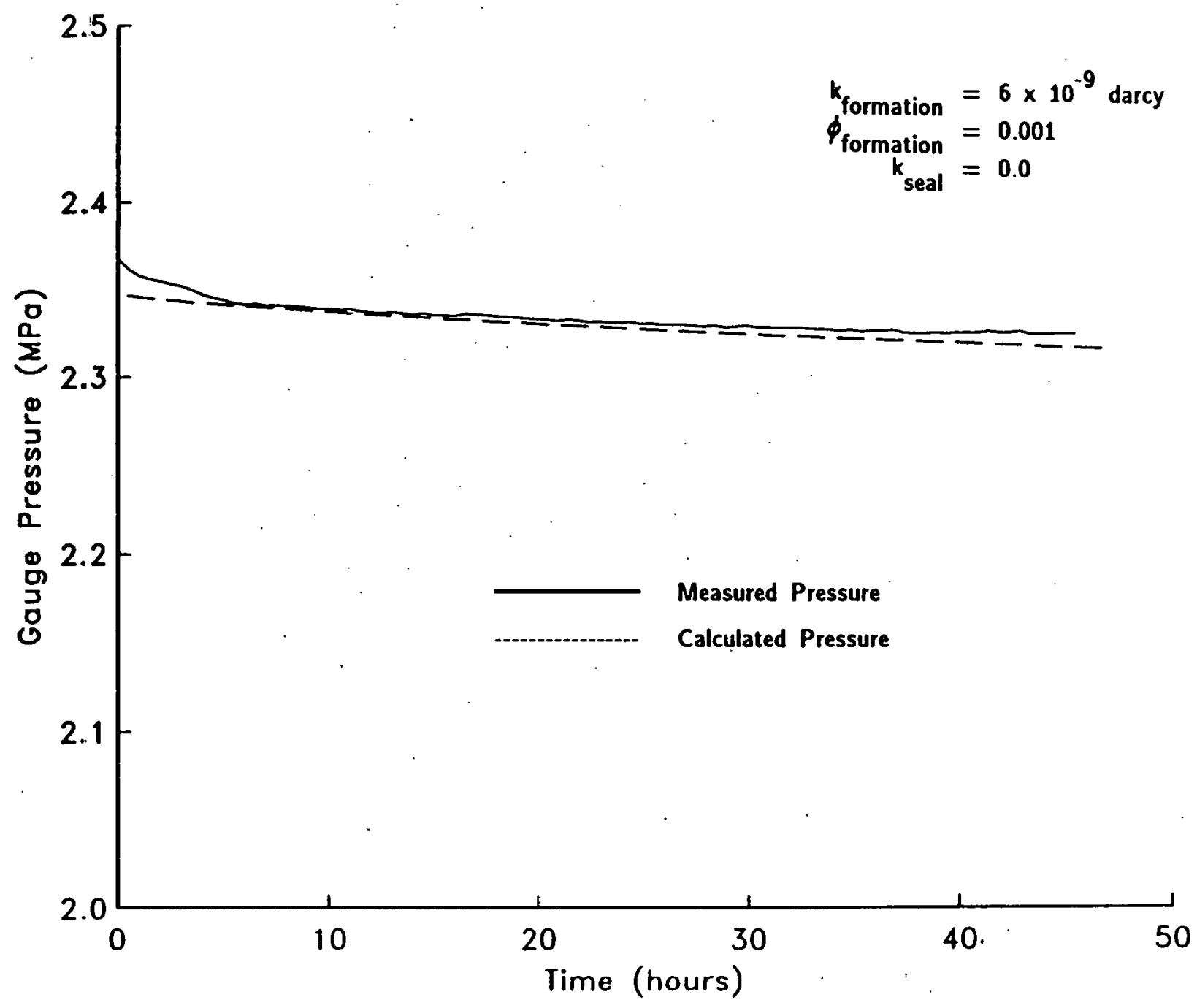

Figure B-6. Comparison of calculated and measured MAE22 pressure decay histories assuming gas flow into an unsaturated formation (see Figure 15). 


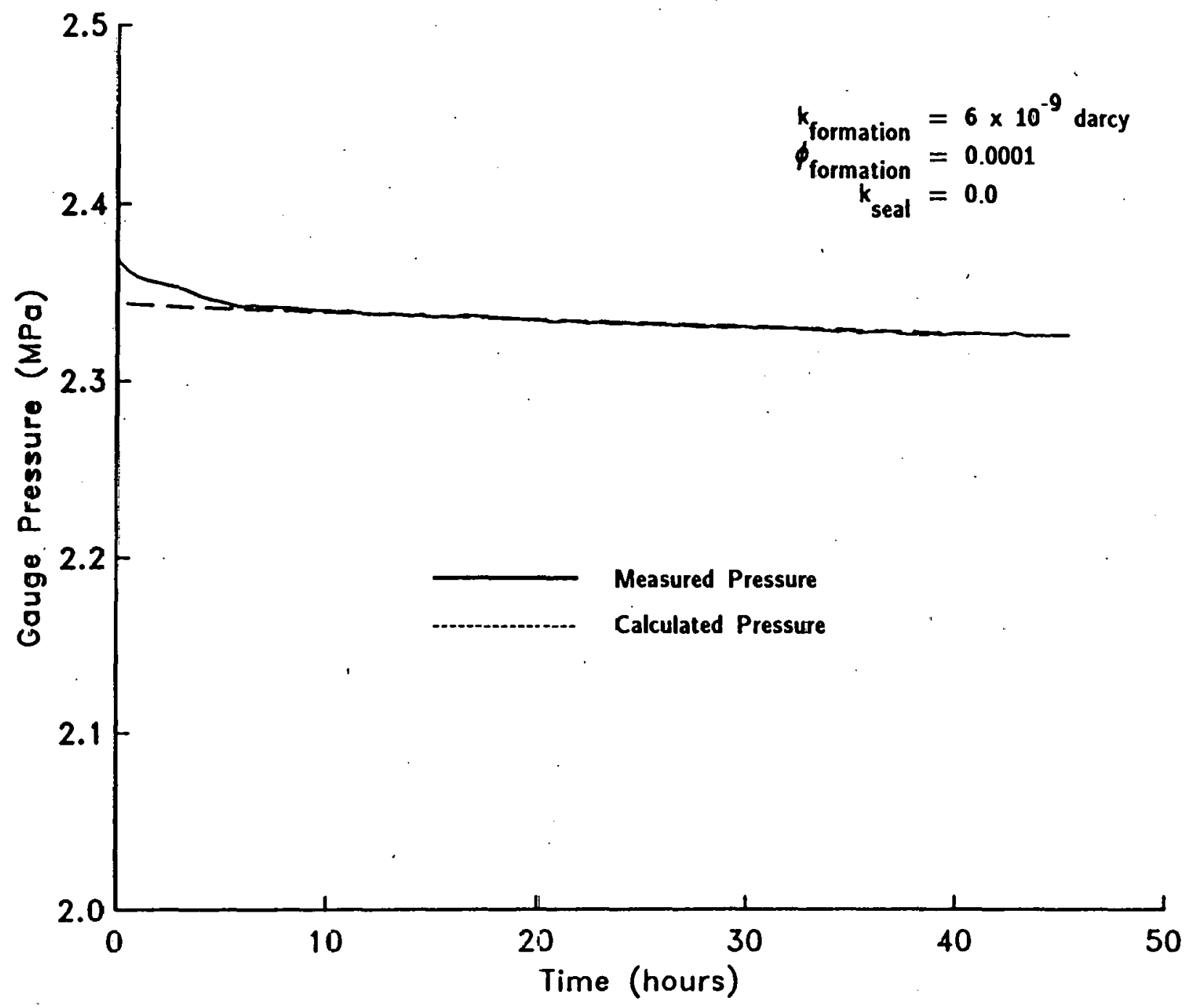

Figure B-7. Comparison of calculated and measured MAE22 pressure decay histories assuming gas flow into an unsaturated formation. (Compare with Figure B-6 to determine the effect of changing the formation porosity from 0.001 to 0.0001 .) 


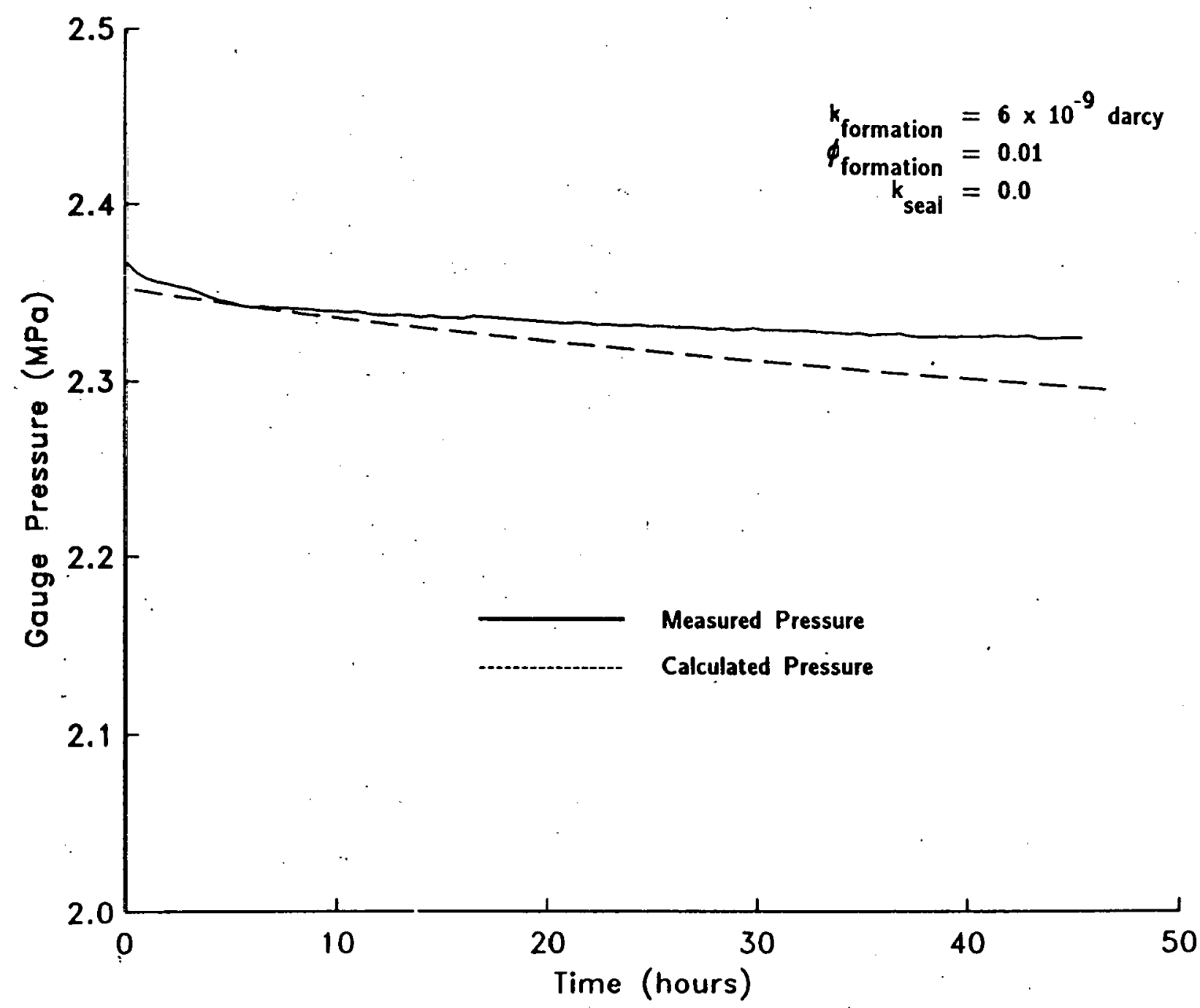

Figure B-E. Compare the calculated and measured MAE22 pressure decay histories assuming gas flow into an unsaturated formation. (Compare with Figure B-6 to determine the effect of changing the formation porosity from 0.001 to 0.01 .) 


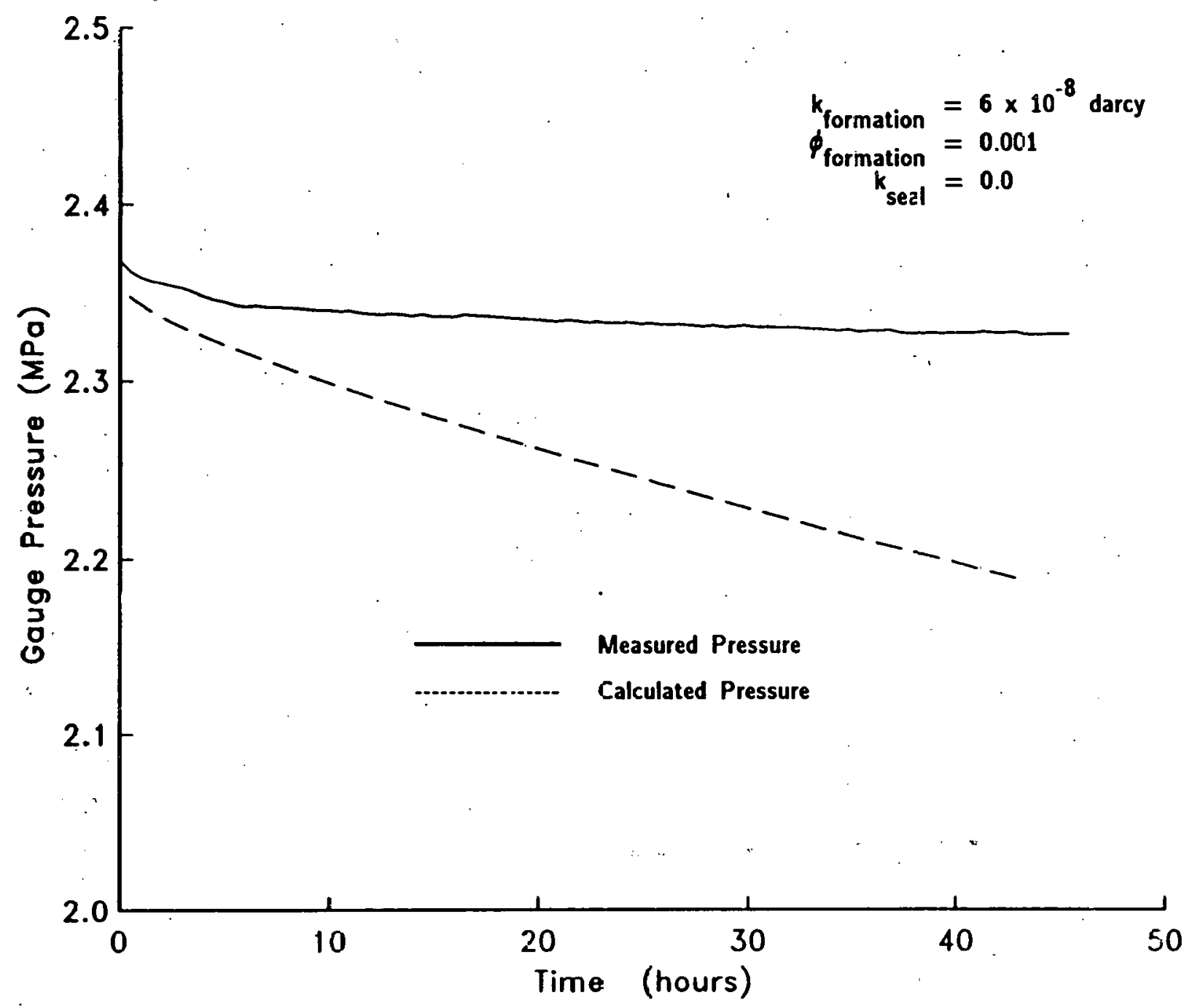

Figure B-9. Compare the calculzted and measured MAE22 pressure decay histories assuming gas flow into an unsaturated formaticn. (Compare with Figure B-6 to determine the effect of changing the formation permeatility from $6 \times 10^{-9}$ darcy to $6 \times 10^{-8}$ darcy.) 


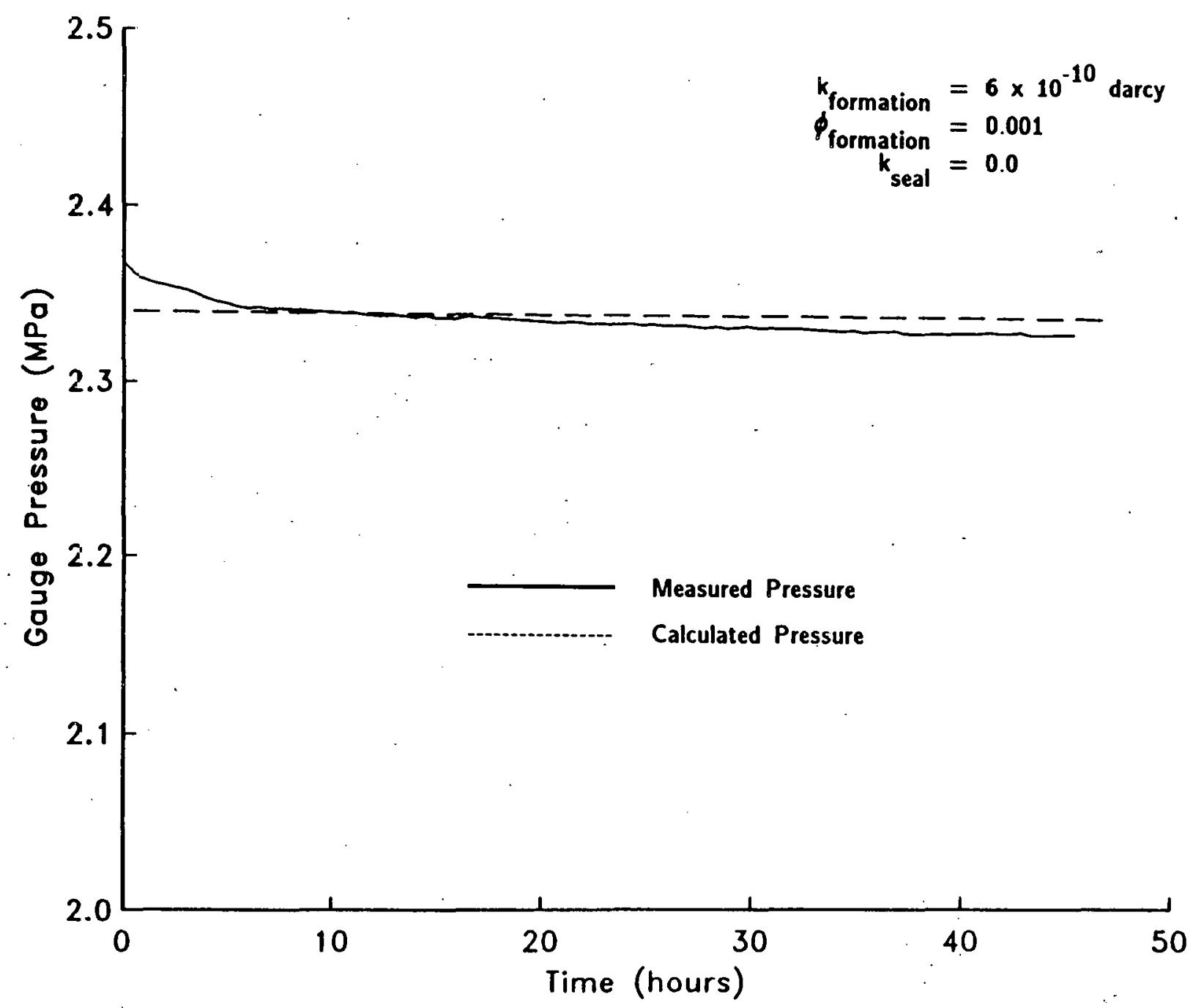

Figure B-10. Compare the calculated and measured MAE22 pressure decay histories assuming gas flow into an unsaturated formation. (Compare with Figure B-6 to determine the effect of changing the formation permeability from $6 \times 10^{-9}$ darcy to $6 \times 10^{-10}$ darcy.) 


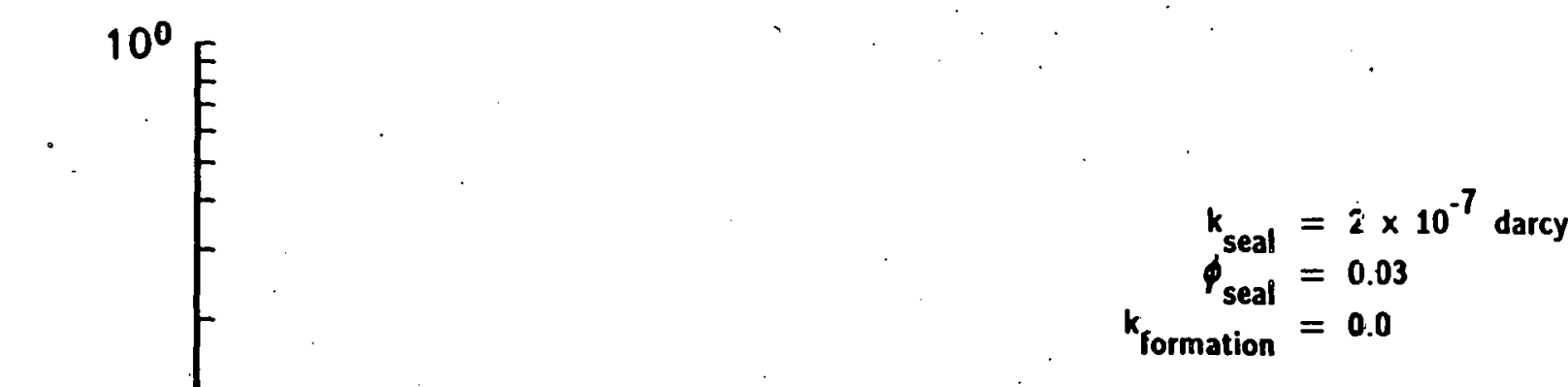

Erine Flow through

Top Surface of Seal

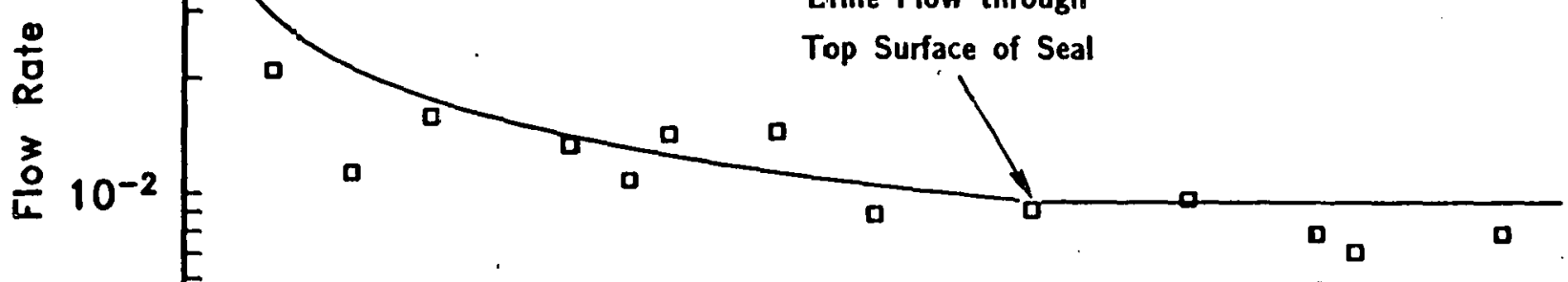

D 0 o 0 a Measured Flow Rate

Calculated Flow Rate

$10^{-3}$

0

20

40

60

Time (days)

Figure B-11. Comparison cf calculated and measured MAE22 brine flowrates assuming flow through an iritially unsaturated seal (see Figure 16). 


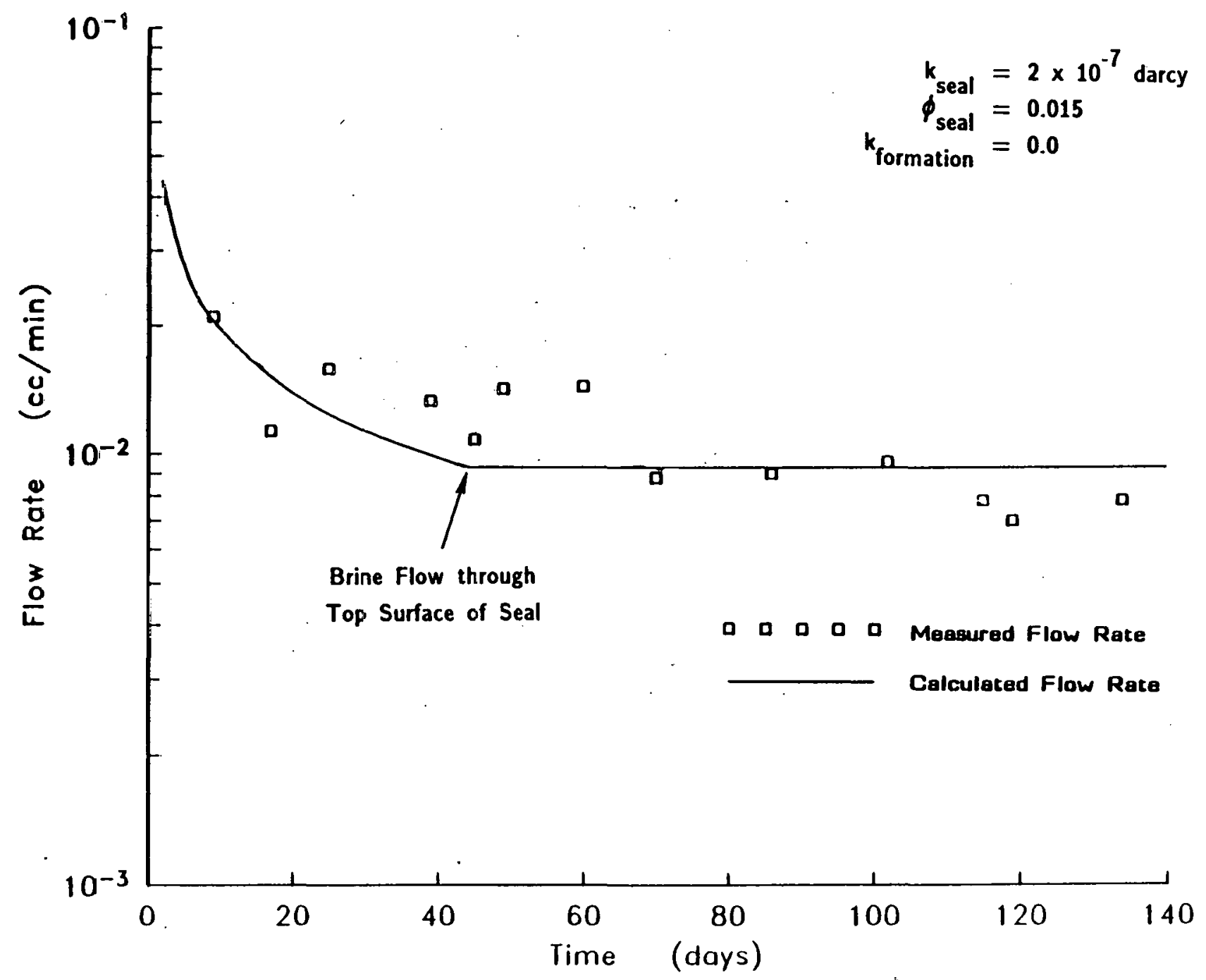

Figure B-12. Comparison of calculated and measured MAE22 brine flowrates assuming flow through an initially unsaturated seal. (Compare with Figure B-11 to determine the effect of changing the seal porosity from 0.03 to 0.015 .) 

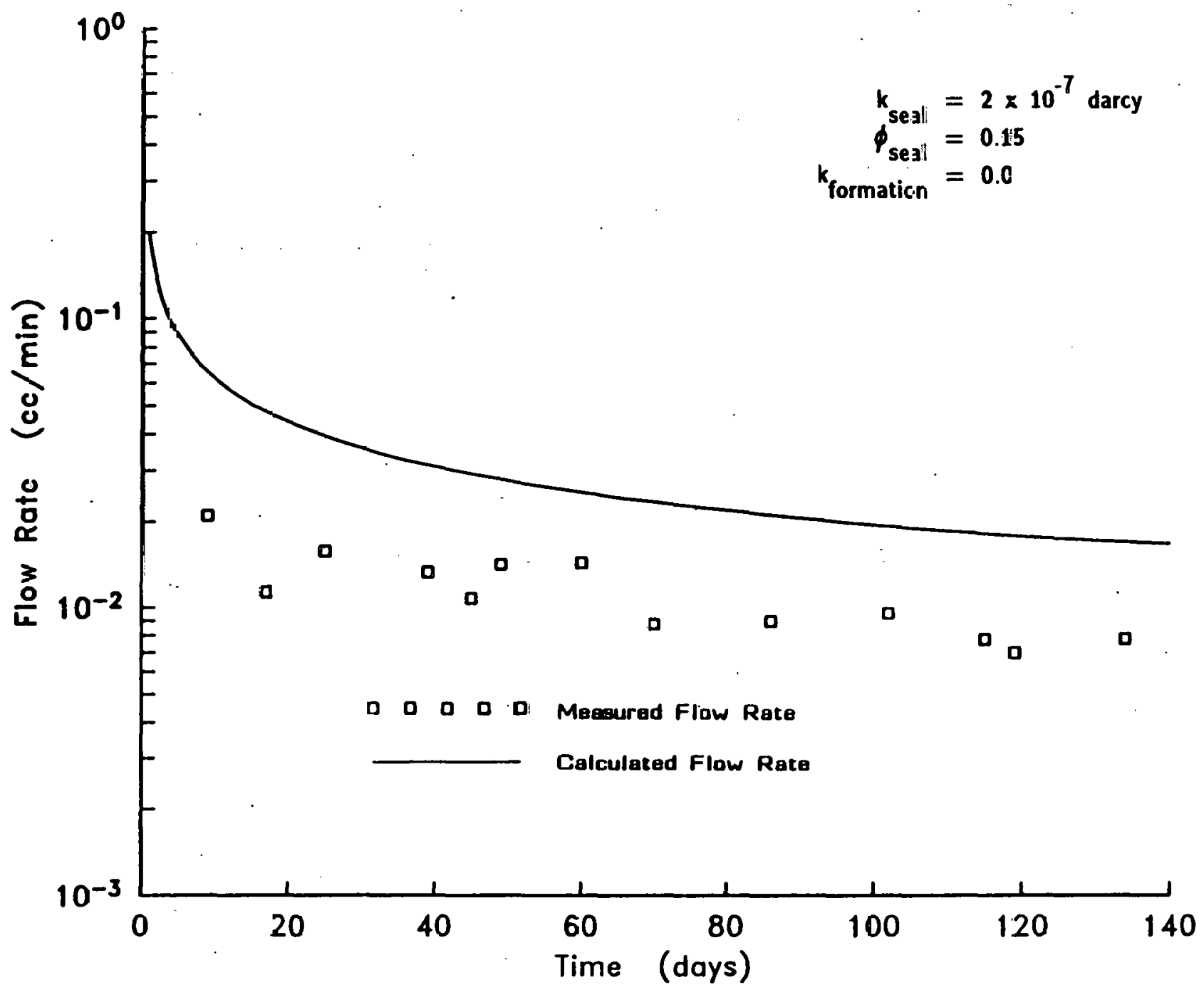

Figure B-13. Comparison of calculated and measured MAE22 brine flowrates assuming flow Ihrough an initially unsaturated seal. (Compare with Figure B-11 to determine the effect of changing the seal porosity from 0.03 to 0.15 .) 




Figure B-14. Comparison of calculated and measured MAE22 brine flowrates assuming flow through an initially unsaturated seal. (Compare to Figure B-11 ato determine the effect of changing the seal permeability from $2 \times 10^{-7}$ darcy to $2 \times 10^{-6}$ darcy.) 


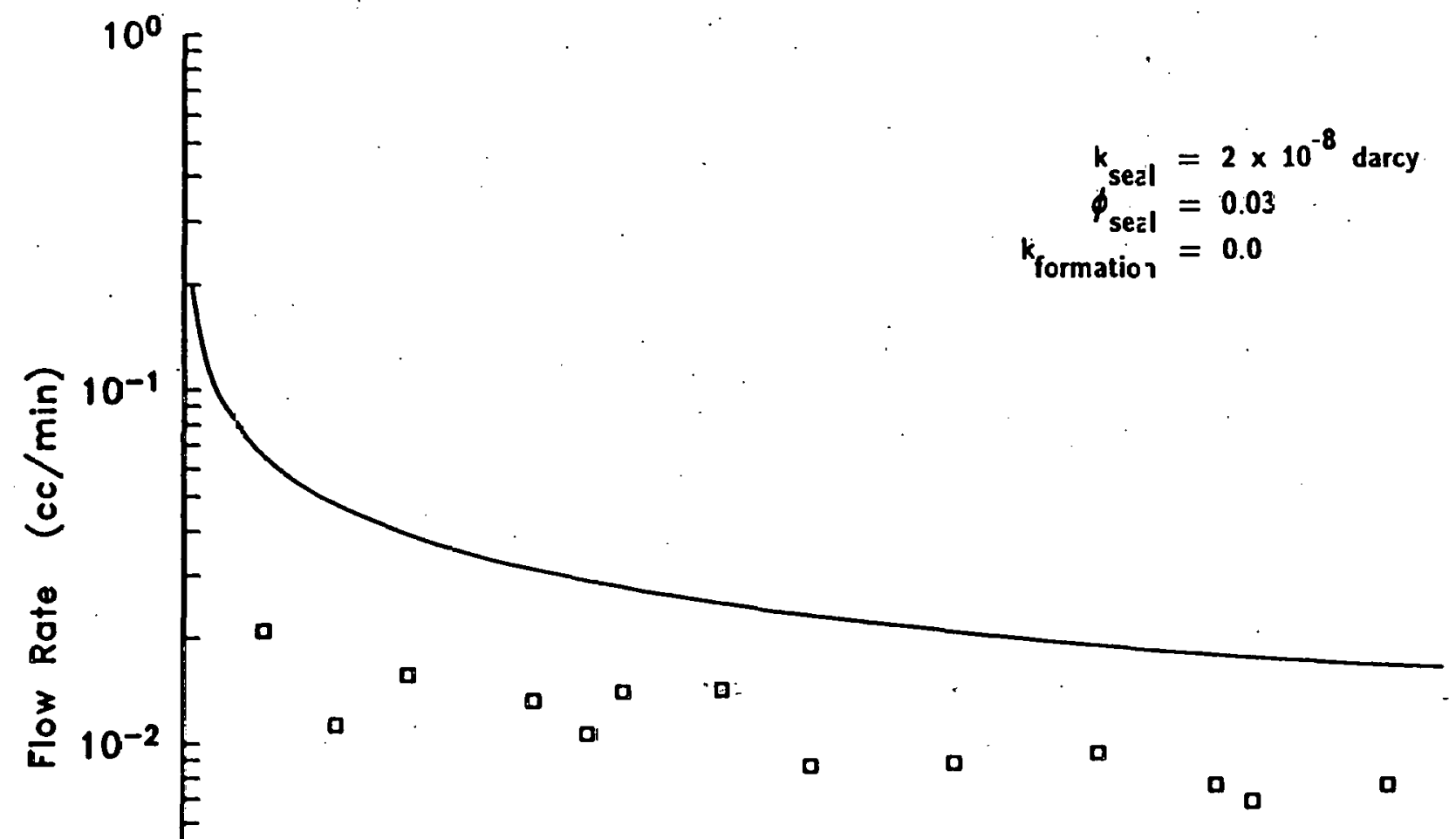

- 0 o 10 Measured Flow Rate

Calculated Flow Rate

Figure B-15. Comparison of calculated and measured MAE22 brine flowrates assuming flow through an initially unsaturated seal. (Compare with Figure B-11 to determine the effect of changing the seal permeability from $2 \times 10^{-7}$ darcy to $2 \times 10^{-8}$ darcy.) 


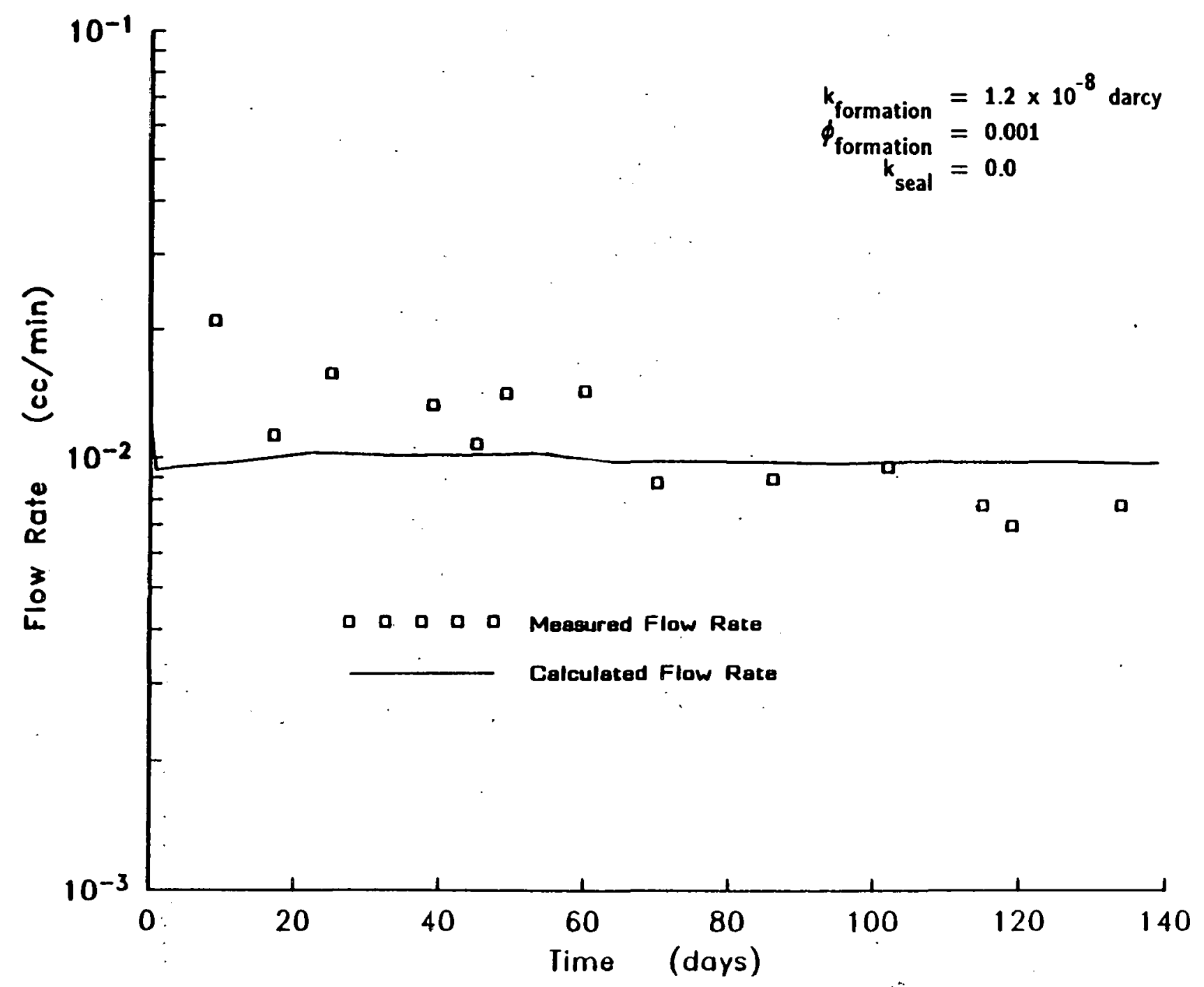

Figure B-16. Comparison of calculated and measured MAE22 brine flowrates assuming flow into a saturated formation (see Figure 17). 


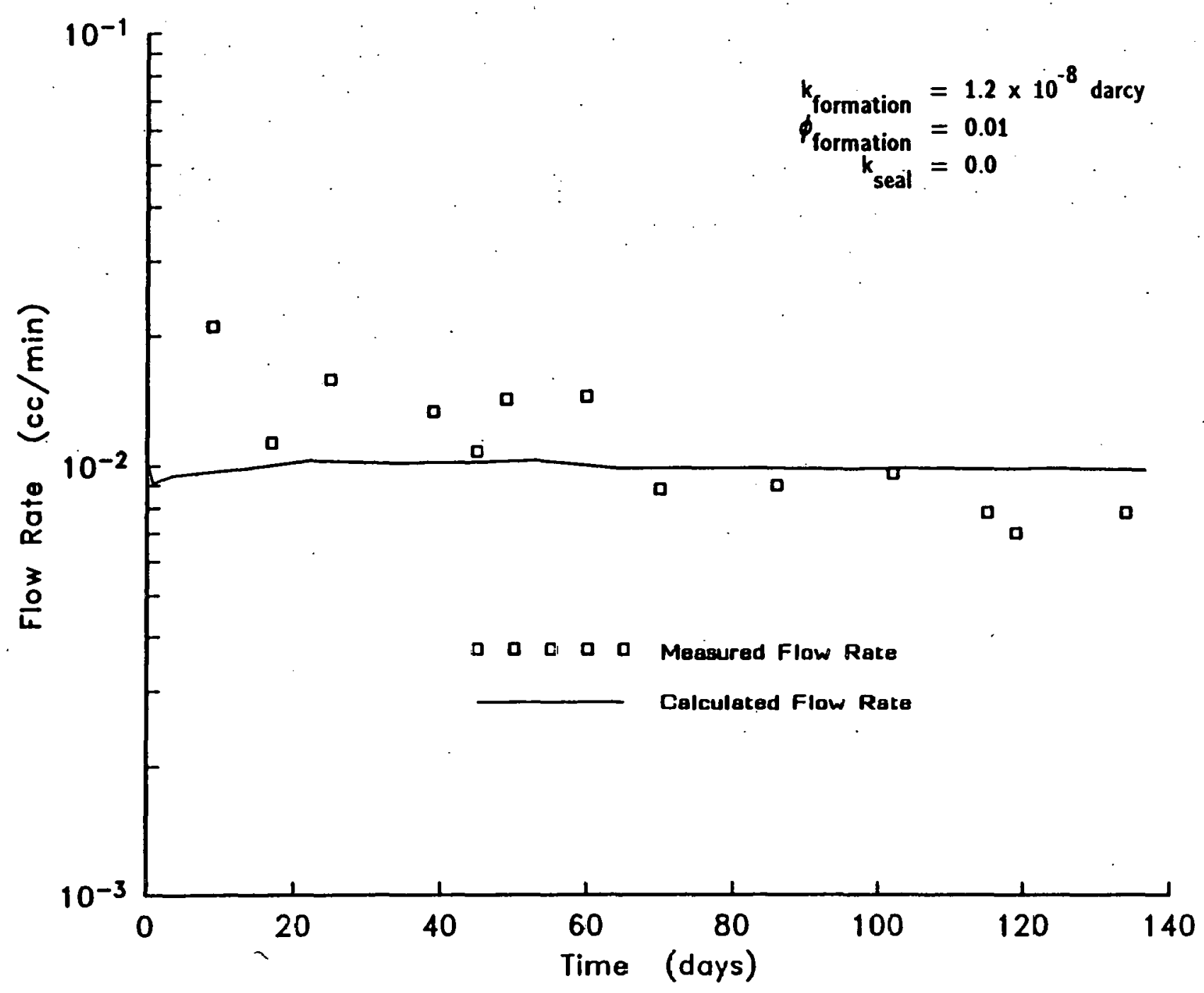

Figure B-17. Comparison of calculated and measured MAE22 brine flowrates assuming flow into a saturated formation. (Compare to Figure B-16 to determine the effect of changing the formation porosity from 0.001 to 0.01 .) 


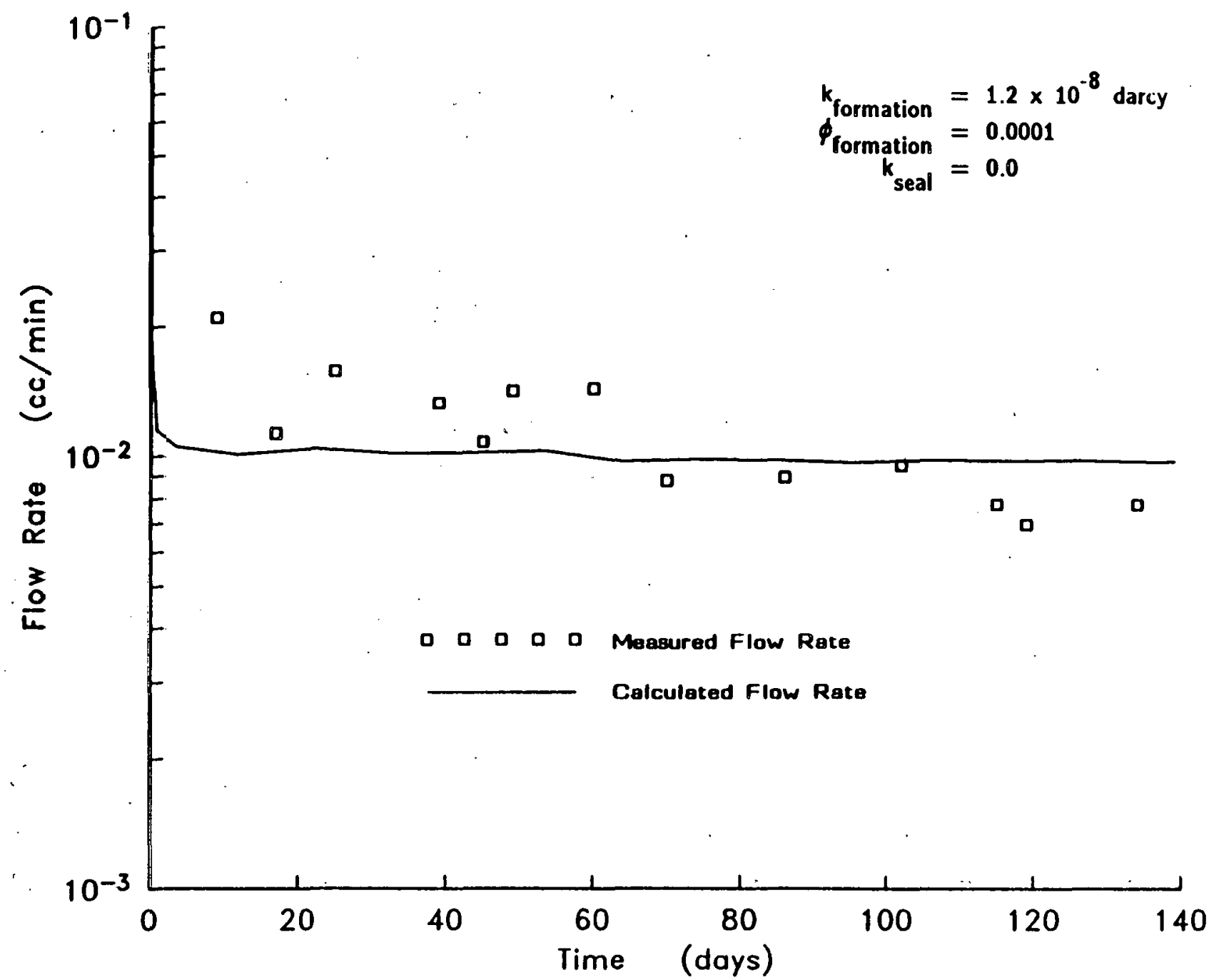

Figure B-18. Comparison of calculated and measured MAE22 brine flowrates assuming flow into a saturated formation. (Compare to Figure B-16 to determine the effect of changing the formation porosity from 0.001 to 0.0001 .) 


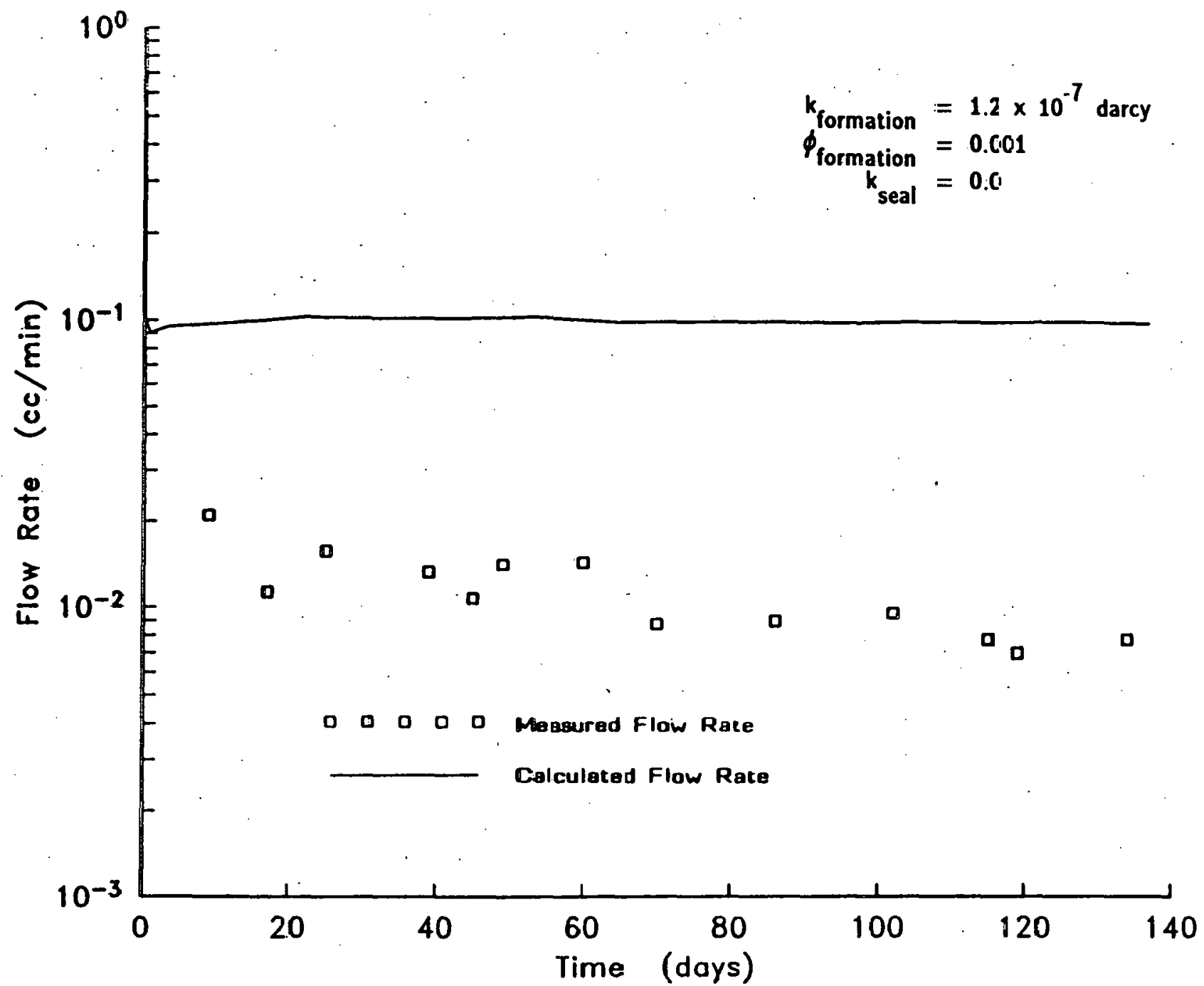

Figure B-19. Comparison of calculated and measured MAE22 brine flowrates assuming flow into a saturated formation. (Compare with Figure B-16 to determire the effect of changing the formation permeability from $1.2 \times 10^{-8}$ darcy to $1.2 \times 10^{-7}$ darcy.) 


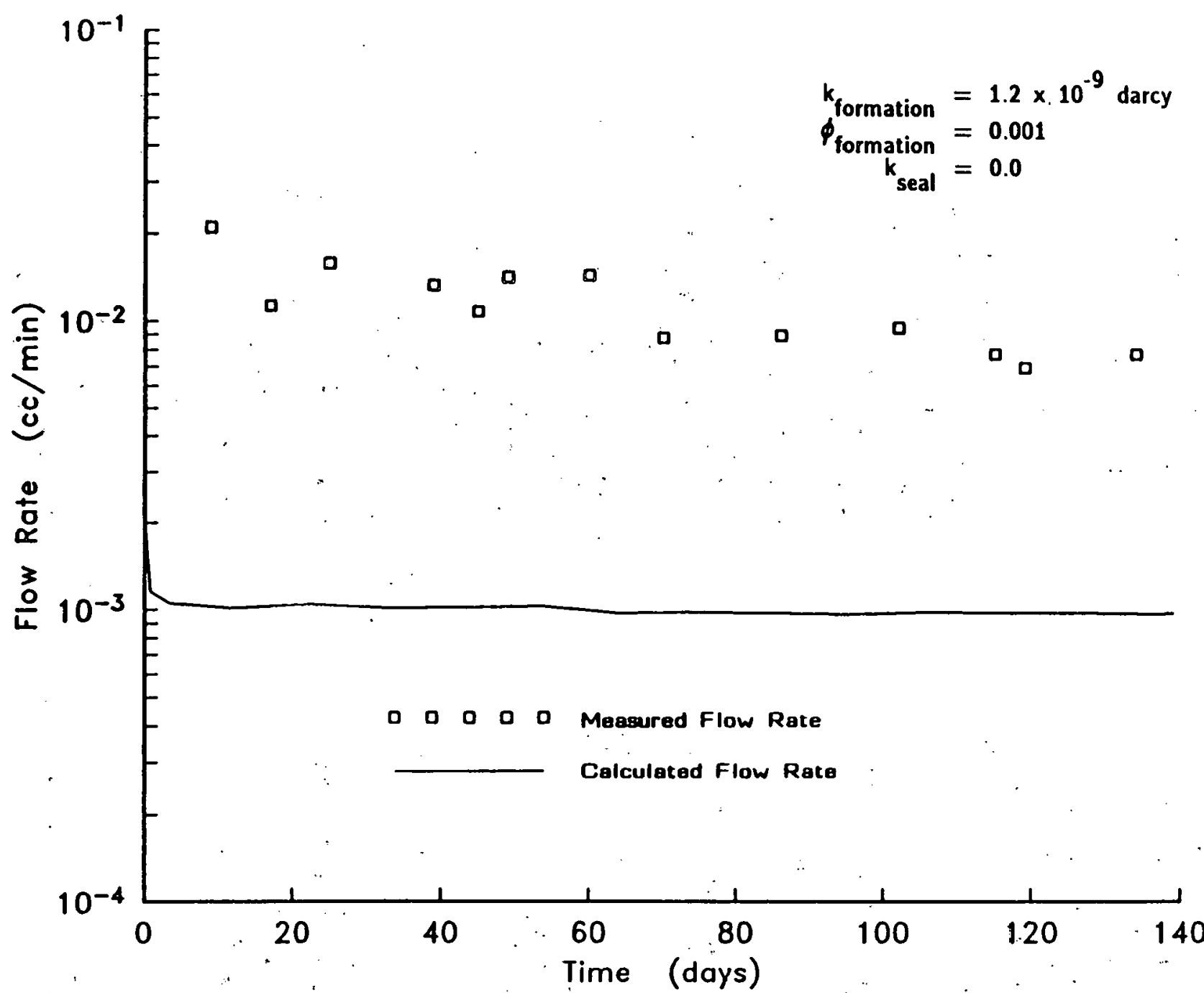

Figure B-20. Comparison of calculated and measured MAE22 brine flowrates assuming flow into a saturated formation. (Compare to Figure B-16 to determine the effect of changing the formation permeability from $1.2 \times 10^{-8}$. darcy to $1.2 \times 10^{-9}$ darcy.) 
U. S. Department of Energy, (5)

Office of Civilian Radioactive Waste Management

Office of Geologic Repositories

Forrestal Building

Washington, DC 20585

Stephen $\mathrm{H}$. Kale - RW-20

Associate Director

T. H. Isaacs - RW-20

Deputy Associate Director

James C. Bresee - RW-22

Director, Repository Coordination Div.

Ralph Stein - RW-23

Director, Engineering \& Geotechnology

James P. Knight. - RW-24

Director, Siting, Licensing and Quality Assurance

U. S. Department of Energy (3)

Albuquerque Operations Office

P.0. Box 5400

Albuquerque, NM 87185

R. G. Romatowski

J. E. Bickel

D. G. Jackson, Director Public Affairs Division

U. S. Department of Energy (8) WIPP Project Office (Carlsbad)

P.0. Box 3090

Carlsbad, NM 88221

J. Tillman (4)

A. Hunt

T. Lukow (2)

V. Daub

U. S. Department of Energy, SRPO (4)

Salt Repository Project Office

$505 \mathrm{King}$ Avenue

Columbus, $\mathrm{OH} 43201$

Jeff 0 . Neff

R. Wunderlich

G. Appel

R. Wu

U. S. Department of Energy

Research \& Technical Support Division

P. 0. Box E

Oak Ridge, TN 37830

D. E. Large
U.S. Department of Energy

Richland Operations Office

Nuclear Fuel Cycle \& Production Division

P.0. Box 500

Richland, WA 99352

R. E. Gerton

U. S. Department of Energy (4)

Office of Defense Waste and

Transportation Management

Washington, DC 20545
J. E. Dieckhoner - DP-122
L. H. Harmon -.... DP-121
A. Follett ...... DP-121
J. Mather ....... DP-121

U. S. Department of Energy (2)

Idaho Operations Office

Fuel Processing and Waste

Management Division

785 DOE Place

Idaho Falls, ID 83402

U.S. Department of the Interior

959 National Center

Geological Survey

Reston, Virginia 22092

E. Roedder

U.S. Nuclear Regulatory Commission (4)

Division of Waste Management

Mail Stop 6235s

Washington, DC 20555

Michael Bell

Hubart Miller

Jacob Philip

NRC Library

F. R. Cook

Nuclear Regulatory Commission

HLW Licensing Branch, Materials

Section

MS 905 SS

Washington, DC 20555

U.S. Geological Survey

Special Projects

MS954, Box 25046

Denver Federal Center

Denver, C0 80255

R. Snyder 
U.S. Geological Survey

Conservation Division

P.0. Box 1857

Roswell, NM 88201

W. Melton

U.S. Geological Survey (2)

Water Resources Division

Western Bank Bldg.

505 Marquette, NW, \#720 \&

Albuquerque, NM 87102

H. Lee Case

Peter Davies

State of New Mexico (3)

Environmental Evaluation Group

320 Marcy Street

P.0. Box 968

Santa Fe, NM 87503

Robert H. Neill, Director

NM Department of Energy \& Minerals

P.0. Box 2770

Santa Fe, NM 87501

Kasey LaPlante, Librarian

New Mexico Bureau of Mines

and Mineral Resources (2)

Socorro, NM 87801

F. E. Kottolowski, Director

J. Hawley

Battelle Memorial Institute (17)

Project Management Division

505 King Avenue

Columbus, $\mathrm{OH} \quad 43201$

ONWI Library

W. Carbiener, General Manager

(3)

S. Basham

P. Hoffman

H. R. Hume

H. N. Kalia

J. Kirchner

D. Moak

J. Moody

L. Page

G. Raines

J. Schornhorst

0 . Swanson

J. Treadwell
Bechtel Inc. (5)

P.0. Box 3965

45-11-B34

San Francisco, CA 94119

$E$. Weber

M. Beathard

H. Taylor

P. Frobenius

D. L. Wu

INTERA Technologies, Inc. (2)

6850 Aust in Center Blvd., \#300

Aust in, TX 78731

G. E. Grisak

J. F. Pickens

INTERA Technologies, Inc.

P.0. Box 2123

Carlsbad, NM 88221

Wayne Stensrud

IT Corporation

P.0. Box 2078

Carlsbad, NM 88221

R. Mckinney

IT Corporation

2340 Alamo, SE

Suite 306

Albuquerque, NM

W. R. Coons

87106

J. Case

J. Myers

RE/SPEC, Inc. (7)

P. 0. Box 725

Rapid City, SD 57709

P. F. Gnirk

L. L. Van Sambeek

D. B. Blankenship

T. Brandshang

G. Callahan

T. Pfeifle

J. L. Ratigan

$\mathrm{RE} / \mathrm{SPEC}$, Inc. (2)

P.0. Box 14984

Albuquerque NM 87191

S. W. Key

D. Labreche 
E. I. Dupont de Nemours Company (6)

Savannah River Laboratory

Aiken, SC 29801

N. Bibler

E. L. Albenisius

M. J. Plodinec

G. G. Wicks

C. Jantzen

J. A. Stone

Systems, Science, and Software (2)

Box 1620

La Jolla, CA 92038

E. Peterson

$P$. Lagus

University of Arizona

Department of Nuclear Enginecring

Tucson, AZ 85721

J. G. MeCray

University of Arizona

Department of Mining and

Geological Engineering

Tucson, AZ 85721

J. J. K. Daemen

University of New Mexico (2)

Geology Department

Albuquerque, NM 87131

D. G. Brookins

Library

The Pennsylvania State Universily

Materials Research Laboratory

University Park, PA 16802

Della Roy

Rustrum Roy

Will White

Texas A\&M University

Center of Tectonophysics

College Station, TX 77840

John Handin

University of Texas at El Paso

Department of Geological Sciences

El Paso, TX 79968

D. W. Powers
Westinghouse Electric Corporation (9)

P.0. Box 2078

Carlsbad, NM 88221

Library

W. Moffitt

V. DeJong

W. Chiquel in

T. Dillon

V. Likar

J. Johnson

J. Sadler

R. Kehrman

National Academy of Sciences, WIPP Panel:

Dr. Konrad B. Krauskopf

Department of Geology

Panama Street

Stanford University

Stanford, CA 94305

Dr. Frárík L. Parker

Department of Environmental and Water Resources Engineering.

Vanderbilt University

Nashville, TN 37235

Dr. John 0. Blomeke

Oak Ridge National Laboratory

P.0. Box X

Oak Ridge, TN 37830

Dr. John D. Bredehoeft.

Western Kegion Hydrologist

Water Resources Division

U.S. Geological Survey

345 Middlefield Road

Menlo Park, CA 94025

Dr. Karl P. Cohen

928 N. California Avenue

Palo Álto, CA 94303

Dr. Fred M. Ernsberger

250 0ld Mill Road

Pittsburgh, PA 15238

Dr. Rodney C. Ewing

Department of Geology

University of New Mexico

200 Yale, NE

Albuquerque, NM 87131 
Dr. Charles Fairhurst

Department of Civil and Mineral Engineering University of Minnesota 500 Pillsbury Dr. SE Minneapolis, MN 55455

Dr. William R. Muehlberger Department of Geological Sciences University of Texas at Austin P.0. Box 7909

Aust in, TX 78712

Dr. D'Arcy A. Shock

233 Virginia

Ponca City, OK 74601

Dr. Peter B. Meyers, Staff Director

National Academy of Sciences

Committee on Radioactive Waste Management

2101 Constitution Avenue

Washington; DC 20418

Ms. Remi Langum

Staff Officer

Board on Radioactive Waste Management

2101 Constitution Avenue

Washington, D. C. 20418

Jan Crawford

Administrative Assistant

Board on Radioactive Waste Management

2101 Constitution Avenue

Washington, DC 20418

Hobbs Public Library

509 N. Ship Street

Hobbs, NM 88248

Ms. Marcia Lewis, Librarian

New Mexico Tech

Martin Speere Meiliorial Library

Campus Street

Socorro, NM 87810

New Mexico State Library

P.0. Box 1629

Santa Fe, NM 87503

Ms. Ingrid Vollenhofer
Zimmerman Library

University of New Mexico

Albuquerque, NM 87131

Zanier Vivian

WIPP Public Reading Room

Atomic Museum

Kirtl and East AFB

Albuquerque, NM 87185

Ms. Gwynn Schreiner

WIPP Public Reading Room

Carlsbad Municipal Library

101 S. Halagueno St.

Carlsbad, NM 88220

Lee Hubbard, Head Librarian

Thomas Brannigan Library

106 W. Hadley St.

Las Cruces," NM 88001

Don Dresp, Head Librarian

Roswell Public Library

$301 \mathrm{~N}$. Pennsylvania Avenue

Roswel1, NM 88201

Ms. Nancy Langston

Svensk Karnbransleforsorjning $A B$ Project KBS

Karnbrans lesakerhet

Box 5864

10248 Stockholm, SWEDEN

Fred Karlsson

Institut fur Tieflagerung (7)

Theodor-Heuss-Strasse 4

D-3300 Braunschweig

FEDERAL REPUPLIC OF GERMANY
K. Kuhn
N. Jockwer
H. Gies
P. Faber
W. Fischle
G. Stampendah1
W. Hanse 1

Bundesanstalt fur Geowissenschaften und Rohstoffe

Postfach 510153

3000 Hannover 51

FEDERAL REPUBLIC OF GERMANY

Michael Langer 
Hahn-Mietner-Institut fur.

Kernforschung (2)

Glienicker Strasse 100

100 Berl in 39

FEDERAL REPUBLIC OF GERMANY

Werner Lutze

$\mathrm{K}$ laus Eckart Maass

Bundesministerium fur Forschung und Technologie

Postfach 200706

5300 Bonn 2

FEDERAL REPUBLIC OF GERMANY Rolf-Peter Randl

Physikalisch-Technische Bundesanstalt

Puslfach 3345

D-3300 Braunschweig

FEDERAL REPUBLIC OF GERMANY

Peter Brenneke

Kernforschug Karlsruhe (3)

Postfach 3640

7500 Karl sruhe

FEDERAL REPUBLIC OF GERMANY

R. Koster

Reinhard Kraemer

K. D. Closs

Atomic Energy of Canada, Ltd. (2)

Whiteshell Research Estab.

Pinewa, Manitoba, CANADA

ROE 1 LO

Peler Haywood

John Tait

Studiecentrum Voor Kernenergie (2).

Centre D'Energie Nucleaire

SCK/CCN

Boeretang 200

B-2400 Mol

BELGIUM

$\mathrm{Mr}$. A. Bonne

Pierre Van Iseghem

Dr. D. K. Mukerjee

Ontario Hydro Research Lab

800 Kipling Avenue

Toronto, Ontario, CANADA

MBZ 554
Claude Sombret

Centre D'Etudes Nucleaires

De La. Vallee Rhone

CEN/VALRHO

S.D.H.A. BP 171

30205 Bagnols-Sur-Ceze

FRANCE

Mr. Jean-Pierre 01 ivier

OECD Nuclear Energy Agency

Division of Radiation Protection and Waste Management

38, Boulevard. Suchet

75016 Paris, FRANCE

D. R. Knowles

Britich Nuclcar Fucla, ple.

Risley, Warrington, Cheshire WA3 $6 A S$

1002607 GREAT BRITAIN

Shingo Tashiro

Japan Atomic Energy Research Institute

Tokai-Mura, Ibaraki-Ken

319-11 JAPAN

Netherlands Energy Research Foundation ECN (2)

3 Westerduinweg

P.0. Box 1

1755 ZG Petten, THE NETHERLANDS

Tuen Deboer, Mgr.

L. H. Vons

Dr. R. 0. Pohl

Cornell University

Department of Physics

Clark Hall

Ithaca, NY 14853

Pañnell Library

New Mexico Junior Coll lege

Lovington Highway

Hobhs, NM 88240

Ms. Ruth Hill

George Pinder

Princeton University

Department of Civil Engineering

Princeton, NJ 08540 
Argonne National Laboratory (3) 9700 South Cass Avenue

Argonne, IL 60439
D. Hambeley
W. Harrison
M. Steindler

Los Alamos Scientific Laboiratory

Los Alamos, NM 87545

B. Erdal, CNC-11

Oak Ridge National Laboratory (4)

Box Y

Oak Ridge, TN 37830
R. E. Blanko
E. Bondietti
C. Claiborne
G. H. Jenks

Oak Ridge National Laboratory

Bldg. 2001

Ecological Sciences Information Center P.0. Box X

Oak Ridge, TN 37830

C. S. Fore

Rockwe 11 International (2)

Rocky Flats Plant

Golden, CO 80401

W. S. Bennett

C. E. Wickland

Bureau of Land Management

Branch of Solid Minerals

NM-921, Box 1449

Santa Fe, NM 87503

James 01 sen

Rockwell International (3)

Atomics International Division

Rockwell Hanford Operations

P.0. Box 800

Richland, WA 99352

J. Nelson (HWVP)

P. Salter

W. W. Schultz

Juhn Holden

Earth Technology Corp.

2405 Spring Creek

Austin, TX 79704
U.S. Army Corps of Engineers Waterways Experiment Station P.0. Box 631

Vicksburg, MS 30180

L. Wakeley

D. Walley

A. Kimbrell

Sandia Internal:

1510

1520

1521

1521

1820

1821

1830

1832

1832

1832

1833

1840

1841

1841

3141

3151

$3154-3$

6000

6230

6232

6233

6233

6233

6300

6310

6330

6330

6331

6331

6331

6331

6331

6332

6332

6332

6332

6332

6332

6332

6332

6332

6332
J. W. Nunziato

C. W. Peterson

R. D. Krieg

H. S. Morgan

R. E. Whan

S. H. Weissman

M. J. Davis

W. B. Jones

J. W. Munford

J. A. Van Den Avyle

G. A. Knorovsky

R. J. Eagan

R. B. Diegle

N. R. Sorensen

S. A. Landenberger (5)

W. L. Garner, For: DOE/TIC (Unlimited Release) (3)

C. H. Dalin, For: DOE/OSTI (28)

D. L. Hartley

W. C. Luth

W. R. Wawersik

T. M. Gerlach

J. L. Krumhans 1

H. W. Stockman

R. W. Lynch

T. 0. Hunter

W. D. Weart

G. R. Romero

A. R. Lappin

R. L. Beauheim

D. J. Borns

S. J. Lambert

K. L. Robinson

L. D. Tyler

J. G. Arguello

R. Beraun

R. V. Matalucci

M. A. Molecke

D. E. Munson

E. J. Nowak

R. J. Roginski

J. C. Stormont (10)

T. M. Torres 


\section{DISTRIBUTION}

6332 Sandia WIPP Central Files (2) 7130

(.410 WPP, .430 WPP/SDHLW)

6333 T. M. Schultheis

6334

7100

7110

7116

7116

7120

7125

7125

7125
D. R. Anderson

C. D. Broyles

J. D. P1 impton

S. R. Dolce

C. W. Cook

M. J. Navratil

R. L. Rutter

J. T. McIlmoyle

J. J. Loukota
7133

7133

7133

7135

8024

8310

8314

8314

8314

8315
J. 0. Kennedy

R. D. Statler

J. W. Mercer

H. C. Walling

P. D. Seward

P. W. Dean (SNLL Library)

R. W. Rhode

S. L. Robinson

N. R. Moody

M. W. Perra

L. A. West 